\title{
Recent progress in red light-emitting diodes by III-nitride materials
}

\author{
Daisuke lida \\ Computer, Electrical and Mathematical Sciences and Engineering (CEMSE) Division, King Abdullah \\ University of Science and Technology (KAUST), Thuwal 23955-6900, Saudi Arabia \\ E-mail: kazuhiro.ohkawa@kaust.edu.sa
}

Received 27 July 2021, revised 8 September 2021

Accepted for publication 12 November 2021

Published 26 November 2021

\begin{abstract}
GaN-based light-emitting devices have the potential to realize all visible emissions with the same material system. These emitters are expected to be next-generation red, green, and blue displays and illumination tools. These emitting devices have been realized with highly efficient blue and green light-emitting diodes (LEDs) and laser diodes. Extending them to longer wavelength emissions remains challenging from an efficiency perspective. In the emerging research field of micro-LED displays, III-nitride red LEDs are in high demand to establish highly efficient devices like conventional blue and green systems. In this review, we describe fundamental issues in the development of red LEDs by III-nitrides. We also focus on the key role of growth techniques such as higher temperature growth, strain engineering, nanostructures, and Eu doping. The recent progress and prospect of developing III-nitride-based red light-emitting devices will be presented.
\end{abstract}

Keywords: InGaN, metalorganic vapor-phase epitaxy, red light-emitting diodes, full width at half maximum, peak wavelength shift

(Some figures may appear in color only in the online journal)

\section{Introduction}

III-nitride semiconductors enable a wide spectral range from the ultraviolet to the infrared. In particular, InGaN can offer emission across the entire visible range corresponding to a bandgap energy of $0.67-3.42 \mathrm{eV}$ by tuning the alloy composition $[1,2]$. InGaN can emit any visible light, and it is suitable for use in white illuminations and full-color displays. In 2010, InGaN-based violet and blue light-emitting diodes (LEDs) realized an extremely high wall-plug efficiency (WPE)

\footnotetext{
* Author to whom any correspondence should be addressed.
}

Original content from this work may be used under the terms of the Creative Commons Attribution 4.0 licence. Any further distribution of this work must maintain attribution to the author(s) and the title of the work, journal citation and DOI. at $84 \%$ [3] and $81 \%$ [4], respectively. This is near the fundamental limitation of the materials.

To achieve the white emissions, blue or violet LEDs are coupled with wavelength-converting phosphors, which are the most efficient white light sources [4-7]. White LEDs have been widely spreading for lighting, which is contributed to saving tremendous energy. Currently, a topic of considerable interest is full-color displays by LEDs. Tiny LED chips on the micrometer scale (e.g. 10-100 $\mu$ m squares) can adopt to all displays including ultra-high definition television, smartphones, smartwatches, virtual reality, and augmented reality. Micro-LED offers high luminance, high ambient contrast ratio, high resolution, energy savings, long lifetimes, fast response, wide view angles, lightweight system etc [8, 9]. These applications require high-performance light-emitting devices with emission in three primary colors: red, green, and blue (RGB). 
Nitride semiconductors are superior candidates for fullcolor micro-LEDs. The InGaN-based light-emitting devices are attractive for the next generation of displays by microLED chips because the III-nitride materials can emit RGB colors by tuning the bandgap energy. However, red LEDs are made from the AlGaInP material because of their outstanding high external quantum efficiencies (EQEs) (>60\%) [10]. In general, the miniaturization of LEDs can reduce the EQE due to the Shockley-Read-Hall (SRH) nonradiative recombination in the form of sidewall damage during the dry etching process [11-14]. Especially, the AlGaInP-based red microLEDs have been reported to suffer from a significant efficiency reduction because of the high surface recombination and long carrier lifetime [15-18]. The efficiency of LEDs strongly depends on the device dimensions, which is a fundamental issue for a unique physical property of the material - the limited efficiency of micro-LEDs based on AlGaInP materials. In contrast, InGaN-based blue micro-LEDs have demonstrated remarkable performance by reducing the device dimensions. The peak EQE was reported to be as high as $33 \%$ when the device dimensions shrank to less than $20 \times 20 \mu \mathrm{m}^{2}$ [19]. The emission peak wavelength has excellent high stability with current increases. Therefore, the performance of blue microLEDs has already fulfilled the feasibility of micro-LED applications. The results suggest that nitride-based micro-LEDs can realize a higher efficiency than AlGaInP when the device dimension shrinks. Therefore, interest in red micro-LED production based on III-nitride materials instead of the AlGaInP ones has grown.

There are crucial matters at longer emission wavelengths than blue. First, the luminous efficiency of green LEDs has improved over time: It was reported that the maximum EQE exceeded 50\% using standard chip sizes [20-22]. However, the green LEDs typically suffer from an emission peak wavelength shift and color purity [23-25]. These phenomena are common features of InGaN-based LEDs with high In content. Normally, the peak shift behavior is attributed to the internal electric field via strain in the active region [26, 27]. The transition energy depends on the injection current due to screening of the electric field. Besides, the In fluctuation in InGaN quantum wells (QWs) will have a large influence on the full width at half maximums (FWHMs). Thus, green LEDs desire small peak wavelength shifts and narrow FWHMs to improve the color gamut in International Commission on Illumination (CIE) 1931.

In recent years, several companies have announced InGaNbased red LEDs on each platform technology. Therefore, interest in InGaN materials in red micro-LEDs has grown. Nitride-based red LEDs can lead to monolithic RGB LEDs constructed from the same material system for next-generation display applications. However, InGaN red LEDs have significantly reduced EQE when the In content increases in the InGaN active region. The low efficiency of red LEDs is the bottleneck for RGB micro-LEDs development. It has been more than 20 years since the first InGaN-based red LEDs were demonstrated by the Nichia company [28]. Currently, the EQE of InGaN-based red LEDs in the spectral range at $630 \mathrm{~nm}$ is as low as $3 \%$ at standard current density (e.g. $>10 \mathrm{~A} \mathrm{~cm}^{-2}$ ) [29].
The major challenge for achieving InGaN-based red LEDs is the significant reduction in the EQE due to the degradation of InGaN crystal quality. In general, the InGaN active region can obtain a longer emission wavelength with increasing In content. The In content of InGaN-based red LEDs is as much higher than 0.3 and two times that of blue LEDs. As a result of the increase in In content in the active region, the crystal quality of InGaN can be degraded by fundamental issues such as low-temperature growth [30,31], and large lattice mismatch $[32,33]$. Besides, the emission peak wavelength shift due to the internal electric field is a more serious issue than in green LEDs [29, 34-36]. The InGaN-based red LEDs are suffered with strong quantum-confined Stark effect (QCSE), resulting in more wavelength shifts and lower internal quantum efficiencies (IQEs). The highly efficient red emissions by InGaN are extremely difficult to realize for these issues.

The object of this paper is to review red LEDs based on nitride semiconductors with emission wavelengths over $600 \mathrm{~nm}$. We then comprehensively explain their crystal growth technology and their characteristics. Various methods have been proposed to realize red emission from nitride semiconductors, and we will introduce several such approaches. This paper is organized as below. Section 2 introduces the fundamental problems such as InGaN growth temperature, followed by the description of approaches to improve the crystal quality of (0001) $c$-plane InGaN such as metalorganic vapor-phase epitaxy (MOVPE) simulation, growth rate, and strain relaxation. Section 3 describes the strain engineering of the (0001) $c$ plane InGaN active regions via InGaN superlattices and strain compensating. Section 4 introduces the InGaN-based LEDs with (000-1) c-plane, semipolar, and nonpolar. In section 5, other interesting approaches will be explained in light of the various low-dimensional structures such as quantum dots (QDs), nanowires (NWs), and platelets. In section 6, we show an alternative approach to obtain red emission: Eu-doping in nitride semiconductors. Those approaches will likely minimize the problems above. In section 7, an overview of the current device performance will be presented. We will also review the state-of-the-art performance of InGaN-based red LEDs.

\section{High-quality and high-In-content InGaN prepared via raised growth temperature}

The MOVPE is well known to produce blue/green lightemitting devices. However, the EQE of nitride-based lightemitting devices in the red range is remarkably low at several percent [28, 29, 35] due to the immiscibility of InN and GaN leading to the degradation of the crystal quality of $\mathrm{InGaN}$ at high In contents [37]. InGaN alloys are usually grown from $700{ }^{\circ} \mathrm{C}$ to $800{ }^{\circ} \mathrm{C}$ because In adatoms are easily re-evaporated during growth with increasing growth temperature [30, 38]. It is well known that $\mathrm{InN}$ can easily decompose at a much lower temperatures than GaN and AlN based on the relationship between equilibrium pressure and growth temperature for group III-nitride semiconductors [39]. Thus, high-In-content InGaN is fundamentally difficult to grow with high crystal 
(a) In atom concentration (Max : $0.13 \mu \mathrm{mol} \mathrm{L}^{-1}$ )

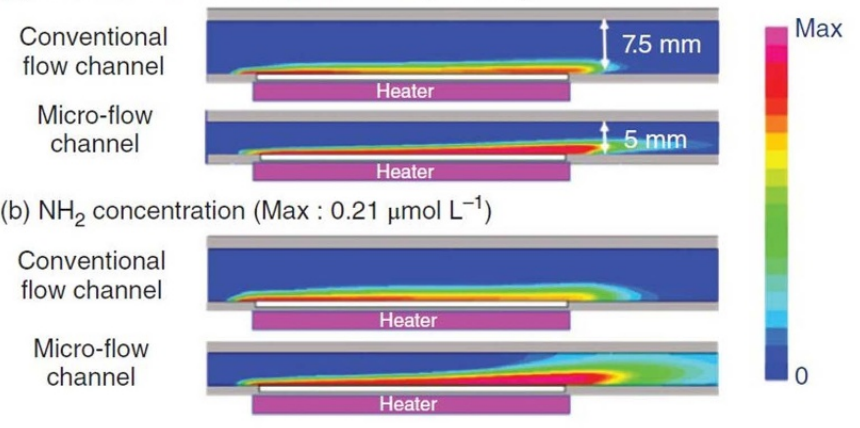

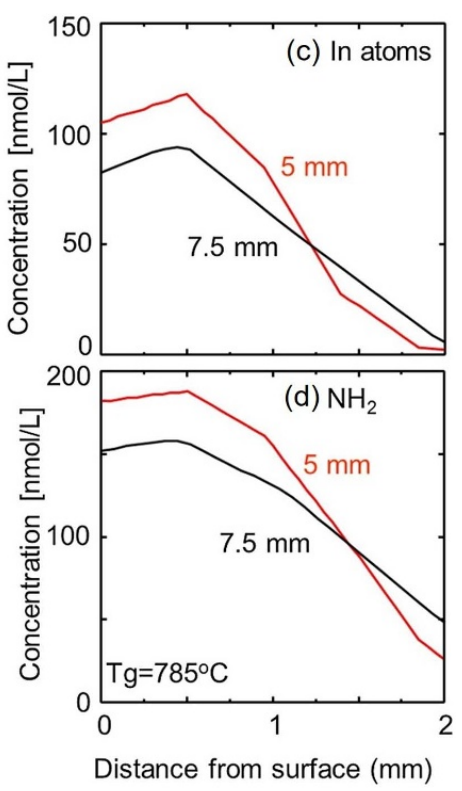

Figure 1. Concentration distributions of (a) In atoms decomposed from TMIn. [50] John Wiley \& Sons. Copyright @ $2020 \mathrm{Wiley-VCH}$ Verlag GmbH \& Co. KGaA. All rights reserved; and (b) $\mathrm{NH}_{2}$ molecules from $\mathrm{NH}_{3}$ in conventional and micro-flow channels. The amount of precursors are identical in both flow channels. Reproduced from [38]. CC BY 4.0. Simulated distributions of (c) In atoms and (d) decomposed $\mathrm{NH}_{2}$ concentrations around the substrate surface at the wafer center. The red and black lines are in cases of the micro-flow channel (5 mm height) or conventional flow channel (7.5 $\mathrm{mm}$ height), respectively. The flow amounts of each precursor are the same in both cases.

quality because one of the crucial factors for controlling the crystallinity is by growth temperature. (0001) $c$-plane InGaN growth at low temperatures has some issues such as phase separation [40, 41], rough surfaces [42, 43], and high impurities $[44,45]$. Thus, higher growth temperatures are essential to growing high-quality InGaN active regions. In this section, we present growth techniques to improve the crystal quality of conventional (0001) c-plane InGaN.

\subsection{Simulation and experiments by MOVPE}

III-nitride semiconductor crystal growth by MOVPE complicates the growth process versus the other materials such as phosphides and arsenides [46-48]. Those growth conditions have been optimized by many experiments. Numerical calculations are also helpful to understand the feasibility of material growth by MOVPE system. The results require comparison with experiments to validate computational approaches. Theoretical works have been carried out to investigate the growth of $\operatorname{In}(\mathrm{Ga}) \mathrm{N}$ [30, 38, 49-52]. Such analysis has contributed to the understanding of $\operatorname{In}(\mathrm{Ga}) \mathrm{N}$ growth in tandem with experimental results. The computational approaches are crucial for understanding the complicated phenomena of crystal growth.

Regarding the thermodynamic calculations, raisedpressure MOVPE was proposed to overcome the stability of $\operatorname{In}(\mathrm{Ga}) \mathrm{N}$ growth at a high temperature [53-55]. In experiments, high-In-content InGaN (as high as 0.42) was demonstrated by $800{ }^{\circ} \mathrm{C}$ growth temperature at $200 \mathrm{kPa}$ [55]. The peak emission wavelength was presented at the deep red emission range up to $720 \mathrm{~nm}$. The crystal quality of $\mathrm{InN}$ drastically improved by high temperature growth at up to $865^{\circ} \mathrm{C}$ at $2 \mathrm{MPa}$
[54]. High-pressure growth provides the material with thermal stability under thermodynamic equilibrium states.

Also, the growth of III-nitrides materials has been numerically investigated by computational fluid dynamics (CFD) simulation $[38,50]$. These CFD simulations are based on a huge number of chemical reactions, which agrees well with the experiment results both qualitatively and quantitatively. Crystal growth modeling can provide useful information related to the optimal growth conditions and reactor designs.

We previously reported the modification of the inside flow channel's height from 7.5 to $5.0 \mathrm{~mm}$ by following the InGaN MOVPE CFD simulation $[38,50,56]$. This is the socalled 'micro-flow channel technique'. This technique helped develop yellow to red LEDs. Figure 1 shows the modeling of In atoms and $\mathrm{NH}_{2}$ molecules in both flow channels by the simulation $[38,50]$. The numerical simulation results found that the concentration of the In atoms and $\mathrm{NH}_{2}$ molecules in the vicinity of the growth surfaces were improved by $27 \%$ and $20 \%$ using the $5 \mathrm{~mm}$ height flow channel versus a conventional flow channel, respectively. The decomposition efficiency of the precursors improved, which leads to grow of high Incontent InGaN. When the micro-flow channel technique was used, the $600 \mathrm{~nm}$ emission wavelength LEDs can produce a growth temperature that is $60^{\circ} \mathrm{C}$ higher than the conventional flow channel [56]. The IQE of $600 \mathrm{~nm}$ emission wavelength LEDs was improved from $4 \%$ to $18 \%$ using the thinner flow channel. The higher growth temperature improved the highIn-content InGaN crystal quality. Also, the deep red emission at $740 \mathrm{~nm}$ was first demonstrated due to the In pulling effect by strain relaxation when the number of the QWs increased from 5 to 16 [56]. Clearly, this micro-flow channel technique is a 
very effective method for producing long emission wavelength devices by InGaN.

MOVPE reactors should become larger with scale-up of wafer diameters (e.g. 8 inches); concurrently, material consumption during production has grown. This is a huge cost for each growth. Growth modeling indicates some crucial information prior to growing the devices, which will save time and costs. In the future, computational methods can facilitate optimal growth modeling leading to high quality crystals and devices.

\subsection{Growth rate}

The growth rate of $\mathrm{InGaN}$ is an essential factor for improving crystalline quality. This parameter is significantly related to various aspects of the growth phenomena such as crystalline defects, impurities, and surface flatness. In general, the lower growth rate in the active region is preferred to obtain good crystallinity. The low growth rate can be obtained via a high V/III ratio, which can compensate for $\mathrm{NH}_{3}$ clacking efficiency at a low growth temperature. The lower growth rate can minimize the formation of point defects, In-rich clustering, In droplets, and impurity incorporations in the InGaN active region due to enhanced surface migration of adatoms. The InGaN layers can enhance step-flow growth and can lead to a smooth surface with sharp interfaces in the QW structures. These efforts have improved the device performance. However, InGaN red QWs are not reasonable to use at a low growth rate due to the significantly high In re-evaporation during InGaN growth even if a high V/III ratio is achieved. This is a complicated issue for high-In-content InGaN QW growth.

Importantly, a higher growth rate has also been proposed to optimize the InGaN growth for red emission [57]. This approach is the complete opposite of typical blue InGaN QWs growth condition, but the crystal quality of InGaN red QWs was improved. These data suggest that the incremental growth rate enhances the In incorporation rate into InGaN because of the In re-evaporation reduction. Figure 2 shows that the In content in InGaN is dependent on growth rates $\left(0.5-5.2 \mathrm{~nm} \mathrm{~min}^{-1}\right)$ and growth temperatures [57]. The surface defect density reduction and the smooth surface on the InGaN QW were realized due to improved surface migration of adatoms with increased growth temperatures. The bright luminous area in $\mathrm{InGaN}$ QWs by photoluminescence (PL) measurements was expanded using optimal high growth rate conditions. Alhassan et al also reported the highly efficient green LEDs using the high growth rate (6 $\mathrm{nm} \mathrm{min}^{-1}$ ) for InGaN QWs [58]. Therefore, a high growth rate of high-In-content InGaN QWs is effective to improve the crystal quality. However, it considers that the point defects and impurities may increase with a higher growth rate because the V/III ratio decrease (i.e. III-material precursors increase). Also, according to thermodynamics, the low V/III ratio is not favorable to grow high-In-content InGaN [30]. The optimization of the increased growth rate is a crucial factor underlying high-In-content $\mathrm{InGaN}$ at high temperatures.

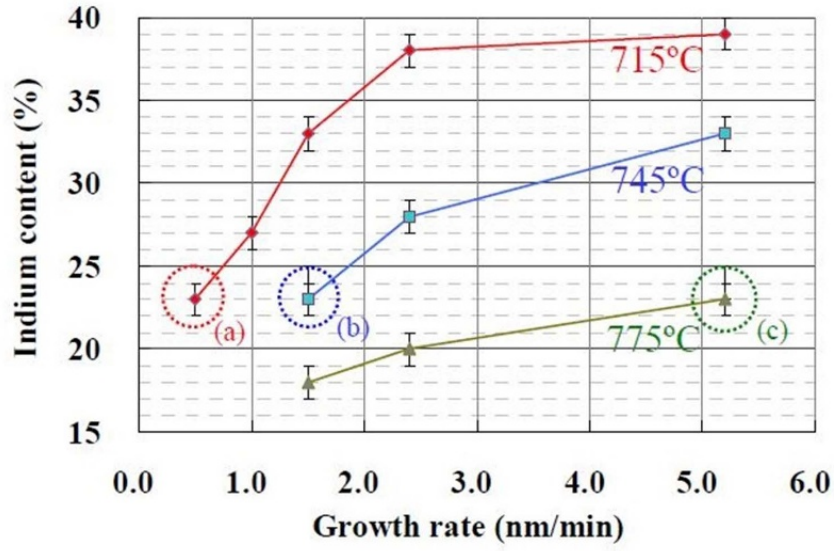

Figure 2. Indium content dependence on growth conditions. [57] John Wiley \& Sons. Copyright @ 2013 WILEY-VCH Verlag GmbH \& Co. KGaA, Weinheim.

\subsection{Relaxed InGaN underlying layers}

The proper In content in the strain-relaxed InGaN underlying layers are required to produce highly efficient lightemitting devices for red emission. However, the lattice mismatch between $\mathrm{GaN}$ and $\mathrm{InN}$ is as large as $11 \%$, which leads to the degradation of InGaN alloys by strain relaxation [33]. The crystal quality of the InGaN active region strongly depends on the in-plane lattice constant in the underlying layers. In general, the accumulation of high compressive stress in InGaN layers grown on $\mathrm{GaN}$ generates misfit and threading dislocations, stacking faults, trench defects, In segregation, and Vshaped pits when the stress-energy releases [33, 59-62]. The increase in defect densities depends on the In content in InGaN layers due to the lattice mismatch with $\mathrm{GaN}$ underlying layers. Therefore, higher In content InGaN alloys have suffered significantly from defect generation. This is a major issue in the production of InGaN devices with high In content. To solve the issue, the community needs to explore the outstanding growth technique to reduce the lattice mismatch between underlying layers and InGaN QWs. The In incorporation rate increases when the InGaN thickness increases-this is strongly involved in the in-plane stress releases during growth. A common phenomenon is the so-called 'compositional pulling effect', which is attributed to an increase in the $a$-lattice constant $[32,63,64]$.

These phenomena lead to the concept of InGaN pseudosubstrates which have less lattice mismatch with the epitaxial structures composed of InGaN to fabricate high-performance LEDs in the red spectral range. Previously, a high degree of relaxation of InGaN underlying layers provided the improved emission efficiency of InGaN active layers in the green spectral range, which represented a proof-of-concept for strainrelaxed $\mathrm{InGaN}[65,66]$. In recent years, the strain-relaxed InGaN layers aim to further increase the $a$-lattice constant to obtain equivalent strain in the red QWs as the blue QWs grown on typical GaN layers. Various efforts have been developed to produce high-quality strain-relaxed InGaN layers. The goal is 

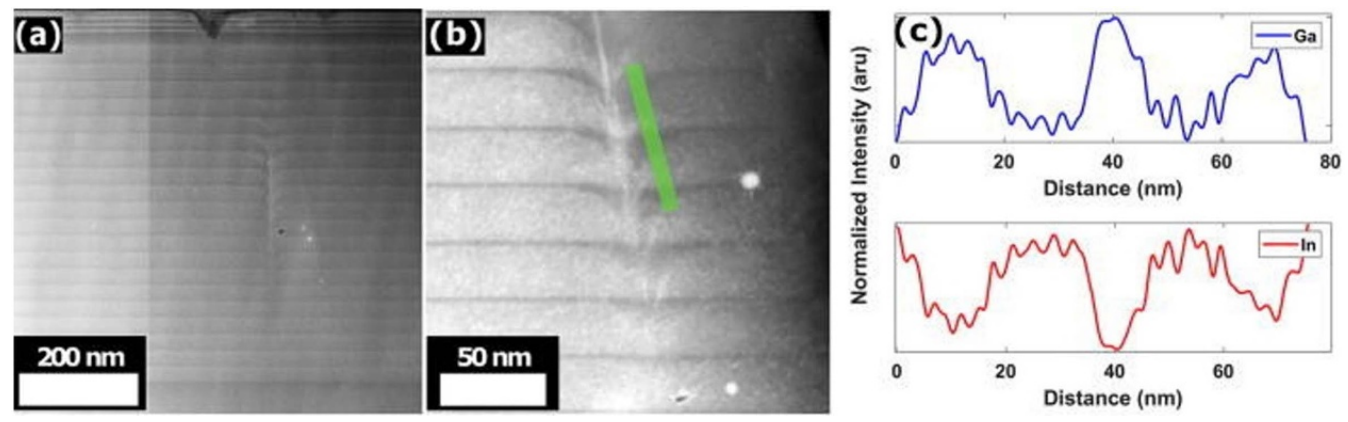

Figure 3. (a) HAADF-STEM of sample $8 \% \mathrm{SB}$, showing a consistent flat growth of InGaN layers. (b) HAADF-STEM of a dislocation showing back-filling of the generated V-pits. (c) EDS along the line profile in (b) showing the backfill of the V-pits demonstrates an increase in the Ga content with a decrease in In. Reprinted from [68], with the permission of AIP Publishing.

to obtain large in-plane $a$-lattice constants via strain relaxation of InGaN layers with superior benefits to minimize the lattice mismatch with InGaN QWs for red emission and suppress the generation of misfit dislocations. Furthermore, the reduction in lattice mismatch can lead to an increase in InGaN growth temperature due to the compositional pulling effect, which can also improve the crystallinity of InGaN QWs. The low in-plane strain in InGaN QWs also leads to a reduction in QCSE to ultimately improve IQE. These approaches are a very important technology for the development of highly efficient InGaN red LEDs. Here, we review several techniques for fabricating strain-relaxed InGaN pseudo-substrates.

2.3.1. Periodic InGaN structures. In general, strain relaxed InGaN layers grown on $\mathrm{GaN}$ layers suffer from rough surfaces and defects [63, 67]. A periodic InGaN/GaN structure (semi-bulk InGaN layers) enlarge the in-plane lattice parameter. Pantzas et al reported that an $\mathrm{In}_{0.09} \mathrm{Ga}_{0.91} \mathrm{~N}$ layer was relaxed to a degree of 0.15 by MOVPE [67]. Similarly, Eldred et al demonstrated a highly relaxed semi-bulk InGaN as shown in figure 3 [68]. Figure 3(a) shows the highangle annular dark-field scanning transmission electron microscopy (HAADF-STEM) image of the semi-bulk $\operatorname{In}_{0.08} \mathrm{Ga}_{0.92} \mathrm{~N}$ capped with three-period InGaN QWs. The semi-bulk structure was obtained and had consistent and flat growth for the InGaN/GaN layers across 20 periods. The V-pit was backfilled with $\mathrm{GaN}$ interlayers as shown in figures 3(b) and (c). This InGaN achieved a high degree of relaxation of $\sim 0.7$. The same group obtained semi-bulk InGaN with In contents of $6 \%$, $7.8 \%, 9 \%$, and $10.2 \%$. This corresponded to degrees of relaxation of $0.55,0.75,0.8$, and 0.85 , respectively. This approach maintains smooth surfaces and is acceptable for further epitaxial growth. Semi-bulk structures are favorable for producing high-quality InGaN templates. The authors demonstrated that the InGaN QWs grown on those InGaN templates had a large redshift of $12-35 \mathrm{~nm}$.

Däubler et al demonstrated metamorphic InGaN buffer layers (i.e. linear composition-graded $\mathrm{InGaN}$ with $\mathrm{GaN}$ interlayers). This material had an enlarged $a$-lattice constant by plasma-assisted molecular beam epitaxy [69]. Metamorphic InGaN templates provided $45{ }^{\circ} \mathrm{C}$ higher growth temperature for InGaN QWs versus the same QW structures grown on conventional GaN templates due to a pronounced compositional pulling effect. Furthermore, the QWs grown on the metamorphic InGaN templates obtained two-fold more IQE enhancement by improved crystallinity and lower QCSE. The metamorphic InGaN technique led to red emission QWs at $640 \mathrm{~nm}$ with comparable IQE (20\%-30\%) for green emission QWs.

2.3.2. InGaN on porous $G a N$. Strain-relaxed InGaN layers on top of porous $\mathrm{GaN}$ were demonstrated by Pasayat et al $[70,71]$. The benefit of porous $\mathrm{GaN}$ is a reduction in the mechanical stiffness of the crystal. This feature allows strain relaxation of pre-strained InGaN prior to $\mathrm{GaN}$ porosification. This shows that the degree of relaxation of InGaN layers can be tuned via the volumetric porosity of the GaN layers. However, these InGaN pseudo-substrates presented surface defects with a degraded surface morphology. The same group also improved the crystal quality of InGaN pseudosubstrates using V-defect-free GaN layers on porous GaN pseudo-substrates [72]. The $100 \mathrm{~nm}$ thick InGaN layer with an In content of 0.12 offers $65 \%$ strain relaxation with a smooth surface morphology (figures 4(a) and (b)). The $a$ lattice constant was as large as $3.216 \AA$ (figure 4(a)) and corresponded to fully relaxed InGaN with an In content of 0.076 . The strain relaxation behavior has markedly thicker InGaN layers. The relaxation increases with thickness. The InGaN layers were not influenced by the GaN capping layer thicknesses (figure 4(a)). However, in the case of no $\mathrm{GaN}$ porous structures, the $200 \mathrm{~nm}$ thick InGaN layer was strained on the typical GaN layer of a sapphire substrate (figure 4(c)). This novel InGaN pseudo-substrate technology is highly versatile, and it can be used not only for InGaN but also for $\mathrm{AlGaN}$ and conventional substrates (e.g. sapphire, $\mathrm{Si}, \mathrm{SiC}$, etc) [73].

The $632 \mathrm{~nm}$ wavelength InGaN red micro-LEDs were demonstrated grown on InGaN pseudo-substrates using GaN on porous $\mathrm{GaN}$ technique [74]. LEDs composed of the strainrelaxed $\mathrm{In}_{0.04} \mathrm{Ga}_{0.96} \mathrm{~N}$ layer with a relaxation degree of 0.56 had a peak emission at $632 \mathrm{~nm}$ of $10 \mathrm{~A} \mathrm{~cm}^{-2}$. This was an on-wafer EQE of $0.2 \%$. The devices achieved a large redshift value of $56 \mathrm{~nm}$ at $5 \mathrm{~A} \mathrm{~cm}^{-2}$ attributed to the strain reduction by the porous underlying layers. Other LED performances on 

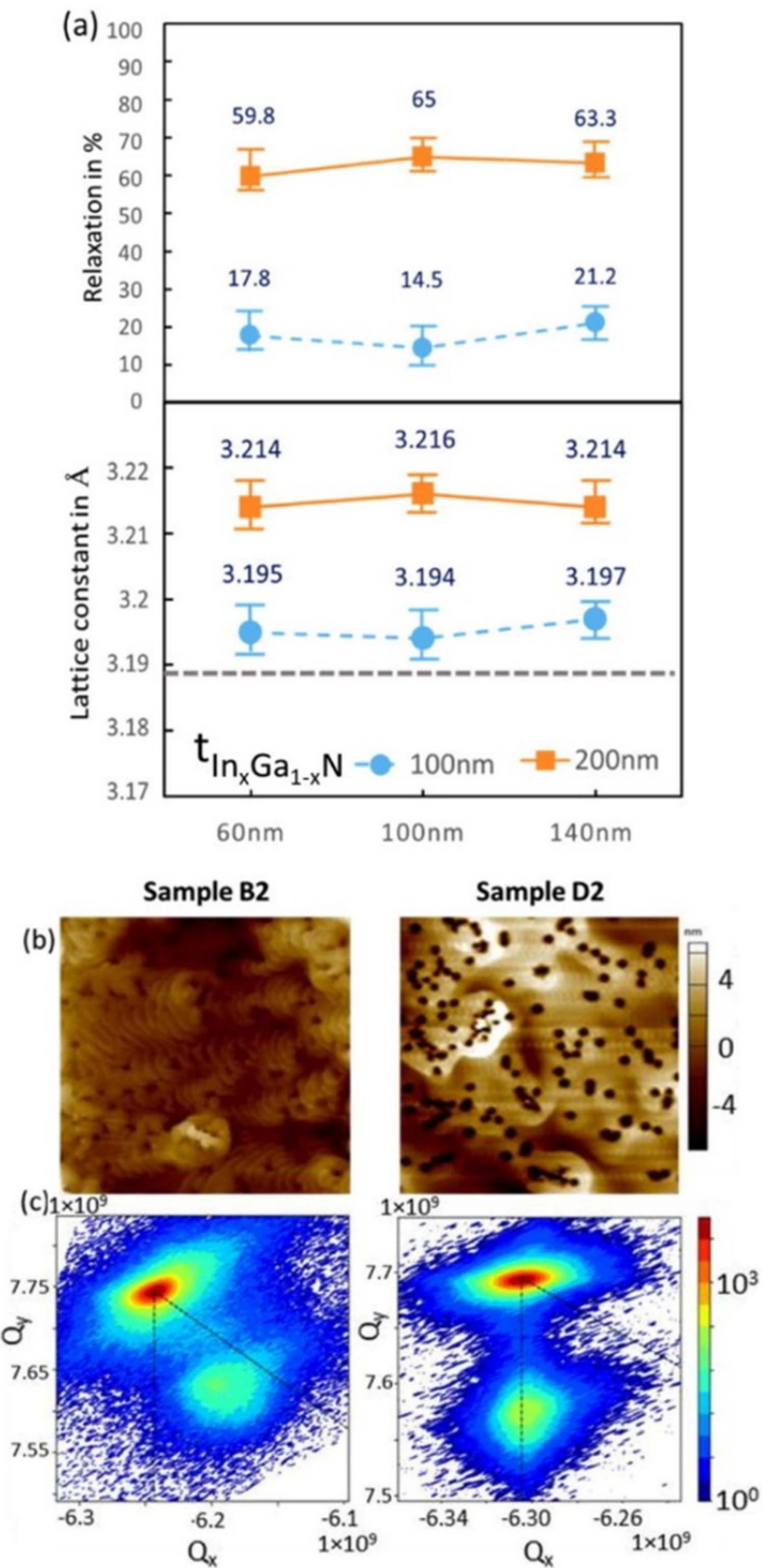

Figure 4. (a) Relaxation and $a$-lattice constant of $100 \mathrm{~nm}$ (circle) and $200 \mathrm{~nm}$ (squares) thick $\operatorname{In}_{x} \mathrm{Ga}_{1-x} \mathrm{~N}$ layers grown on GaN-on-porous-GaN pseudo-substrates with different GaN cap layer thicknesses. The dotted gray straight line in the bottom figure corresponds to the lattice constant of the coherently strained $\mathrm{In}_{x} \mathrm{Ga}_{1-x} \mathrm{~N}$ layer grown on the co-loaded $\mathrm{GaN}$ on a sapphire reference sample. (b) The $5 \mu \mathrm{m} \times 5 \mu \mathrm{m}$ atomic force microscopy images of sample B2 (GaN cap thickness $=100 \mathrm{~nm}, \mathrm{In}_{x} \mathrm{Ga}_{1-x} \mathrm{~N}$ thickness $=200 \mathrm{~nm})$ on the left and sample D2 $\left(\operatorname{In}_{x} \mathrm{Ga}_{1-x} \mathrm{~N}\right.$ thickness $=200 \mathrm{~nm}$ grown strained on a co-loaded GaN-on-sapphire wafer) on the right. (c) Reciprocal space maps of samples B2 (left) and D2 (right) around the $\mathrm{GaN}(-1-124)$ reflection. Reprinted from [72], with the permission of AIP Publishing.

similar InGaN pseudo-substrates were reported with redshift values of 40 and $45 \mathrm{~nm}$ at green emission ranges [70, 72]. The enhancement of In content incorporation into InGaN QWs was attributed to the compositional pulling effect by $a$-lattice constant increases.

2.3.3. Novel InGaN pseudo-substrate. Soitec developed a novel InGaN pseudo-substrate (InGaNOS substrate) based on Smart Cut ${ }^{\mathrm{TM}}$ and epilayer transfer technologies [75-79]. This substrate is composed of a thin and relaxed InGaN seed layer $\left(800 \times 800 \mu \mathrm{m}^{2}\right.$ or $\left.500 \times 500 \mu \mathrm{m}^{2}\right)$ on a carrier sapphire substrate with a buried oxide layer. The InGaNOS achieved a 4 inch wafer scale on a carrier sapphire substrate. InGaNOS technique provides for a reduction in the lattice mismatch between InGaN QWs and the buffer layers.

In 2017, Even et al reported the performance of InGaN QWs grown on the $150 \mathrm{~nm}$ thick relaxed InGaN buffer layers with different $a$-lattice constants: 3.190, 3.200, and $3.205 \AA$ [75]. Figure 5 shows the PL spectra of InGaN multiple quantum wells (MQWs) grown on those InGaNOS substrates and typical GaN templates [75]. The peak emission of MQWs had a redshift value of 49 and $62 \mathrm{~nm}$ for InGaNOS$3.205 \AA$ samples due to the compositional pulling effect. The PL intensity at $594 \mathrm{~nm}$ emission of the InGaNOS-3.205 sample was enhanced two-fold compared to that of InGaNOS$3.200 \AA$ sample. Very recently, $\operatorname{InGaN~QWs~}(\lambda=624 \mathrm{~nm})$ grown on the InGaNOS-3.205 $\AA$ substrate with InGaN/GaN superlattices had improved material quality with a large redshift of $85 \mathrm{~nm}$ compared to the QWs $(\lambda=539 \mathrm{~nm})$ grown on the GaN template [79]. This technique has crucial benefits including a high In incorporation rate as well as mitigation of the internal piezoelectric field [76].

InGaN-based red micro-LEDs $\left(50 \times 50 \mu \mathrm{m}^{2}\right)$ were demonstrated using an InGaNOS substrate with an $a$-lattice constant of $3.2069 \AA$ [77]. The dislocation density presents $2 \times 10^{8} \mathrm{~cm}^{2}$ which is the same as the initial InGaN/GaN layers before the InGaNOS substrate process. The micro-LEDs achieved red emission corresponding to the narrow FWHM of $48 \mathrm{~nm}$ at $630 \mathrm{~nm}$. The maximum EQE of $0.09 \%$ was obtained for an emission wavelength of $616 \mathrm{~nm}$ at $40 \mathrm{~A} \mathrm{~cm}^{-2}$. However, the lattice parameter of InGaNOS substrates was still not sufficient because the additional dislocation was introduced from the QWs. The IQE value was $6.5 \%$ at $624 \mathrm{~nm}$ via a PL intensity ratio of LT/RT. Larger $a$-lattice constants can mitigate the strain leading to highly efficient InGaN red LEDs.

2.3.4. Lattice-matched substrates. The lattice-matched substrates have been proposed to fabricate high-In-content InGaN-based LEDs. There are two candidates $(\mathrm{ZnO}$ and $\mathrm{ScAlMgO}_{4}$ ) that can be lattice-matched under certain InGaN layers.

According to the literature, InGaN layers were grown on $\mathrm{ZnO}$ substrates by pulsed laser deposition [80-82] or pulsed sputter deposition (PSD) [83]. However, the (In)GaN layers must be grown at lower temperatures $\left(<550{ }^{\circ} \mathrm{C}\right)$ [84] to suppress the poor-quality interfacial $\mathrm{Ga}_{2} \mathrm{ZnO}_{4}$ and $\mathrm{Ga}_{2} \mathrm{O}_{3}$ layers [85-87]. This low-temperature growth is unsuitable for MOVPE with a major nitride epitaxial growth method. InGaN epi-layers incorporated $\mathrm{Zn}$ and $\mathrm{O}$ with high impurity levels at $>10^{20} \mathrm{~cm}^{-3}$ from the substrates [88]. These impurities were 

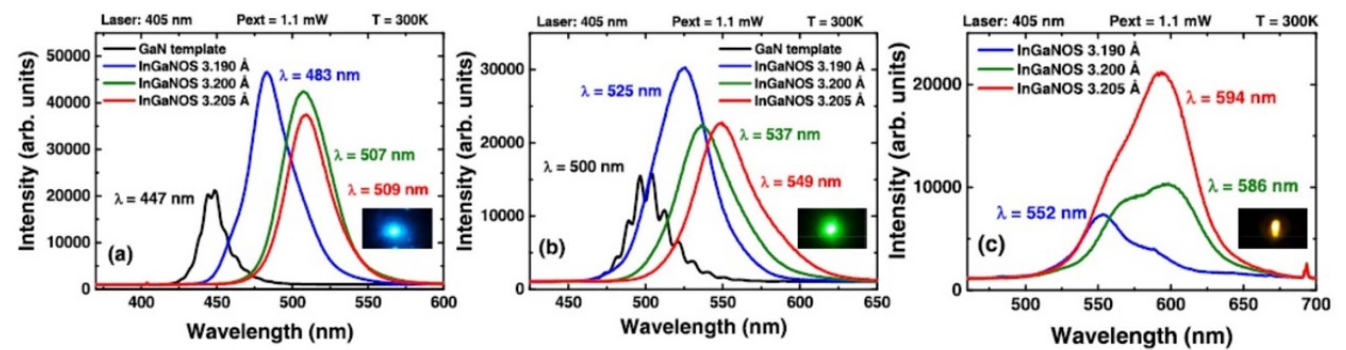

Figure 5. PL spectra at $300 \mathrm{~K}$ of InGaN 5QWs on InGaNOS: (a) standard blue InGaN QWs, (b) the growth temperature was decreased by $20^{\circ} \mathrm{C}$ from standard blue condition, and (c) the growth temperature was decreased by $20^{\circ} \mathrm{C}$ from the standard blue condition with a three times higher InGaN growth rate (the blue curve is related to InGaNOS $3.190 \AA$, green curve is $3.200 \AA$, red curve is $3.205 \AA$, and black curve is the reference sample.). Insets: pictures of emission under laser excitation from InGaNOS samples of (a) $3.190 \AA$ A blue luminescence, (b) $3.200 \AA$ green luminescence, and (c) $3.205 \AA$ amber luminescence. Reprinted from [75], with the permission of AIP Publishing.

due to the self-decomposition of $\mathrm{ZnO}$ by high temperature suggesting low emission efficiency of InGaN-based LEDs on a $\mathrm{ZnO}$ substrate [87, 89].

$\mathrm{ScAlMgO}_{4}$ with the $3.249 \AA a$-lattice constant leads to a sample lattice-matched with $\operatorname{In}_{0.17} \mathrm{Ga}_{0.83} \mathrm{~N}$ and $1.8 \%$ latticemismatched with GaN. Using MOVPE growth, InGaN-based blue LEDs on (0001) $\mathrm{ScAlMgO}_{4}$ substrates were demonstrated [90, 91]. GaN layers can be obtained with high crystal quality, which is comparable with GaN on sapphire $[90,92]$. This implies no interfacial reaction between $\mathrm{GaN}$ and $\mathrm{ScAlMgO}_{4}$ at high temperatures. These blue LEDs on $\mathrm{ScAlMgO}_{4}$ substrates achieved a high performance similar to those on a typical sapphire substrate. Also, $\mathrm{In}_{x} \mathrm{Ga}_{1-x} \mathrm{~N} / \mathrm{In}_{y} \mathrm{Ga}_{1-y} \mathrm{~N}$ red MQWs $(x>0.2, y \sim 0.17)$ structures grown on lattice-matched $\operatorname{In}_{y} \mathrm{Ga}_{1-y} \mathrm{~N}$ layers on $\mathrm{ScAlMgO}_{4}$ substrates were demonstrated by Ozaki et al in 2019 [93]. The emission peak wavelengths were at $680 \mathrm{~nm}$ for the InGaN QWs grown on $\mathrm{ScAlMgO}_{4}$ and $550 \mathrm{~nm}$ for that on sapphire at $731{ }^{\circ} \mathrm{C}$. InGaN MQWs grown on $\mathrm{ScAlMgO}_{4}$ achieved a $30{ }^{\circ} \mathrm{C}-40{ }^{\circ} \mathrm{C}$ higher growth temperature compared to MQWs on sapphire. This suggests a large redshift attributed to the compositional pulling effect. We also note that $\mathrm{ScAlMgO}_{4}$ substrates lead to the longer emission peak wavelength of InGaN QWs due to the lower thermal conductivity $\left(6.2 \mathrm{~W} \mathrm{~m}^{-1} \mathrm{~K}^{-1}\right)$ [94]. The critical thickness of highIn-content InGaN leads to an increase when the unstrained $\mathrm{In}_{0.17} \mathrm{Ga}_{0.83} \mathrm{~N}$ layers are utilized. We also expect to reduce the piezoelectric field caused by strain reduction.

Figure 6 shows the temperature dependences of the integrated PL intensities of the InGaN QWs on both $\mathrm{ScAlMgO}_{4}$ and sapphire substrates at $\sim 625 \mathrm{~nm}$ emission [93]. The PL intensity ratios between LT and RT were obtained at $13.6 \%$ for the InGaN QWs on $\mathrm{ScAlMgO}_{4}$ and $0.35 \%$ for that on sapphire, which indicates a large IQE enhancement factor of $\sim 40$. In general, the $c$-plane InGaN QWs should have a blueshift with increasing excitation intensity due to the state-filling effect and the screening of the polarization field $[26,28]$. In contrast, the blueshift behavior of the InGaN QWs on $\mathrm{ScAlMgO}_{4}$ is noted where the peak wavelength is almost independent of the excitation intensity increase. This is the appropriate feature for fabricating display applications via micro-LEDs.

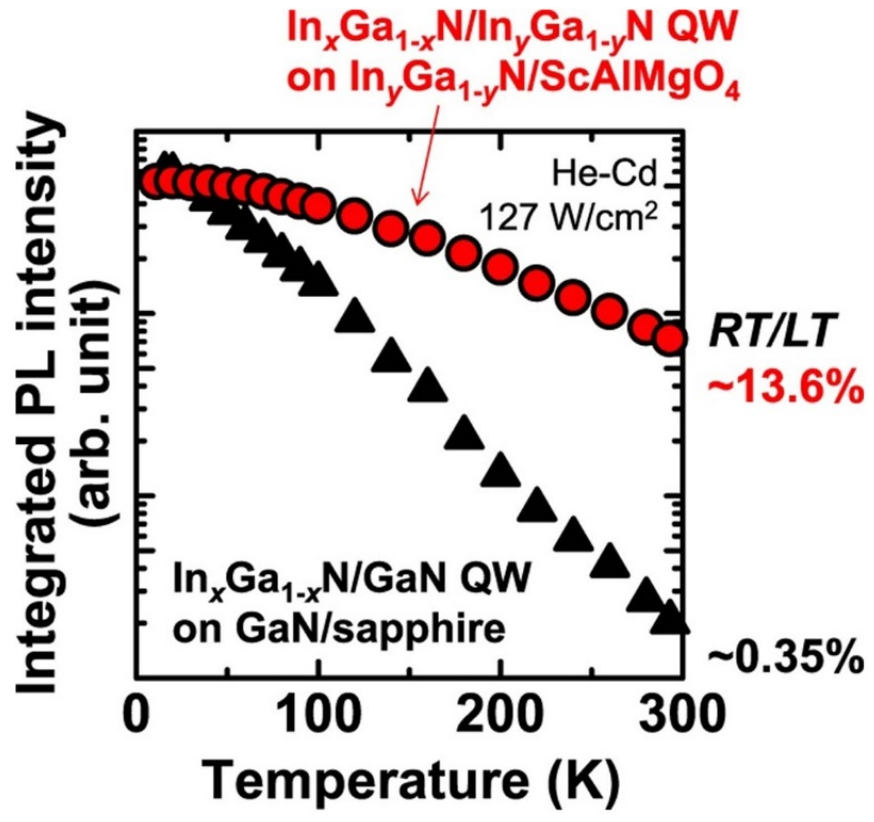

Figure 6. (a) Temperature dependence of the integrated PL intensities of the $\operatorname{In}_{x} \mathrm{Ga}_{1-x} \mathrm{~N} / \mathrm{In}_{y} \mathrm{Ga}_{1-y} \mathrm{~N}$ QW on $\mathrm{ScAlMgO}_{4}$ and $\mathrm{In}_{x} \mathrm{Ga}_{1-x} \mathrm{~N} / \mathrm{GaN} \mathrm{QW}$ on sapphire emitting at $\sim 625 \mathrm{~nm}$. Reproduced from [93]. () IOP Publishing Ltd. All rights reserved.

2.3.5. Redshift. The redshift values of the peak emission from InGaN QWs depends on the $a$-lattice constant as listed in table 1 . The redshift was obtained from the difference in peak emission wavelengths of InGaN QWs grown on InGaN and $\mathrm{GaN}$ templates. Some of the results suggest that the $a$-lattice constant of InGaN layers was determined by the degree of relaxation and the presumed GaN $a$-lattice constant (i.e. $3.184 \AA$ [75]). Figure 7 shows that the redshift can be enhanced with the $a$-lattice constant as the number of InGaN layers increases suggesting the compositional pulling effect. Note that again, $\mathrm{ScAlMgO}_{4}$ thermal conductivity is as low as $6.2 \mathrm{~W} \mathrm{~m}^{-1} \mathrm{~K}^{-1}$ [95] compared with a sapphire substrate (25 $\mathrm{W} \mathrm{m}^{-1} \mathrm{~K}^{-1}$ [94]), which could affect growth temperature. InGaN QWs with a high In content have green to red spectral range emissions that were particularly more redshifted. 
Table 1. Characteristics of InGaN QWs emission using InGaN templates with various In contents and relaxation degrees. The peak wavelengths were given by PL or electroluminescence (EL) measurements. The redshift values were obtained from the difference of InGaN QWs' peak wavelengths between samples grown on InGaN and GaN templates. Some of InGaN $a$-lattice constants were estimated using the reference GaN lattice constant of $3.184 \AA^{*}$ [75].

\begin{tabular}{|c|c|c|c|c|c|c|c|c|c|}
\hline Affiliation & $\begin{array}{l}\text { Growth } \\
\text { method }\end{array}$ & $\begin{array}{l}\text { Structure of } \\
\text { InGaN template }\end{array}$ & $\begin{array}{c}\text { In } \\
\text { content } \\
\text { in InGaN } \\
\text { template }\end{array}$ & $\begin{array}{l}\text { Degree of } \\
\text { relaxation }\end{array}$ & $\begin{array}{c}a \text {-lattice } \\
\text { constant }(\AA)\end{array}$ & $\begin{array}{l}\text { MQWs } \\
\lambda_{\text {peak }} \\
(\mathrm{nm})\end{array}$ & $\begin{array}{l}\text { Redshift } \\
\text { (nm) }\end{array}$ & Year & Reference \\
\hline $\begin{array}{l}\text { Georgia Institute } \\
\text { of Technology }\end{array}$ & MOVPE & Semibulk InGaN & 0.05 & 0.15 & $3.187^{*}$ & 454 (PL) & 17 & 2017 & [96] \\
\hline $\begin{array}{l}\text { North Carolina } \\
\text { State Univ. }\end{array}$ & MOVPE & Semibulk InGaN & 0.06 & 0.55 & $3.195^{*}$ & $483(\mathrm{PL})$ & 12 & 2021 & [97] \\
\hline $\begin{array}{l}\text { North Carolina } \\
\text { State Univ. }\end{array}$ & MOVPE & Semibulk InGaN & 0.078 & 0.75 & $3.204^{*}$ & 475 (PL) & 31 & 2021 & [97] \\
\hline $\begin{array}{l}\text { North Carolina } \\
\text { State Univ. }\end{array}$ & MOVPE & Semibulk InGaN & 0.09 & 0.80 & $3.209^{*}$ & $486(\mathrm{PL})$ & 35 & 2021 & [97] \\
\hline $\begin{array}{l}\text { North Carolina } \\
\text { State Univ. }\end{array}$ & MOVPE & Semibulk InGaN & 0.102 & 0.85 & $3.214^{*}$ & 489 (PL) & 43 & 2021 & [97] \\
\hline UCSB & MOVPE & InGaN/porous GaN & 0.118 & 0.65 & 3.216 & $547(\mathrm{EL})$ & 40 & 2020 & {$[72]$} \\
\hline UCSB & MOVPE & InGaN/porous GaN & 0.04 & 0.56 & $3.192^{*}$ & $646(\mathrm{EL})$ & 56 & 2021 & {$[74]$} \\
\hline $\begin{array}{l}\text { Univ. Grenoble } \\
\text { Alpes, Soitec }\end{array}$ & MOVPE & InGaNOS & 0.015 & - & 3.190 & 483 (PL) & 36 & 2017 & {$[75]$} \\
\hline $\begin{array}{l}\text { Univ. Grenoble } \\
\text { Alpes, Soitec }\end{array}$ & MOVPE & InGaNOS & 0.055 & - & 3.200 & 507 (PL) & 60 & 2017 & {$[75]$} \\
\hline $\begin{array}{l}\text { Univ. Grenoble } \\
\text { Alpes, Soitec }\end{array}$ & MOVPE & InGaNOS & 0.077 & 0.7 & 3.205 & 509 (PL) & 62 & 2017 & {$[75]$} \\
\hline $\begin{array}{l}\text { Univ. Grenoble } \\
\text { Alpes, Soitec }\end{array}$ & MOVPE & InGaNOS & 0.015 & - & 3.190 & $525(\mathrm{PL})$ & 25 & 2017 & {$[75]$} \\
\hline $\begin{array}{l}\text { Univ. Grenoble } \\
\text { Alpes, Soitec }\end{array}$ & MOVPE & InGaNOS & 0.055 & - & 3.200 & 537 (PL) & 37 & 2017 & [75] \\
\hline $\begin{array}{l}\text { Univ. Grenoble } \\
\text { Alpes, Soitec }\end{array}$ & MOVPE & InGaNOS & 0.077 & 0.7 & 3.205 & 549 (PL) & 49 & 2017 & {$[75]$} \\
\hline Kyoto Univ. & MOVPE & $\mathrm{InGaN} / \mathrm{ScAlMgO} 4$ & 0.17 & 1 & 3.249 & $680(\mathrm{PL})$ & 130 & 2019 & [93] \\
\hline
\end{tabular}

We conclude that highly efficient InGaN-based pure red LEDs require the fabrication of high-quality strain-relaxed InGaN templates. The large redshift expressed the availability of increasing InGaN growth temperature, which leads to a further improvement in the crystal quality of InGaN. The benefit is not only the redshift of peak emission but also the reduction of QCSE. Due to these effects, the concept of an enlarged $a$-lattice constant for the underlying layers is expected to improve the IQE of InGaN red QWs.

\subsection{GaN underlying layers}

Epitaxial layers with residual strain have been introduced by the mismatches of lattice parameters and thermal expansions [98]. Thus, the residual strain is determined by substrate materials. The most common substrate is sapphire and is used for commercial blue and green LEDs. To reduce mass-production costs, several institutes and companies have developed $\mathrm{GaN}$ on $\mathrm{Si}$ technology. We show the behavior of GaN layers on several substrates for red LEDs.

InGaN-based red LEDs grown on sapphire substrates have been developed by several research groups. In general, the $a$-lattice constant of GaN layers corresponds to the residual strain. GaN layers on sapphire have a compressive strain at RT, which can be reduced as the thickness increases [98-100]. That means that the $a$-lattice constant can be increased to near the freestanding lattice constant. Our group reported the redshifting behavior of the $633 \mathrm{~nm}$ wavelength InGaN-based red LEDs by varying the thickness of the underlying GaN layers as shown in figure 8 [35]. The redshift was approximately $16 \mathrm{~nm}$ and was because the underlying $n$-GaN layer thickness increased from 2 to $8 \mu \mathrm{m}$. It was equivalent to a $5{ }^{\circ} \mathrm{C}$ growth temperature difference. The EL intensity of red LEDs grown on $8 \mu \mathrm{m}$ thick $n$-GaN layers was enhanced 1.3 times relative to $4 \mu \mathrm{m}$ thick $n-\mathrm{GaN}$, which is attributed to the increased growth temperature of the $\mathrm{InGaN}_{\mathrm{QWs}}$ by the 


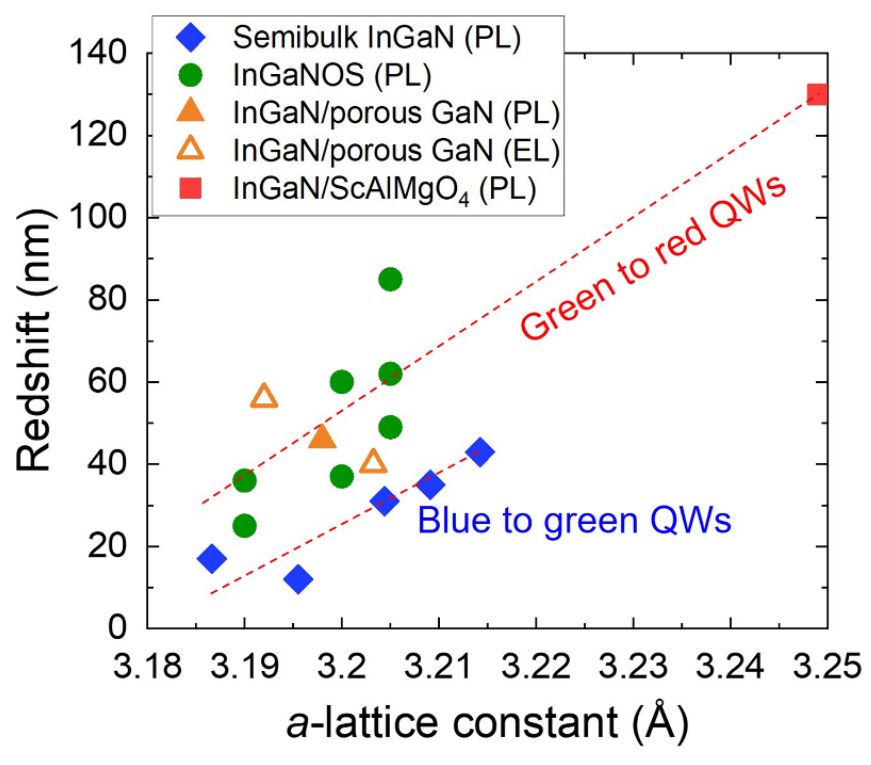

Figure 7. Redshift values of EL and PL peak wavelengths as a function of $a$-lattice constant of InGaN templates. The dashed lines are a guide for the eye.

$a$-lattice constant increases. The red LEDs have a $8 \mu$ m thick underlying $n$-GaN layers and offered a light-output power of $0.64 \mathrm{~mW}$ and an EQE of $1.6 \%$ at $20 \mathrm{~mA}(3.3 \mathrm{~V})$.

To mitigate the residual strain in GaN layers, we demonstrated $665 \mathrm{~nm}$ wavelength InGaN-based red LEDs grown on very low strained $\mathrm{GaN}$ on $(-201) \beta-\mathrm{Ga}_{2} \mathrm{O}_{3}$ substrates in 2020 [34]. The substrates provide a low lattice mismatch $(\sim 4.7 \%)$ with $\mathrm{GaN}$, which can be due to high-quality $\mathrm{GaN}$ layers with $\sim 1.9( \pm 0.2) \times 10^{8} \mathrm{~cm}^{-2}$ dislocation density [101]. The inplane strain of GaN layers presented a very slight tensile strain by Raman analysis. The $E 2$ (high) peak was at $567.93 \mathrm{~cm}^{-1}$, which was slightly shifted $-0.07 \mathrm{~cm}^{-1}$ from freestanding $\mathrm{GaN}$ $\left(568 \mathrm{~cm}^{-1}\right)$ [101]. In our experiments, the InGaN QWs grown on $(-201) \beta-\mathrm{Ga}_{2} \mathrm{O}_{3}$ substrates can increase the growth temperature by $10^{\circ} \mathrm{C}$ compared to that grown on sapphire substrates. Therefore, $\mathrm{GaN}$ on $(-201) \beta-\mathrm{Ga}_{2} \mathrm{O}_{3}$ substrates can provide a great In incorporation rate into InGaN QWs leading to pure red emission.

The concept of GaN on Si technology is done at the large wafer-scale and introduces tensile strain in a GaN layer during growth. The tensile strain introduces an increase in the $a$-lattice constant which is enhanced during In incorporation into InGaN QWs. Note that the strain in GaN layers depends on the overall structures. Recently, highly efficient green to red InGaN-based LEDs were demonstrated by Nanchang University [20, 36, 102-104]. The tensile strain leads to a higher growth temperature at $20{ }^{\circ} \mathrm{C}$ for InGaN QWs on Si compared to that of structures on sapphire [105]. Higher growth temperatures improve the crystal quality of the InGaN QWs.

\section{InGaN active regions}

The device performance is fundamentally determined by the material quality. To improve the IQE of the InGaN red LEDs,
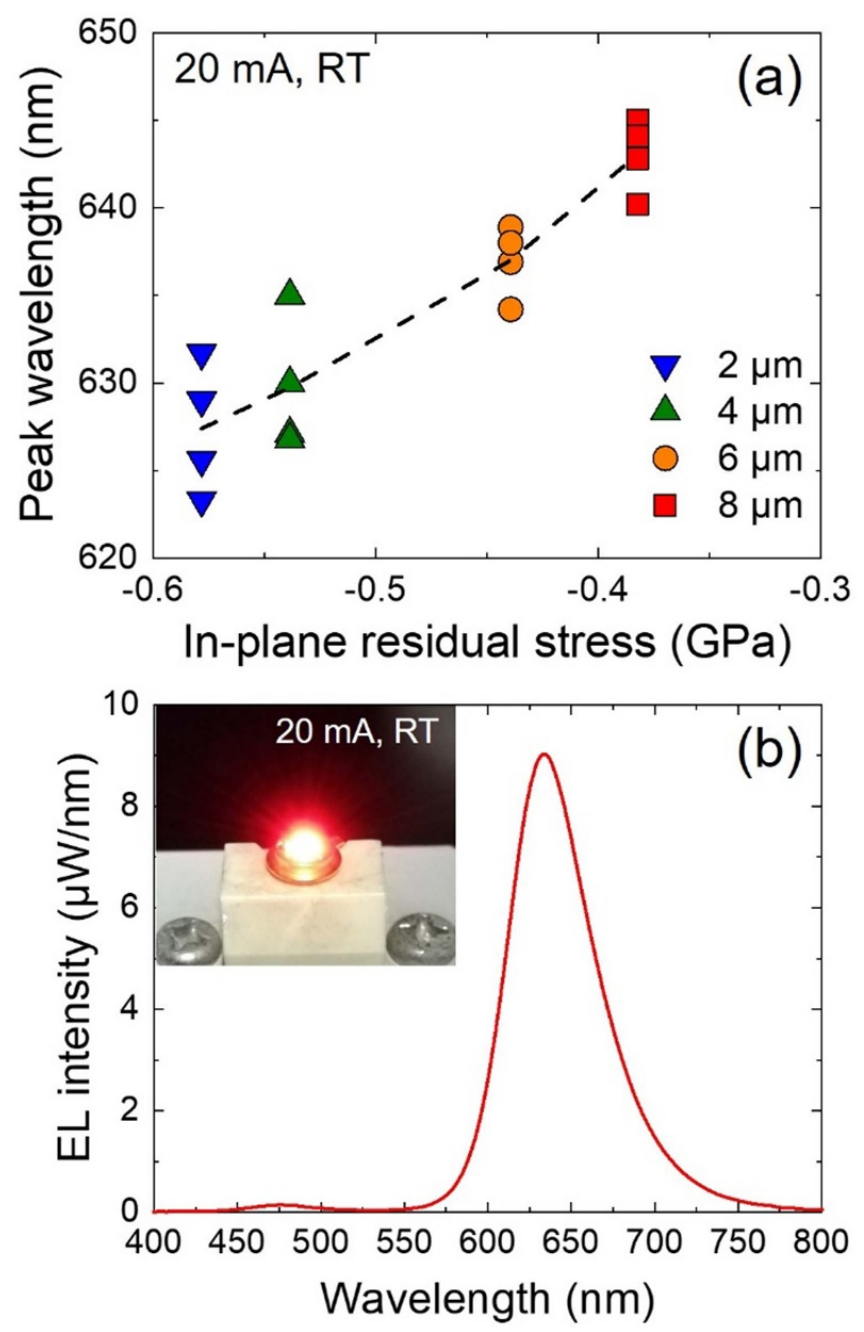

Figure 8. (a) EL peak emission wavelength as a function of in-plane stress in underlying $n$-GaN layers at $20 \mathrm{~mA}$ injection. There were four samples from each wafer. The dashed lines are visual guides for the average values. (b) EL spectrum of InGaN-based red LEDs at $20 \mathrm{~mA}$. The inset shows the red LED at a $20 \mathrm{~mA}$ driving current. Reproduced from [35]. CC BY 4.0.

the key factors are not only the InGaN growth temperature but also the structure of its active region. The InGaN preparation layers and strain-compensating structures are promising to suppress the defects in the InGaN QWs. Thus, the structural design of the active region is a key point to improve the crystalline quality of materials. Here, we will discuss the structure of the conventional (0001) $c$-plane InGaN active regions toward highly efficient red emission.

\subsection{Preparation layers}

InGaN preparation layers are commonly used to improve the efficiency of InGaN-based blue/green LEDs. The InGaN preparation layers such as SLs can prevent the point defect propagation and slightly release of the InGaN QWs strain. Typical growth for the InGaN-based LEDs occurs during growth interruption to accommodate a drastic change in the growth condition such as from $n$-layers to the MQW structure. 
We suggest that the growth interruption is a trigger to form point defects. Haller et al found that InGaN and InAlN inserting layers prevented the propagation of point defects from the underlying GaN layers [106, 107]. Also, Akasaka et al reported that the InGaN underlying layer reduced the nonradiative recombination centers of the QWs [108, 109]. The role of the In-incorporated material such as InGaN preparation layers reduces the defects of nonradiative recombination centers prior to growing the active region. This prevents propagation of defects into the QWs. Therefore, this technique is essential to fabricating highly efficient visible LEDs.

Meanwhile, the InGaN/GaN SLs structure is very helpful in reducing the strain in the QWs. The strain relaxation degree is not large but even slight strain relaxation is effective to improve the crystal quality of InGaN QWs and reduce the QCSE. This is the same concept as the strain relaxed InGaN templates. Meanwhile, the V-pits formed from InGaN/GaN SLs exhibited noteworthy effects while improving the overall device performance.

Hangleiter et al reported the mechanism underlying the unexpectedly high emission efficiency of InGaN-based QWs with V-pits [110]. The V-pit structure is induced from threading dislocations and can prevent the carrier from nonradiative recombination due to the self-screening effect [102, 111-114]. Li et al reported a three-dimensional numerical analysis about the role of the V-pits [115]. This model explained not only the V-pit self-screening effect but also hole injection into QWs, which proposed three-dimensional hole injection passing from $p$-GaN to QWs via V-pit structures. InGaN LEDs with green to red emissions suffer from the high forward voltage due to a high polarization field and a high potential barrier in the QWs compared to the typical blue LEDs. V-pit structures can enhance the hole injection into MQWs via the sidewalls rather than via standard $c$-plane direction due to the lower polarization charge densities in the sidewall structure of $\{10-11\}$ semipolar facet planes with low In contents and thin layer thicknesses [20, 36, 102, 114, 116]. Therefore, V-pits are effective at reducing the forward voltage. The additional presence of the hole injection enhancement is also helpful to improve the efficiency limitations of LEDs. Very recently, Nanchang University's group reported highly efficient orangered LEDs $\left(1 \times 1 \mathrm{~mm}^{2}\right.$ chip size $)$ that included a WPE up to $24.0 \%$ at $0.8 \mathrm{~A} \mathrm{~cm}^{-2}$ with a wavelength of $608 \mathrm{~nm}$ using V-pit effects [36]. This work realized a low forward voltage operation at $\sim 2 \mathrm{~V}$. These interesting concepts about V-pit effects can remarkably improve the WPE of the LEDs even though high dislocation densities.

We reported a hybrid MQW LED inserted a blue-green single QW underneath a main orange-red QWs [117]. This structure had improved crystal quality with orange-red QWs $(\lambda=620 \mathrm{~nm})$. It exhibited efficiency improvement and narrower FWHMs (51 nm at $20 \mathrm{~mA}$ ). The light output power and EQE were $0.23 \mathrm{~mW}$ and $0.6 \%$ at $20 \mathrm{~mA}$ operation. According to Yoshida et al, for InGaN QWs grown on sapphire substrates, the first QW grown has a large possibility to generate misfit dislocations due to the large lattice mismatch [118]. The role of the inserting blue-green single QW suggests preventing the generation of misfit dislocations in orange-red QWs.
Meng et al also reported amber LEDs with dual-wavelength structures [119]. The emission peak wavelength was obtained at 609-591 nm with an injection current of 5-100 mA. Very recently, this same group demonstrated red LEDs using the same growth technique [120]. The small blueshift was attributed to the partial strain relaxation by the lower In content InGaN QWs. However, the FWHM was $85-94 \mathrm{~nm}$, which is broader than the other reports $(47-59 \mathrm{~nm}[29,36,117])$ due to In-rich clusters.

\subsection{Strain-compensating barriers}

$\mathrm{Al}(\mathrm{Ga}) \mathrm{N}$ interlayers located between InGaN QWs and GaN barriers were reported to improve the efficiency of the highIn-content InGaN LEDs in the green to red spectral ranges $[29,35,58,121,122]$. The $\mathrm{Al}$ content of the $\mathrm{Al}(\mathrm{Ga}) \mathrm{N}$ interlayer increases with In content as the InGaN QW increases. For red LEDs, the $\mathrm{Al}$ content in $\mathrm{Al}(\mathrm{Ga}) \mathrm{N}$ interlayers were employed at $>0.9$ [29]. To discuss the band engineering of the QW structures, the $\mathrm{Al}(\mathrm{Ga}) \mathrm{N}$ interlayers affect the electron carrier confinement in the QW because they provide high band offset. The electron wave function will shift toward the zone center in the QW. Therefore, one benefit of $\mathrm{Al}(\mathrm{Ga}) \mathrm{N}$ interlayers is that it leads to an increase in the overlap between electron and hole wave functions. On the other hand, high$\mathrm{Al}$-content $\mathrm{Al}(\mathrm{Ga}) \mathrm{N}$ interlayers induced a tensile strain that can improve the crystal quality of InGaN QWs by strain compensation [29, 121, 123]. Also, the interlayers are helpful to suppress the In re-evaporation from InGaN QWs during the barrier layer growth due to the thermal budget.

The barrier layer's thickness and composition provided a larger strain-compensating effect than the interlayers between QWs and the barriers. Lekhal et al reported the behavior of the $\mathrm{AlGaN}$ barrier thickness for the strain-compensating effect, as shown in figure 9 [124]. The PL intensity was enhanced as the AlGaN barrier thickness increased from 1.4 to $10.6 \mathrm{~nm}$. The peak emission wavelength was redshifted due to an increase in the internal electric field in the InGaN QWs. In general, the behavior of redshifting and IQE has been understood as a trade-off: The material quality of the InGaN QWs was significantly improved due to suppressed defect generation by strain compensation.

We demonstrated InGaN-based amber/orange/red LEDs using the strain-compensating barriers of $\mathrm{Al}(\mathrm{Ga}) \mathrm{N}$ [34, 35, 117, 121]. Those LEDs have enhanced EQE and narrowed FWHMs due to improved crystal quality of the InGaN QWs. The $\mathrm{Al}$ content in $\mathrm{AlGaN}$ barriers needs to be increased with the longer peak emission wavelength due to strain compensation. The disadvantage of AlN and AlGaN barrier structures is the high operation voltage (e.g. 3.3-4.5 V at $\left.\sim 10 \mathrm{~A} \mathrm{~cm}^{-2}[29,121]\right)$ due to a large barrier potential increase.

\section{Growth orientation}

The crystal orientations such as (000-1) N-polar and semipolar are attractive and can grow high-In-content InGaN 


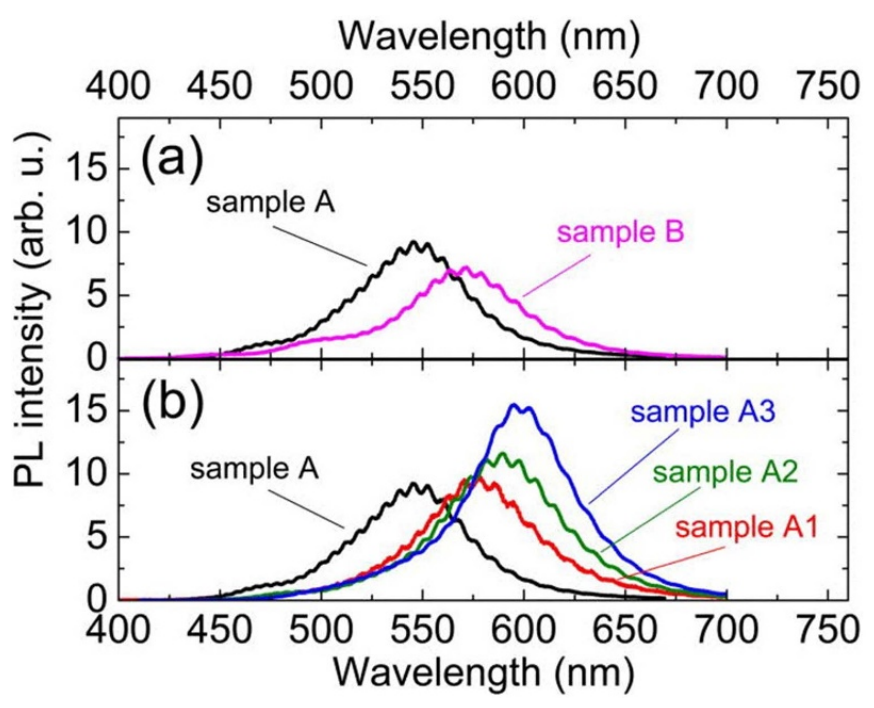

Figure 9. Room temperature photoluminescence spectra of (a) InGaN/GaN and (b) InGaN/AlGaN/GaN multiple QWs. The In content in InGaN is 0.21 (samples A, A1, A2, and A3) and 0.22 (sample B) for growth temperatures of $715{ }^{\circ} \mathrm{C}-700{ }^{\circ} \mathrm{C}$. The thickness of the $\mathrm{Al}_{0.2} \mathrm{Ga}_{0.8} \mathrm{~N}$ increased from 0 to $1.4 \mathrm{~nm}, 5.2 \mathrm{~nm}$, and $10.6 \mathrm{~nm}$ for samples A, A1, A2, and A3, respectively. Reprinted from [124], with the permission of AIP Publishing.

because of the much higher In incorporation compared to a conventional (0001) Ga-polar orientation [125-129]. N-polar orientation provides the reversed spontaneous and piezoelectric fields compared to conventional Ga-polar systems due to polarization engineering in the case of light-emitting devices. This orientation in turn leads to a low forward voltage and reduction in efficiency loss $[130,131]$. Also, semipolar and nonpolar orientations have a significant advantage for the reduction of QCSE [132-134]. These characteristics improve the efficiency of the high-In-content InGaN light-emitting devices. We will next discuss the detailed performance of the $\mathrm{N}$-polar and semipolar orientated (In)GaN growth.

\section{1. (000-1) N-polar growth}

$\mathrm{N}$-polar growth favors In incorporation into InGaN; therefore, it can offer red emission. Shojiki et al demonstrated Npolar InGaN-based red LEDs grown by MOVPE owing to the high In uptake efficiency resulting in an EL intensity of $0.7 \mathrm{~mW} \mathrm{~cm}^{-2}(0.47 \mu \mathrm{W})$ with the peak emission wavelength of $633.4 \mathrm{~nm}$ at $20 \mathrm{~mA}\left(29 \mathrm{~A} \mathrm{~cm}^{-2}\right)$ [128]. Even though the InGaN growth temperature increases, the LED efficiency was low. Also, the $633 \mathrm{~nm}$ wavelength InGaN QW emissions was indicated a large FWHM of $114 \mathrm{~nm}$ at $20 \mathrm{~mA}$ suggesting that the In fluctuation occurred due to undulation and surface step bunching of GaN surfaces by misoriented off-angle species in the sapphire substrates. Thus, the development of the InGaNbased LEDs with N-polar orientation is not sufficiently progressed due to difficulties in crystal growth. For example, the (In)GaN crystalline quality is not sufficient due to dislocation density issues [135], the formation of hexagonal hillocks [136, 137], and residual impurities [138, 139]. To overcome these issues, crystal quality has improved over time using several growth techniques such as the optimization of V/III ratio [138, 140, 141], In [142], Mg [136, 143] surfactants, and misorientation angles [135, 137].

Especially, in the case of MOVPE, N-polar (In)GaN growth has suffered from high residual impurities such as $\mathrm{C}$ and $\mathrm{O}$, which were reported over one magnitude higher than that in Ga-polar systems under the same growth condition [144, 145]. Notably, Lund et al reported that the residual C concentration is as low as $2 \times 10^{16} \mathrm{~cm}^{-3}$ using triethylgallium (TEGa) and triethylindium (TEIn) precursors for InGaN MQWs growth [141]. They identified the residual O concentrations of $3-5 \times 10^{16} \mathrm{~cm}^{-3}$ for N-polar InGaN. This was still much higher than $4-8 \times 10^{15} \mathrm{~cm}^{-3}$ for Ga-polar systems. Based on this, the PL intensity of the N-polar InGaN MQWs was one magnitude lower than the Ga-polar one. This result suggests that nonradiative recombination channels were related to the metal-vacancy-oxygen complexes [146]. Ueno et al also demonstrated N-polar InGaN LEDs grown by PSD [147]. The crystalline quality of N-polar GaN layers indicated that the FWHM of x-ray rocking curves for (0002) and (10-12) diffractions were 313 and 394 arcsec, respectively. The FWHM values are comparable to the typical Gapolar GaN. However, the background electron concentration of undoped N-polar GaN was available and could reduce the system to $8.5 \times 10^{16} \mathrm{~cm}^{-3}$ suggesting that the $\mathrm{O}$ concentration was still higher than that of Ga-polar GaN. Those results suggest that the controlling of $\mathrm{O}$ incorporation during growth is critical to improving the IQE of InGaN QWs.

\subsection{Non-c-plane growth}

Semipolar and nonpolar growth can lead to highly efficient InGaN-based LEDs with a longer emission wavelength due to mitigation of QCSE in the InGaN QWs. A few works concerned with the InGaN-based amber-red LEDs grown on semipolar and nonpolar $\mathrm{GaN}$ have been reported. Semipolar (11-22) InGaN-based amber LEDs were grown on freestanding semipolar (11-22) GaN substrates [132] and $m$-plane patterned sapphire substrates [133]. Seo et al reported nonpolar (11-20) $a$-plane orange LEDs grown on $r$-plane sapphire substrates [148]. Those reports exhibited a small blueshift compared to conventional $c$-plane amber LEDs suggesting an effective suppression in QCSE.

Strain relaxation also leads to reduced piezoelectric fields. For example, the poor-crystalline quality of materials is easier for strain relaxed materials in the InGaN MQWs [118]. Kawaguchi et al demonstrated semipolar (20-21) InGaNbased red LEDs grown on freestanding semipolar (20-21) GaN substrates with a low forward voltage operation of $2.8 \mathrm{~V}$ at $20 \mathrm{~mA}$ [149].

Semipolar growth techniques have provided highperformance laser diode (LD) and vertical cavity surfaceemitting laser including blue and green emissions [150153]. However, the growth techniques are still very difficult to extend the emission wavelength. This suggests that semipolar growth needs further optimization of growth conditions. 


\section{Three-dimensional structures}

Three-dimensional structures can realize high crystalline quality InGaN red LEDs. An excellent advantage of functional nanostructures such as NWs, nanopyramids, and platelets is that they offer defect-free structures and free-strain (i.e. polarization) for realizing high-performance LEDs. Those nanostructures are very attractive for light-emitting devices and have great potential to improve IQE. Three-dimensional structures can also improve the light extraction efficiency. Therefore, these nanostructures can provide an excellent platform for improving EQE. This is a very attractive way to improve the efficiency of the micro-LEDs because such bottom-up approaches can avoid nonradiative recombination by surfaces damaged during mesa etching. We will next review the nanoscale growth techniques for fabricating InGaN red LEDs.

\subsection{Nanowire (NW) growth}

Many efforts have been used to fabricate red emission NW structures by MBE. Kikuchi et al demonstrated $645 \mathrm{~nm}$ wavelength InGaN multiple quantum disks embedded in nanocolumns in 2004 (for convenience, equal to NWs). These were red LEDs on $n$-type (111) Si substrates and had self-assembled growth [154]. Following those nanocolumn growth techniques, several groups reported the NWs red LEDs $(\lambda=600$ $700 \mathrm{~nm}$ ) with embedded InGaN quantum disks/dots by MBE growth [155-161].

For example, Jahangir et al also demonstrated $650 \mathrm{~nm}$ wavelength red NWs LEDs with a high IQE [155]. The postgrowth NW surfaces were passivated by parylene, which led to significantly improved IQE from $10 \%$ to $52 \%$. Nguyen et al proposed the InGaN/AlGaN quantum disks/dots LEDs with the AlGaN barrier shell structures. This led to a remarkable EL emission enhancement compared to typical GaN barriers [162]. One can further decrease the nonradiative surface recombination and improve the carrier injection.

Zhao et al demonstrated InGaN/GaN quantum-disks in NW LEDs $(\lambda=\sim 700 \mathrm{~nm})$; these were self-assembled directly on metal-substrates by MBE [158, 159]. The devices obtained a light-output power as high as $8 \mathrm{~mW}$ at $600 \mathrm{~mA}$ operation. Bui et al also reported extremely small blueshift values operating at 50-350 mA $1.5 \mathrm{~nm}$ for the blue micro-LEDs and $3 \mathrm{~nm}$ for the red ones [160]. The blueshift behavior indicated a negligible level due to the reduced polarization field attributed to the screening of the QCSE via a high current density operation. This work also suggests that the lateral strain relief in NWs contributed to reduced polarization. Such spontaneously selfassembled NW structures will have a broad emission spectrum (FWHM: >90 nm [155, 158, 160]) because the emission wavelength and intensity varied by wire-to-wire fluctuations. This broad spectrum is favorable and can lead to phosphor-free white emission with a relatively high color rendering index.

High-performance nanostructure devices are useful for high-definition displays and must have a precise arrangement in terms of periodicity and diameter. Vadivelu et al first demonstrated a InGaN QWs nanocolumn with red LEDs via a selective area growth technique [156]. Figure 10 shows that

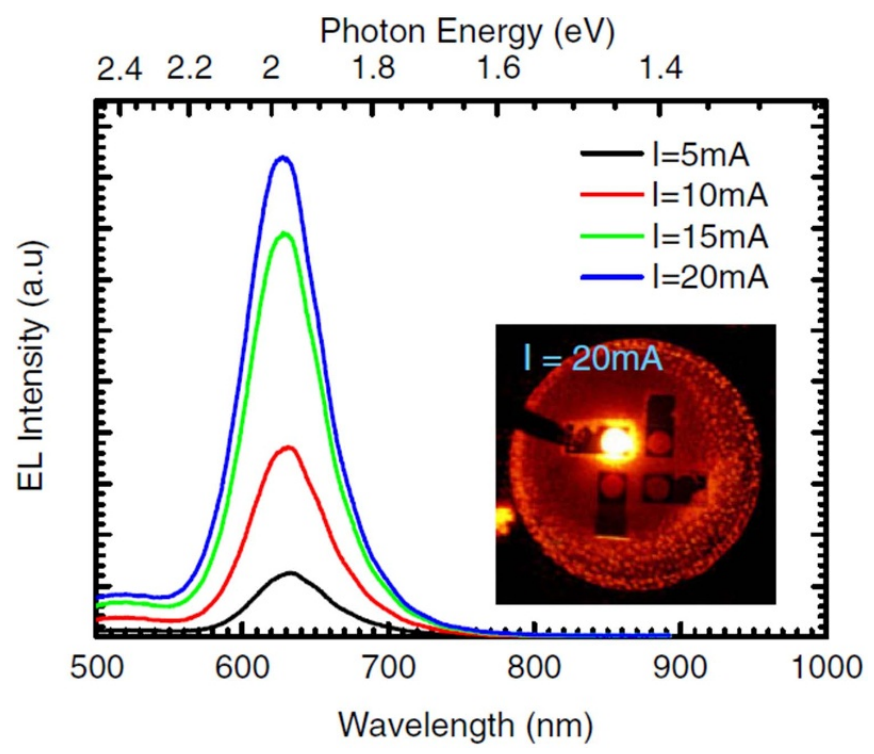

Figure 10. The EL spectra of an LED for an injection current from 5 to $20 \mathrm{~mA}\left(65-255 \mathrm{~A} \mathrm{~cm}^{-2}\right)$. The near field emission image at $20 \mathrm{~mA}$ is shown in the inset. Reproduced from [156]. C IOP Publishing Ltd. All rights reserved.

the emission peak wavelength and FWHM were $633 \mathrm{~nm}$ and $185 \mathrm{meV}(\sim 60 \mathrm{~nm})$ at $5 \mathrm{~mA}\left(65 \mathrm{~A} \mathrm{~cm}^{-2}\right)$, respectively. This indicates a small blueshift of $5 \mathrm{~nm}$ because of the high current density operation that contributes to the screening of the polarization field. It also suggests that the polarization and band filling effects are negligible due to the strain relief in the active regions. The light-output power was as low as $16 \mu \mathrm{W}$ at $20 \mathrm{~mA}$. The same group reported nanocolumns red LEDs with a very narrow FWHM of $15 \mathrm{~nm}$ at a $637 \mathrm{~nm}$ peak emission wavelength [161]. This showed that the periodic arrangement of nanocolumns architecture leads to photonic crystal effects [163]. As a result, the directional beam profile produced a small radiation angle of $\pm 30^{\circ}$ due to the light diffraction at the photonic band edge.

The selective area growth techniques for NWs are a very attractive way to fabricate the monolithic integrated three primary colors on the same wafers. Sekiguchi et al controlled the In content in InGaN QW via nanocolumn diameters in 2010 [164]. The emission wavelengths were controlled from blue $(479 \mathrm{~nm})$ to red $(632 \mathrm{~nm})$ with increasing diameters. The effect was explained by the beam shadowing of the neighboring nanocolumns and the adatoms diffusion length from the sidewall surfaces. The same group demonstrated integrated red, green, blue, and yellow micro-LEDs on the same wafer [165].

Ra et al also reported a single or a few NWs on the same LED chips with emission wavelength tunable via the NW diameter [166]. The active region was composed of InGaN QDs in NWs. The reduction in the NW diameters led increased the amount of In adatoms on the top region due to both impingent adatoms and migrated adatoms from the sidewall surfaces. These offer a longer emission wavelength. The monolithically integrated multicolor single NW LED pixels show four EL peak wavelengths based on by varied NW diameters: 
$659 \mathrm{~nm}$ (diameter: $220 \mathrm{~nm}$ ), $625 \mathrm{~nm}$ (diameter: $320 \mathrm{~nm}$ ), $526 \mathrm{~nm}$ (diameter: $420 \mathrm{~nm}$ ), and $461 \mathrm{~nm}$ (diameter: $630 \mathrm{~nm}$ ). These approaches are promising for the development of fullcolor light-emitting devices for various applications.

A few works have reported on NW red LEDs grown by MOVPE. InGaN core-shell NW LEDs grown on GaN templates use selective area growth technique and were demonstrated by Hong et al in 2011 [167]. Embedded InGaN QWs were anisotropically grown on the topmost plane/facet and the sidewall surfaces. The LEDs have a color-tunable emission from red to blue due to the non uniform current injection path. The red emission was obtained from the topmost InGaN QWs. The LEDs exhibited a peak emission wavelength at 680-690 nm under lower current densities $\left(<20 \mathrm{~A} \mathrm{~cm}^{-2}\right)$.

Glō is a leading company producing nitride-based NW LEDs - they have reported InGaN core-shell NW LEDs in the orange-red spectral range. LEDs with a $600 \mathrm{~nm}$ peak wavelength had an estimated encapsulated EQE of approximately $3 \%$ at $0.5 \mathrm{~A} \mathrm{~cm}^{-2}$ [168]. Kum et al demonstrated excellent wafer-level uniformity of GaN NW structures on $100 \mathrm{~mm}$ sapphire substrates using a two-step self-limited method via MOVPE [169]. The InGaN/GaN core-shell NW LEDs were fabricated and show that the RGB emissions on the same wafer had a varied pitch for the NWs [169]. The EL peak emission wavelength was obtained at $600 \mathrm{~nm}$ for $65 \mathrm{~mA}$ $\left(1.5 \mathrm{~A} \mathrm{~cm}^{-2}\right)$.

Recently, triangular-shaped semipolar (11-22) InGaN/GaN MQW shells in NW LEDs were grown on an amorphous glass substrate using MOCVD by Johar et al [170]. The high crystalline quality GaN NW growth on a glass substrate was based on catalyst-assisted growth technique including two-step growth vapor-liquid-solid and vapor-solid methods. The GaN NWs were formed along the $m$-axis orientation using a $\mathrm{Au}$ catalyst [171]. The red PL emission is up to $703 \mathrm{~nm}$ and was observed from InGaN MQW shells. The estimated IQE was as high as $35.6 \%$ via the ratio of integrated PL intensity at LT and RT. This can lead to longer emission wavelengths using InGaN QWs.

\subsection{Nanopyramid and platelet structures}

Another attractive way has been proposed for high-crystalline quality InGaN templates using nanostructures such as nanopyramids and platelets; these materials have great potential for high-efficiency red LEDs [172-174]. Such syntheses can take advantage of strain relaxation, low dislocation densities, and a reduction in the piezoelectric field. In turn, the InGaN QWs on those nanostructures can improve IQE. Chang et al reported a $600 \mathrm{~nm}$ wavelength amber LED on nanopyramid GaN structures [175]. The IQE was as high as $21 \%$. However, the amber LEDs had no EL emission until $40 \mathrm{~mA}$ due to a considerable current leakage due to defects on the coalesced pyramid boundaries. Ko et al demonstrated a $650 \mathrm{~nm}$ emission InGaN double heterostructure grown on GaN nanopyramids. This system formed semipolar facet planes using an
MOVPE selective area growth method with nanoimprinting [174]. The role of nanopyramid structures is to grow highIn-content InGaN owing to the surface diffusion of adatoms and the compositional pulling effect. This is a very interesting approach to obtain red emission. Very crystalline nanopyramids offer good IQE improvements of $0.56 \%-7.2 \%$ compared to the planar structures.

InGaN nanopyramid structures have been proposed as templates for the growth of high-In-content LEDs. To realize highly selective InGaN growth on $\mathrm{GaN}$ templates with dielectric-masked nano-holes, a pulse interruption of Ga precursors was introduced during InGaN growth [176, 177]. Several groups have reported the fabrication of high-crystalline quality InGaN hexagonal nanopyramid structures with a relatively high In content using a nanoscale selective area during MOVPE growth [174, 178-180]. GaN nuclei growth during opening of nano-holes is essential to obtaining precisely controlled InGaN pyramids $[177,178]$. The InGaN nanopyramids showed six smooth sidewall semipolar facets corresponding to $\{10-11\}$ planes. The nanopyramid structures were dislocation-free because the window area was very small (100 nm diameter) to induce elastic strain relaxation. This growth technique is an attractive way to obtain high-quality crystals and very homogeneous InGaN nanostructures for red LEDs.

Bi et al demonstrated high-crystalline quality InGaN platelets combined with selective area MOVPE growth and in situ annealing process [173]. Figure 11 shows the procedure for InGaN-based LED grown on platelet structures [173]. The in situ annealing process provided $c$-plane surfaces formed by etching down from the InGaN pyramid apex. The LED structures were grown on those InGaN platelets. Notably, the FWHM of red LEDs was very narrow and as low as $48 \mathrm{~nm}$ (150 meV); there was no blueshift with current increases as shown in figure $11(\mathrm{~g})$. To further improve the crystalline quality of InGaN platelets, InGaN pyramids were polished from the apex by a chemical mechanical polishing technique [172]. In this way, the InGaN platelet is not required to grow InGaN layers with intermediate to low In contents-this prevents the generation of dislocations due to lattice mismatch. Such strainrelaxed InGaN platelets are a new platform for high-In-content InGaN light-emitting devices and are superior to develop the application for micro-LED displays.

\subsection{Quantum dots (QDs)}

Conventional InGaN active regions consist of QW structures but QDs can also facilitate red emission. The QD-active regions can improve the crystalline quality of high-In-content InGaN and reduce QCSE by strain relaxation compared to conventional QW structures. In general, the QD-active region provides superior advantages such as stronger quantum confinement [181-183], carrier localization [184, 185], short radiative carrier lifetime [186], high wavelength stability $[182,183,186]$, and high temperature stability of emissions $[182,184]$. 


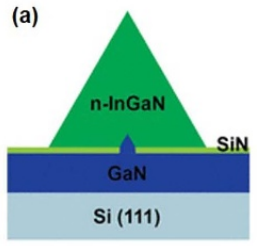

(d)
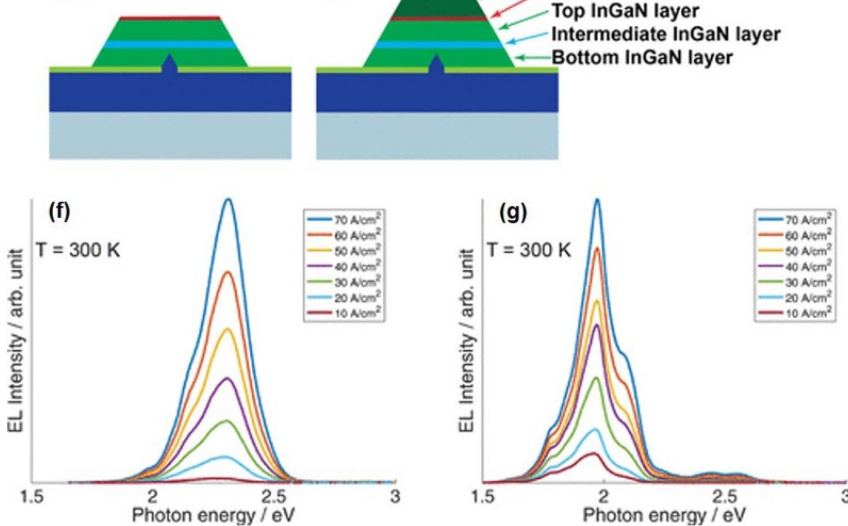

Figure 11. Procedures to synthesize InGaN platelets and LED structures. (a) InGaN pyramids grown by selective area MOVPE. (b) Bottom InGaN layer with a top $c$-plane formed by etching down from the pyramid apex using in situ annealing. (c) InGaN regrowth to flatten the rough $c$-plane formed in panel $\mathrm{b}$. An intermediate layer of InGaN is grown first with an indium content of $<5 \%$. A top InGaN layer is then grown with an indium content similar to that of the bottom InGaN layer in panel b. (d) InGaN single QW growth on the $c$-plane of the InGaN platelet templates. (e) Prototype LED structure with $p$-InGaN grown above the single $\mathrm{QW}$ with definitions of all InGaN layers. (f), (g) EL spectra obtained at different current injection levels for the green LEDs grown on $\mathrm{In}_{0.09} \mathrm{Ga}_{0.91} \mathrm{~N}$ platelets and the red ones on $\mathrm{In}_{0.18} \mathrm{Ga}_{0.82} \mathrm{~N}$ platelets, respectively. The current density in both legends was calculated according to the actual QW area rather than the contact area. Reprinted with permission from [173]. Copyright (2019) American Chemical Society.

The red LEDs with self-assembled InGaN QDs with InGaN wetting layers were formed via the Stranski-Krastanov (SK) growth mode. InGaN QDs red LEDs with composite InGaN/AlN/GaN active regions were formed by TMIn treatment of the wetting InGaN layers with a peak emission wavelength of $661 \mathrm{~nm}$ at $60 \mathrm{~mA}$ [187]. The InGaN QDs were obtained via a growth interruption method. The emission peak wavelength was $729 \mathrm{~nm}$ at $80 \mathrm{~mA}$ [188]. The composite $\mathrm{InGaN} / \mathrm{GaN}$ structures were formed by phase-separation due to surface roughness of the underlying $n$-GaN layer; emission was at $610 \mathrm{~nm}$ [189]. QD-like clusters formed into InGaN QWs due to InGaN phase-separation, which indic-

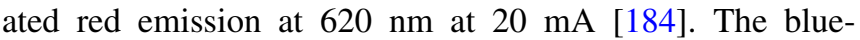
shift behavior was only $2 \mathrm{~nm}$ with current injection from 40 to $100 \mathrm{~mA}$. This suggests that the QCSE in such QD structures is suppressed by strain relaxation. Very recently year, Wang et al reported near-ultraviolet to red LEDs with Volmer-Weber (VW) InGaN QDs by MOVPE [186]. The carrier lifetime of VW QDs was much shorter than SK ones.
This property is very attractive for visible light communication applications.

\section{A unique approach for red emission by Eu-doping}

An alternative approach has been proposed for red emissions from Eu-doped $\mathrm{GaN}$ active layers [190]. The ${ }^{5} \mathrm{D}_{0}-{ }^{7} \mathrm{~F}_{2}$ transition of the $4 \mathrm{f}$ shell in $\mathrm{Eu}^{3+}$ ions is known as the $\sim 621 \mathrm{~nm}$ emission with an ultra-narrow FWHM of $\sim 1 \mathrm{~nm}$ [190]. This is a very attractive optical property for display applications compared to typical InGaN red LEDs that have a FWHM as large as $50 \mathrm{~nm}$ [29]. Also, the GaN:Eu active layers do not suffer from the QCSE issue, therefore, the emission peak wavelengths can be stabilized.

To date, many efforts have been reported for Eu-doped $\mathrm{GaN}$ fabrication of high-purity red-emitting systems such as a ion implantation with post-thermal annealing [191, 192], MBE [190, 193-200], and MOVPE [200-207]. Co-doping into $\mathrm{GaN}$ :Eu have been proposed to improve the efficiency of the red emissions. Takagi et al demonstrated a drastic Eu luminescence enhancement of 20 fold via Mg co-doping [196]. The same group also reported that the $\mathrm{Mg}$ co-doped $\mathrm{GaN}: \mathrm{Eu}$ nanocolumns using red LEDs had feasible crystal quality even though there was heavy Eu doping at up to $6 \times 10^{20} \mathrm{~cm}^{-3}$ [200].

Lee et al demonstrated that $\mathrm{Mg}-\mathrm{Si}-\mathrm{Eu}$ co-doping in $\mathrm{GaN}$ provided a new Eu luminescence with stable thermal annealing in an ambient $\mathrm{N}_{2}$ environment [208]. Mitchell et al reported the utilization of $\mathrm{O}$ co-doping into $\mathrm{GaN}: \mathrm{Eu}$, which increased the homogeneity of Eu incorporation into Ga-sites without Eu precipitation on the surface [203, 209]. These techniques led to the formation of new Eu centers related to $\mathrm{Mg}$ or $\mathrm{O}$. This improves the energy transfer efficiency. Codoping is an important technique to create high-performance GaN:Eu-based red LEDs with controlled Eu ion luminescence centers.

Fujiwara's group demonstrated the low forward voltage operation of GaN:Eu-based red LEDs using MOVPE in 2009 [207]. By further optimizing the growth conditions such as growth pressure [206], growth temperature [202], V/III ratio [204], multilayer structure [201, 209], and co-doping [203, 209], GaN:Eu-based red LEDs achieved a light-output power of $1.25 \mathrm{~mW}$ at $20 \mathrm{~mA}$. This was an EQE of $3.3 \%$, as shown in figure 12 [209]. The maximum EQE was as high as $9.2 \%$. The device features are comparable with InGaN-based red LEDs.

Fujiwara's group first demonstrated monolithically integrated RGB LEDs with InGaN QWs and GaN:Eu,O active layers [23]. Notably, the optical properties such as blueshift and FWHM behaviors of GaN:Eu,O LEDs were remarkably stabilized by current injection compared to InGaN-based LEDs. The GaN:Eu LEDs had $100 \%$ purity of the $621 \mathrm{~nm}$ wavelength red emission due to the ultra-narrow FWHM of $\sim 1 \mathrm{~nm}$. The RGB LEDs had a high coverage of $91.2 \%$ of the Rec. 2020 


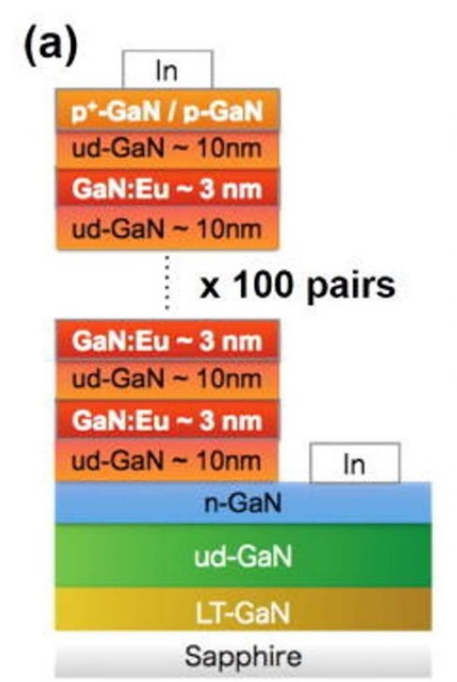

Modulation-doped structure

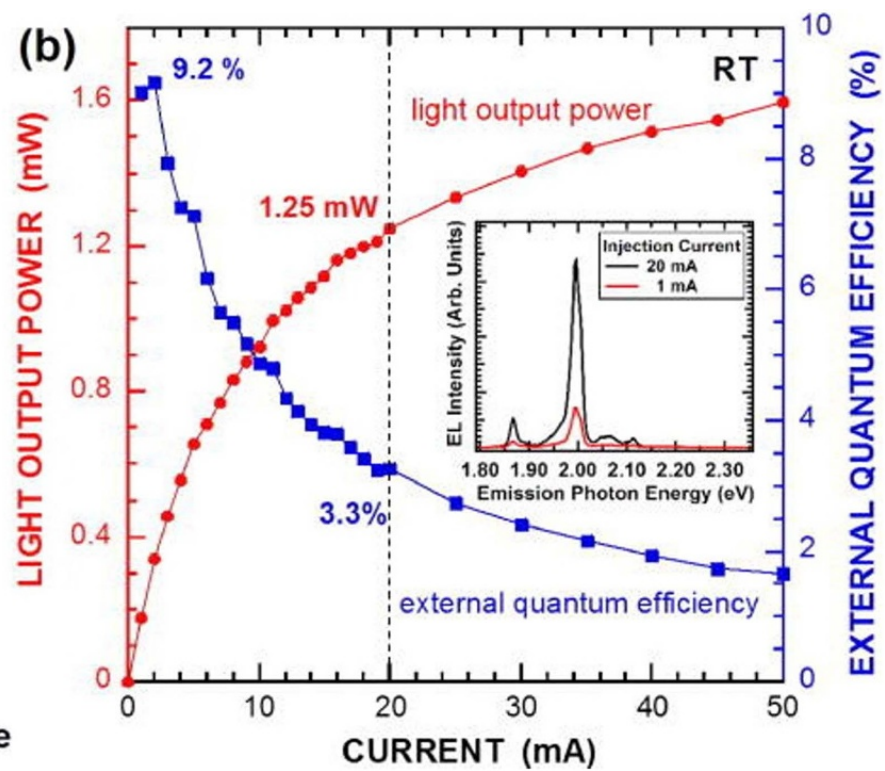

CURRENT (mA)

Figure 12. (a) Schematic of an LED with an active layer comprised of 100 pairs of alternating GaN and GaN:Eu layers. (b) The output power and EQE of this LED is plotted as a function of injection current. The maximum output power at $20 \mathrm{~mA}$, was $1.25 \mathrm{~mW}$, and the maximum EQE was $9.2 \%$ at $2 \mathrm{~mA}$. The inset shows the emission spectra from this LED at two different injection currents. Reprinted from [209], with the permission of AIP Publishing.

standard in CIE 1931. This way is favorable and can realize high pixel density micro-LED applications.

\section{Device characterizations}

This chapter describes the device performance of (In)GaNbased LED at longer emission wavelengths in the range of yellow to red. We review state-of-the-art performance features such as EQEs, FWHMs, blueshifts, and thermal stability in (In)GaN-based LEDs.

\section{1. $E Q E$ in InGaN-based red LEDs}

This section summarizes the characteristics of the InGaNbased LEDs with emission longer than $580 \mathrm{~nm}$ (tables 2-4). Figure 13 describes the EQE as a function of the peak emission wavelength. The light extraction efficiency is not the same between each publication because efficiency is quite sensitive to device configuration (resin packaging, surface roughening, and patterned sapphire substrates). Device size could also be influenced by the IQE due to SRH nonradiative recombination [14].

In 2013, the Toshiba company first demonstrated $629 \mathrm{~nm}$ wavelength InGaN-based red LEDs with light-output power exceeding $1 \mathrm{~mW}$ at $20 \mathrm{~mA}\left(\sim 10 \mathrm{~A} \mathrm{~cm}^{-2}\right)$ [29]. The EQE was as high as $2.9 \%$. They adopted the AlGaN interlayer in the active regions to improve the crystalline quality of InGaN QWs and increase the overlap between electron and hole wave functions. However, this structure suffers from disadvantages such as high forward voltage operation (4.4 V at $20 \mathrm{~mA}$ ), which negatively affects WPE.

Recently, the Nanchang University group demonstrated a peak WPE of orange-red LEDs that was as high as $24.0 \%$ at a low current density $\left(0.8 \mathrm{~A} \mathrm{~cm}^{-2}\right.$ at $\left.2.0 \mathrm{~V}\right)$ [36]. The LEDs utilized $\mathrm{GaN}$ on $\mathrm{Si}$, which led to improved crystalline quality of InGaN via growth based on temperature increases. They adopted V-pit structures that improved hole injection to obtain a low forward voltage operation. When comparing these data (table 2), the operation current density should be closely maintained because most of the reported EQE values are given by a current density of $10-30 \mathrm{~A} \mathrm{~cm}^{-2}$. Devices will blueshift (ca. 20-30 nm) and efficiency will decrease at high current density operations $\left(\geqslant 10 \mathrm{~A} \mathrm{~cm}^{-2}\right)$ due to polarization effects, Auger recombination, and current leakage. Also, the same group reported the $585 \mathrm{~nm}$ wavelength yellow LEDs with a EQE of $12.6 \%$ at $20 \mathrm{~A} \mathrm{~cm}^{-2}$ [104]. These findings suggest that the efficiency trend is similar to Toshiba's result when the devices operate at a high current density.

These efforts have contributed to improved efficiency of the LEDs. Nevertheless, the EQEs of state-of-the-art InGaNbased red LEDs are far worse than conventional blue and green LED systems. The low-efficiency obstacle with InGaN-based red LEDs is a large QCSE and a low-crystalline quality in the active regions. This means that the red LEDs need further progress in the growth methods mentioned in sections 2-3; breakthrough growth techniques are needed.

\subsection{Spectral characteristics}

In this section, we report details of the spectral characteristics of InGaN-based red LEDs. The FWHMs of emission spectra are a critical parameter to govern the apparent colors of InGaN-based red LEDs. Figure 14 shows the FHWMs of InGaN-based LEDs with various peak emission wavelengths listed in tables 2-4. The FWHM values tend to be larger with 
Table 2. Structures and characteristics of the reported (0001) $c$-plane (In)GaN-based LEDs with yellow to red emission. Most LEDs were grown by MOVPE but one used a PSD method. The EQE values were obtained by on-wafer testing when the device area was $50 \times 50 \mu \mathrm{m}^{2}$ or smaller.

\begin{tabular}{|c|c|c|c|c|c|c|c|c|c|}
\hline Year & Affiliation & Active region & Substrate & $\begin{array}{l}\lambda_{\text {peak }} \\
(\mathrm{nm})\end{array}$ & $I(\mathrm{~mA})$ & $\begin{array}{l}\text { Device area } \\
(\mu \mathrm{m} \times \mu \mathrm{m})\end{array}$ & $\mathrm{EQE}(\%)$ & $\begin{array}{l}\text { FWHM } \\
(\mathrm{nm})\end{array}$ & Reference \\
\hline 1998 & Nichia & $2.5 \mathrm{~nm}$ InGaN SQW & Sapphire & 594 & 20 & $350 \times 350$ & 3.35 & 50 & [210] \\
\hline 1999 & Nichia & $6 \mathrm{~nm} \mathrm{InGaN} \mathrm{SQW}$ & Sapphire & 675 & 20 & $350 \times 350$ & 0.82 & - & {$[28]$} \\
\hline 2002 & Nichia & $3 \mathrm{~nm}$ InGaN SQW & Sapphire & 631 & 20 & $350 \times 350$ & 1.1 & - & {$[211]$} \\
\hline 2006 & $\begin{array}{l}\text { National Taiwan } \\
\text { Univ. }\end{array}$ & InGaN/GaN 5QWs & Sapphire & 600 & 20 & $300 \times 300$ & - & 57 & {$[212]$} \\
\hline 2012 & $\begin{array}{l}\text { Tokyo Univ. of } \\
\text { Science }\end{array}$ & InGaN/(In)GaN 16QWs & Sapphire & 740 & 20 & $500 \times 500$ & - & 138 & {$[56]$} \\
\hline 2014 & Toshiba & $\begin{array}{l}\mathrm{In}_{0.35} \mathrm{Ga}_{0.65} \mathrm{~N} / \mathrm{AlGaN} / \\
\mathrm{InGaN} 4 \mathrm{QWs}\end{array}$ & PSS & 629 & 20 & $460 \times 460$ & 2.9 & 53 & [29] \\
\hline 2014 & $\begin{array}{l}\text { The Univ. of } \\
\text { Tokyo }\end{array}$ & $30 \mathrm{~nm} \mathrm{In}_{0.33} \mathrm{Ga}_{0.67} \mathrm{~N}$ & $\begin{array}{l}\text { Graphene/ } \\
\mathrm{SiO}_{2}\end{array}$ & 640 & 20 & - & - & 60 & {$[213]$} \\
\hline 2015 & $\begin{array}{l}\text { Chinese } \\
\text { Academy of } \\
\text { Sciences }\end{array}$ & InGaN/GaN 5QWs & Sapphire & 585 & 50 & $500 \times 1000$ & 1.4 & - & [214] \\
\hline 2016 & $\begin{array}{l}\text { Tokyo Univ. of } \\
\text { Science }\end{array}$ & $\begin{array}{l}\text { InGaN/AlN/GaN/AlGaN/ } \\
\text { GaN 2QWs }\end{array}$ & Sapphire & 600 & 20 & $370 \times 370$ & 0.8 & 50 & {$[121]$} \\
\hline 2016 & $\begin{array}{l}\text { Tokyo Univ. of } \\
\text { Science }\end{array}$ & $\begin{array}{l}\text { InGaN/AlN/GaN/AlGaN/ } \\
\text { GaN 2QWs }\end{array}$ & Sapphire & 620 & 20 & $370 \times 370$ & 0.6 & 51 & [117] \\
\hline 2016 & $\begin{array}{l}\text { Tokyo Univ. of } \\
\text { Science }\end{array}$ & $\begin{array}{l}\text { InGaN/AlN/GaN/AlGaN/ } \\
\text { GaN 2QWs }\end{array}$ & Sapphire & 631 & 20 & $370 \times 370$ & 0.4 & 52 & {$[117]$} \\
\hline 2017 & $\begin{array}{l}\text { Chonbuk } \\
\text { National Univ. }\end{array}$ & $\begin{array}{l}\operatorname{In}_{0.45} \mathrm{Ga}_{0.55} \mathrm{~N} / \mathrm{In}_{0.13} \mathrm{Ga}_{0.87} \mathrm{~N} \\
\text { 5QWs }\end{array}$ & PSS & 596 & 80 & - & - & 69 & {$[215]$} \\
\hline 2017 & $\begin{array}{l}\text { Chonbuk } \\
\text { National Univ. }\end{array}$ & $\begin{array}{l}\operatorname{In}_{0.42} \mathrm{Ga}_{0.58} \mathrm{~N} / \mathrm{In}_{0.13} \mathrm{Ga}_{0.87} \mathrm{~N} \\
\text { 5QWs }\end{array}$ & PSS & 597 & 20 & $1000 \times 1000$ & 1.2 & 62 & [216] \\
\hline 2017 & Osaka Univ. & $\mathrm{GaN}: \mathrm{Eu}$ & Sapphire & 621 & 20 & - & 0.94 & $\sim 1$ & [201] \\
\hline 2018 & Osaka Univ. & $\mathrm{GaN}: \mathrm{Eu}$ & Sapphire & 621 & 20 & - & 3.3 & $\sim 1$ & [209] \\
\hline 2019 & Nanchang Univ. & InGaN/GaN 8QWs & $\mathrm{Si}(111)$ & 585 & 200 & $1000 \times 1000$ & 12.6 & 48.6 & [104] \\
\hline 2019 & $\begin{array}{l}\text { Chinese } \\
\text { Academy of } \\
\text { Sciences }\end{array}$ & InGaN/GaN 2QWs & PSS & 603 & 20 & - & - & 75 & [119] \\
\hline 2020 & $\begin{array}{l}\text { Univ. of } \\
\text { Grenoble-Alpes }\end{array}$ & $\begin{array}{l}\mathrm{In}_{y} \mathrm{Ga}_{1-y} \mathrm{~N} / \mathrm{In}_{x} \mathrm{Ga}_{1-x} \mathrm{~N} \\
\text { 5QWs }\end{array}$ & InGaNOS & 620 & 11 & $300 \times 300$ & - & 67 & {$[77]$} \\
\hline 2020 & $\begin{array}{l}\text { Univ. of } \\
\text { Grenoble-Alpes }\end{array}$ & $\begin{array}{l}\mathrm{In}_{y} \mathrm{Ga}_{1-y} \mathrm{~N} / \mathrm{In}_{x} \mathrm{Ga}_{1-x} \mathrm{~N} \\
\text { 5QWs }\end{array}$ & InGaNOS & 623 & 0.3 & $50 \times 50$ & - & 58 & {$[77]$} \\
\hline 2020 & $\begin{array}{l}\text { Univ. of } \\
\text { Grenoble-Alpes }\end{array}$ & $\begin{array}{l}\mathrm{In}_{y} \mathrm{Ga}_{1-y} \mathrm{~N} / \mathrm{In}_{x} \mathrm{Ga}_{1-x} \mathrm{~N} \\
\text { 5QWs }\end{array}$ & InGaNOS & 612 & 15.3 & $300 \times 300$ & 0.01 (on wafer) & - & {$[77]$} \\
\hline 2020 & $\begin{array}{l}\text { Univ. of } \\
\text { Grenoble-Alpes }\end{array}$ & $\begin{array}{l}\mathrm{In}_{y} \mathrm{Ga}_{1-y} \mathrm{~N} / \mathrm{In}_{x} \mathrm{Ga}_{1-x} \mathrm{~N} \\
\text { 5QWs }\end{array}$ & InGaNOS & 616 & 1 & $50 \times 50$ & 0.09 (on wafer) & - & [77] \\
\hline 2020 & KAUST & $\begin{array}{l}\text { InGaN/AlN/GaN/AlGaN/ } \\
\text { GaN 2QWs }\end{array}$ & PSS & 633 & 20 & $400 \times 400$ & 1.6 & 59 & {$[35]$} \\
\hline 2020 & KAUST & $\begin{array}{l}\text { InGaN/AlN/GaN/AlGaN/ } \\
\text { GaN 2QWs }\end{array}$ & $\begin{array}{l}(-201) \beta- \\
\mathrm{Ga}_{2} \mathrm{O}_{3}\end{array}$ & 665 & 20 & $650 \times 250$ & 0.19 & 67 & {$[34]$} \\
\hline 2020 & Nanchang Univ. & InGaN/GaN 2QWs & Si (111) & 608 & 8 & $1000 \times 1000$ & 23.5 & 43.5 & [36] \\
\hline 2021 & UCSB & InGaN/AlGaN/GaN 3QWs & $\begin{array}{l}\text { InGaN } \\
\text { on porous } \\
\text { GaN/sapphire }\end{array}$ & 632 & 0.004 & $6 \times 6$ & 0.2 (on wafer) & 62 & [74] \\
\hline 2021 & $\begin{array}{l}\text { Chinese } \\
\text { Academy of } \\
\text { Sciences }\end{array}$ & InGaN/GaN 2QWs & PSS & 615 & 20 & - & - & 87 & {$[120]$} \\
\hline 2021 & KAUST & $\begin{array}{l}\text { InGaN/AlN/GaN/AlGaN/ } \\
\text { GaN 2QWs }\end{array}$ & PSS & 626 & 0.09 & $47 \times 47$ & 0.36 (on wafer) & 52 & {$[24]$} \\
\hline 2021 & KAUST & $\begin{array}{l}\text { InGaN/AlN/GaN/AlGaN/ } \\
\text { GaN 2QWs }\end{array}$ & PSS & 606 & 0.44 & $47 \times 47$ & 0.56 (on wafer) & 50 & [217] \\
\hline
\end{tabular}


Table 3. Structures and characteristics of the reported semipolar, nonpolar, and (000-1) N-polar orientated InGaN-based LEDs with yellow to red emission.

\begin{tabular}{|c|c|c|c|c|c|c|c|c|c|c|}
\hline Year & Affiliation & $\begin{array}{l}\text { Growth } \\
\text { method }\end{array}$ & Active region & Orientation & $\begin{array}{l}\lambda_{\text {peak }} \\
(\mathrm{nm})\end{array}$ & $I(\mathrm{~mA})$ & $\begin{array}{l}\text { Device area } \\
(\mu \mathrm{m} \times \mu \mathrm{m}), \text { or } \\
\text { diameter }(\mu \mathrm{m}) \text { or } \\
\text { emission area }\end{array}$ & $\begin{array}{l}\text { EQE } \\
(\%)\end{array}$ & $\begin{array}{l}\text { FWHM } \\
\text { (nm) }\end{array}$ & Reference \\
\hline 2006 & Kyoto Univ. & MOVPE & $\begin{array}{l}3 \text { nm InGaN/ } \\
\text { GaN SQW }\end{array}$ & $(11-22)$ & 590 & 20 & $320 \times 320$ & 1.3 & 53 & {$[132]$} \\
\hline 2011 & $\begin{array}{l}\text { Korea Electronics } \\
\text { Technology } \\
\text { Institute }\end{array}$ & MOVPE & $\begin{array}{l}18 \mathrm{~nm} \\
\mathrm{InGaN} / \mathrm{GaN} \\
\text { SQW }\end{array}$ & $(11-20)$ & 612.2 & 20 & $200 \times 500$ & - & 72 & {$[148]$} \\
\hline 2013 & UCSB & MOVPE & $\begin{array}{l}3 \text { nm InGaN/ } \\
\text { GaN SQW }\end{array}$ & $(20-21)$ & 624 & 20 & 340 & - & - & {$[149]$} \\
\hline 2015 & Univ. of Sheffield & MOVPE & $\begin{array}{l}\text { InGaN/GaN } \\
\text { SQW }\end{array}$ & $(11-22)$ & 584 & 20 & $330 \times 330$ & - & 70 & {$[133]$} \\
\hline 2015 & Univ. of Sheffield & MOVPE & $\begin{array}{l}\text { InGaN/GaN } \\
\text { SQW }\end{array}$ & $(11-22)$ & 608 & 20 & $330 \times 330$ & - & - & {$[133]$} \\
\hline 2015 & Univ. of Sheffield & MOVPE & $\begin{array}{l}\text { InGaN/GaN } \\
\text { SQW }\end{array}$ & $(11-22)$ & 594 & 100 & $330 \times 330$ & - & 88 & {$[133]$} \\
\hline 2015 & Tohoku Univ. & MOVPE & $\begin{array}{l}\text { InGaN/GaN } \\
5 \mathrm{QWs}\end{array}$ & $(000-1)$ & 633.4 & 20 & $67600 \mu \mathrm{m}^{2}$ & - & 114 & {$[128]$} \\
\hline 2015 & Tohoku Univ. & MOVPE & $\begin{array}{l}\mathrm{InGaN} / \mathrm{GaN} \\
5 \mathrm{QWs}\end{array}$ & $(000-1)$ & 600.5 & 20 & $67600 \mu \mathrm{m}^{2}$ & - & 97 & {$[128]$} \\
\hline 2017 & $\begin{array}{l}\text { The Univ. of } \\
\text { Tokyo }\end{array}$ & PSD & $\begin{array}{l}10 \mathrm{~nm} \\
\mathrm{In}_{0.4} \mathrm{Ga}_{0.6} \mathrm{~N}\end{array}$ & $(000-1)$ & 609 & 20 & - & - & 94 & {$[147]$} \\
\hline
\end{tabular}

a longer peak emission wavelength. This is a typical phenomenon of InGaN-based LEDs, which can be described by an energy potential distribution due to disordered alloy compositions and thicknesses. Strain relaxation causes the InGaN active regions to induce inhomogeneous In incorporation via defects (dislocations and trench defects) [121]. Residual strain can propagate from patterned substrates to induce a wide distribution of In content and QCSE [218]. Therefore, the FWHM behaviors depend on the configuration of the device structures such as growth orientations, design of active regions, patterning of substrates, and dimensions.

Semipolar and nonpolar orientations are required for larger In content in InGaN QWs compared to $c$-plane systems because of a low QCSE. This presumes a high possibility of generating defects due to the strain relaxation, which induces disordered In incorporation into InGaN-active regions. The FWHMs of (000-1) $c$-plane LEDs are as large as the (0001) $c$-plane systems. The origin of broad spectra of (000-1) $c$-plane LEDs is large In fluctuations and QW thickness disorders due to step bunching and surface undulation [135, 141, 219]. The misorientation angles of substrates are associated with those issues. Meanwhile, the disorder of In incorporation (phase separation) is due to the In-rich InGaN QD structures leading to red emissions. However, based on the reason above, the FWHMs of QD structures increase drastically compared to that of conventional QW structures. InGaN nanostructured devices such as NWs and InGaN platelets were formed by spontaneous self-assembly or controlled mask-patterned growth methods. In incorporation is very sensitive to the diameter of the nanostructures $[164,166]$. Therefore, the emission of spontaneously self-assembled random nanostructures becomes broad due to wire-to-wire fluctuations compared to that of controlled ones.

The hue of InGaN QWs emission is determined by the peak wavelengths and their FWHMs. The hue of the InGaN red QWs emission is not matched with its peak emission wavelength due to the broad spectra. Robin et al reported on the hue of InGaN QWs emission in the red spectral range. The red spectral range can be obtained via high color saturation even with large FWHMs [25]. However, the broad spectra led to a large hue blueshift over $575 \mathrm{~nm}$ emission-this is known as the Abney effect; the hue of monochromatic light can be affected by bandwidth. Mizokami et al reported on the relationship between emission wavelength and its bandwidth for estimating the Abney effect [220]. Figure 14 shows the wavelength tendency according to the Abney effect. The hue of the emission wavelength (apparent wavelength) depends on its FWHMs. According to the Rec. 2020 standard, primary red, green, and blue colors are located at $(0.708,0.292),(0.17$, 0.797), and $(0.131,0.046)$ in Commission Internationale de l'Eclairage (CIE) 1931 chromaticity coordinates, respectively. Thus, it requires red emission whose apparent wavelength is $630 \mathrm{~nm}$.

To realize the apparent emission wavelength at $630 \mathrm{~nm}$ for the Rec. 2020 standard, current reports suggest that InGaNbased red LEDs are required to emit at a peak wavelength over $660 \mathrm{~nm}$. The broad spectra are obstacles to realizing highlyefficiency LEDs with a pure red emission. Some InGaNbased red LEDs have been reported in an unexpected additional short-wavelength peak emission attributed to the InGaN phase-separation in the active regions [28, 29, 35, 77, 121]. This issue is affected by the color saturation of the LEDs. 
Table 4. Structures and characteristics of the reported nanostructured InGaN-based LEDs with yellow to red emission.

\begin{tabular}{|c|c|c|c|c|c|c|c|c|c|c|}
\hline Year & Affiliation & $\begin{array}{l}\text { Growth } \\
\text { method }\end{array}$ & Active region & $\begin{array}{l}\text { Array nano } \\
\text { structure }\end{array}$ & $\begin{array}{l}\lambda_{\text {peak }} \\
(\mathrm{nm})\end{array}$ & $I(\mathrm{~mA})$ & $\begin{array}{l}\text { Device area } \\
(\mu \mathrm{m} \times \mu \mathrm{m}) \text {, } \\
\text { or diameter } \\
(\mu \mathrm{m}) \text { or } \\
\text { surface area }\end{array}$ & $\begin{array}{l}\text { FWHM } \\
(\mathrm{nm})\end{array}$ & $\begin{array}{l}\mathrm{EQE} \\
(\%)\end{array}$ & Reference \\
\hline 2007 & Boston Univ. & MBE & InGaN/GaN QDs & Random & 640 & 20 & - & 97 & - & {$[222]$} \\
\hline 2010 & $\begin{array}{l}\text { A STAR, National } \\
\text { Univ. of Singapore }\end{array}$ & MOVPE & $\begin{array}{l}\text { InGaN/AlN/GaN } \\
\text { QDs }\end{array}$ & Random & 582 & 30 & - & 57 & - & [223] \\
\hline 2010 & $\begin{array}{l}\text { A STAR, National } \\
\text { Univ. of Singapore }\end{array}$ & MOVPE & $\begin{array}{l}\text { InGaN/AlN/GaN } \\
\text { QDs }\end{array}$ & Random & 617 & 30 & - & 99 & - & [223] \\
\hline 2011 & $\begin{array}{l}\text { A STAR, National } \\
\text { Univ. of Singapore }\end{array}$ & MOVPE & $\begin{array}{l}\text { InGaN/AlN/GaN } \\
\text { QDs }\end{array}$ & Random & 661 & 60 & - & 120 & - & [187] \\
\hline 2011 & Yeungnam Univ. & MOVPE & $\begin{array}{l}30 \mathrm{~nm} \text { InGaN } \\
\text { QDs }\end{array}$ & Random & 610 & 20 & $300 \times 300$ & 75 & - & [189] \\
\hline 2012 & McGill Univ. & MBE & $\begin{array}{l}\text { InGaN/GaN QDs } \\
\text { in NWs }\end{array}$ & Random & 652 & 50 & $500 \times 500$ & 90 & - & [224] \\
\hline 2013 & Sophia Univ. & MBE & $\begin{array}{l}\mathrm{InGaN} / \mathrm{GaN} \\
\text { 3QWs in NWs }\end{array}$ & Controlled & 597 & 10 & 65 & 54 & - & {$[225]$} \\
\hline 2013 & $\begin{array}{l}\text { Univ. of Michigan, } \\
\text { OSRAM }\end{array}$ & MBE & $\begin{array}{l}\mathrm{In}_{0.54} \mathrm{Ga}_{0.46} \mathrm{~N} \\
\text { quantum disks in } \\
\text { NWs }\end{array}$ & Random & 650 & 30 & $7.8 \times 10^{-4} \mathrm{~cm}^{-2}$ & 95 & - & {$[155]$} \\
\hline 2013 & $\begin{array}{l}\text { National Chiao Tung } \\
\text { Univ. }\end{array}$ & MOVPE & $\begin{array}{l}\text { Nanopyramid } \\
\text { InGaN/GaN } \\
\text { MQWs }\end{array}$ & Controlled & 645 & 50 & $300 \times 300$ & 119 & - & {$[175]$} \\
\hline 2013 & Tsinghua Univ. & MOVPE & InGaN/GaN QDs & Random & 738 & 75 & $300 \times 300$ & 112 & - & [188] \\
\hline 2013 & Tsinghua Univ. & MOVPE & InGaN/GaN QDs & Random & 708 & 100 & $300 \times 300$ & 145 & - & [188] \\
\hline 2013 & Sophia Univ. & MBE & $\begin{array}{l}\text { InGaN/GaN } \\
\text { 3QWs in NWs }\end{array}$ & Controlled & 633 & 5 & 100 & 60 & - & {$[156]$} \\
\hline 2014 & $\begin{array}{l}\text { Univ. of Michigan, } \\
\text { OSRAM }\end{array}$ & $\mathrm{MBE}$ & $\begin{array}{l}\mathrm{In}_{0.51} \mathrm{Ga}_{0.49} \mathrm{~N} \\
\text { quantum disks in } \\
\text { NWs }\end{array}$ & Random & 610 & - & - & 74 & - & {$[157]$} \\
\hline 2015 & Sophia Univ. & MBE & $\begin{array}{l}\mathrm{InGaN} / \mathrm{GaN} \\
5 \mathrm{QWs} \text { in NWs }\end{array}$ & Controlled & 670 & 10 & 65 & 62 & 0.07 & [226] \\
\hline 2016 & $\begin{array}{l}\text { McGill Univ., } \\
\text { McMaster Univ., } \\
\text { Samsung }\end{array}$ & $\mathrm{MBE}$ & $\begin{array}{l}\text { InGaN/GaN QDs } \\
\text { in NWs }\end{array}$ & Controlled & 659 & $4.5 \times 10^{-3}$ & 0.22 & 103 & - & [166] \\
\hline 2016 & $\begin{array}{l}\text { McGill Univ., } \\
\text { McMaster Univ., } \\
\text { Samsung }\end{array}$ & MBE & $\begin{array}{l}\text { InGaN/GaN QDs } \\
\text { in NWs }\end{array}$ & Controlled & 625 & $4.5 \times 10^{-3}$ & 0.32 & 72 & - & [166] \\
\hline 2016 & KAUST & $\mathrm{MBE}$ & $\begin{array}{l}\text { InGaN quantum } \\
\text { disks in NWs }\end{array}$ & Random & 710 & 350 & 400 & - & 0.7 & {$[158]$} \\
\hline 2016 & KAUST & $\mathrm{MBE}$ & $\begin{array}{l}\text { InGaN quantum } \\
\text { disks in NWs }\end{array}$ & Random & 705 & 400 & 200 & - & 0.2 & [159] \\
\hline 2017 & $\begin{array}{l}\text { New Jersey Institute } \\
\text { of Technology }\end{array}$ & MBE & $\begin{array}{l}\text { InGaN/AlGaN } \\
\text { QDs in NWs }\end{array}$ & Random & 645 & 400 & $300 \times 300$ & 125 & - & [227] \\
\hline 2018 & $\begin{array}{l}\text { Chinese Academy of } \\
\text { Sciences }\end{array}$ & MOVPE & $\begin{array}{l}\text { Shell- and QD- } \\
\text { like clusters in } \\
\text { MQWs }\end{array}$ & Random & 619 & 20 & 一 & 85 & - & [184] \\
\hline 2019 & Lund Univ. & MOVPE & $\begin{array}{l}\text { InGaN SQW in } \\
\text { InGaN platelet }\end{array}$ & Controlled & 626 & $\sim 70$ & 360 & 48 & - & {$[173]$} \\
\hline 2019 & $\begin{array}{l}\text { New Jersey Institute } \\
\text { of Technology }\end{array}$ & $\mathrm{MBE}$ & $\begin{array}{l}\text { InGaN/AlGaN } \\
\text { QDs in NWs }\end{array}$ & Random & 645 & 100 & 50 & 93 & - & {$[160]$} \\
\hline 2019 & Sophia Univ. & $\mathrm{MBE}$ & $\begin{array}{l}120 \mathrm{~nm} \text { InGaN in } \\
\text { NWs }\end{array}$ & Controlled & 637 & 10 & 100 & 15 & - & {$[161]$} \\
\hline 2020 & Sophia Univ. & $\mathrm{MBE}$ & $\begin{array}{l}70 \mathrm{~nm} \text { InGaN in } \\
\text { NWs }\end{array}$ & Controlled & 647 & 0.8 & $5 \times 5$ & 112 & - & [165] \\
\hline
\end{tabular}




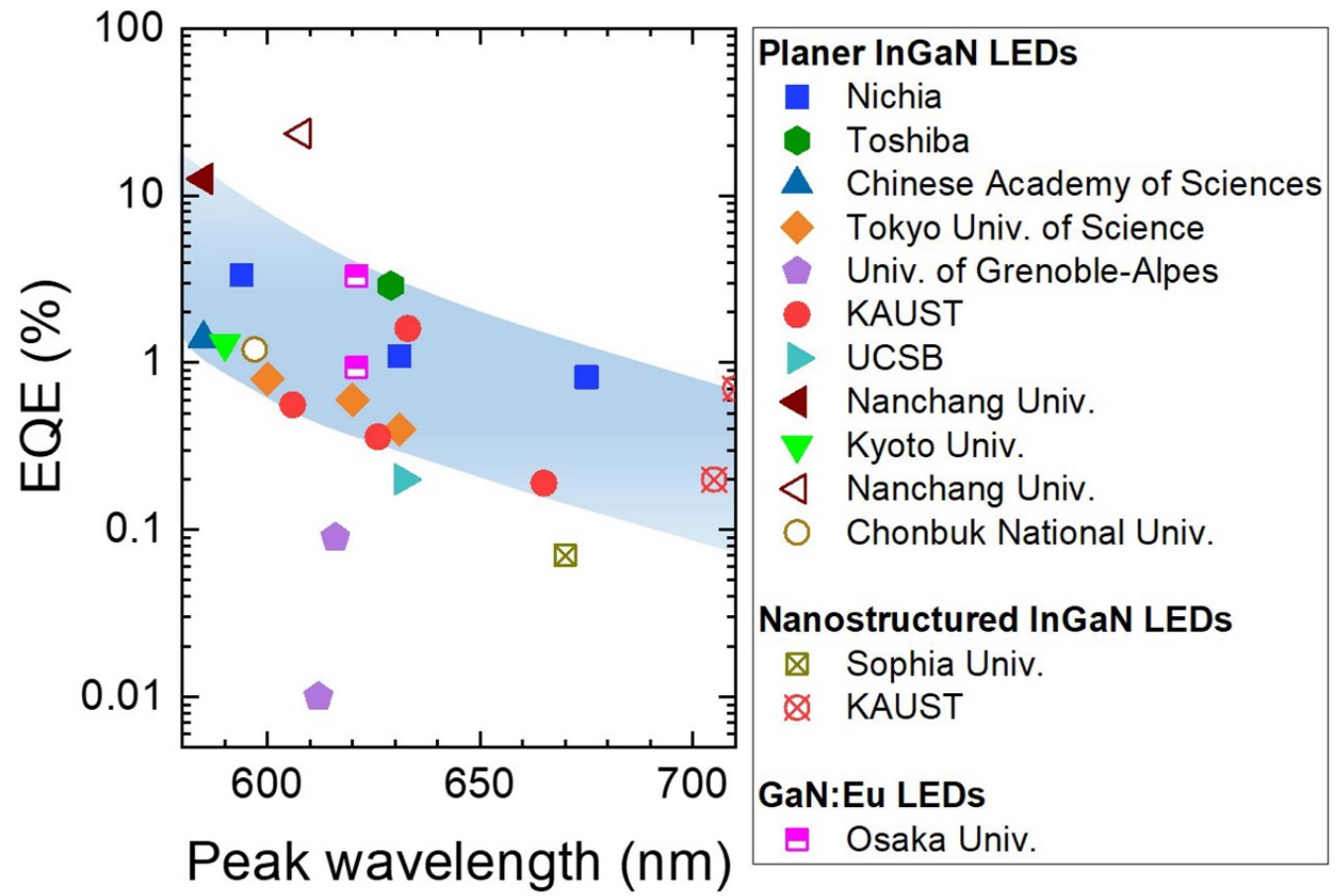

Figure 13. EQE of (In)GaN-based LEDs with peak wavelength ranges from 580 to $710 \mathrm{~nm}$. Solid and open symbols are given by high $\left(\geqslant 10 \mathrm{~A} \mathrm{~cm}^{-2}\right)$ and low $\left(<10 \mathrm{~A} \mathrm{~cm}^{-2}\right)$ current densities for planar InGaN LEDs, respectively. The other data correspond to nanostructured InGaN LEDs and GaN:Eu LEDs. The shaded area indicates the general trend between efficiencies and peak wavelength at standard current density $\left(\geqslant 10 \mathrm{~A} \mathrm{~cm}^{-2}\right)$.

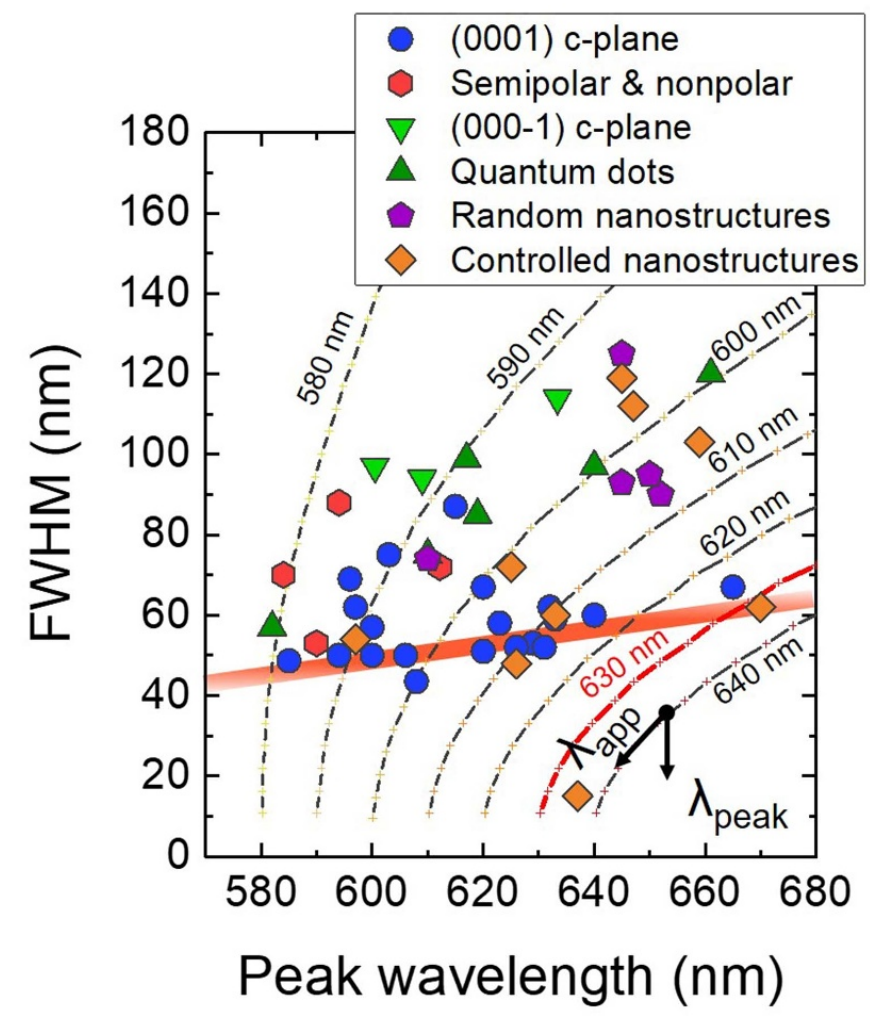

Figure 14. FWHM of InGaN-based LEDs as a function of the peak wavelength. Dashed lines correspond to the apparent wavelength $\left(\lambda_{\text {app }}\right)$ which corresponds to the hue in the CIE diagram according to [220]. The red belt is a guide for the eye. 


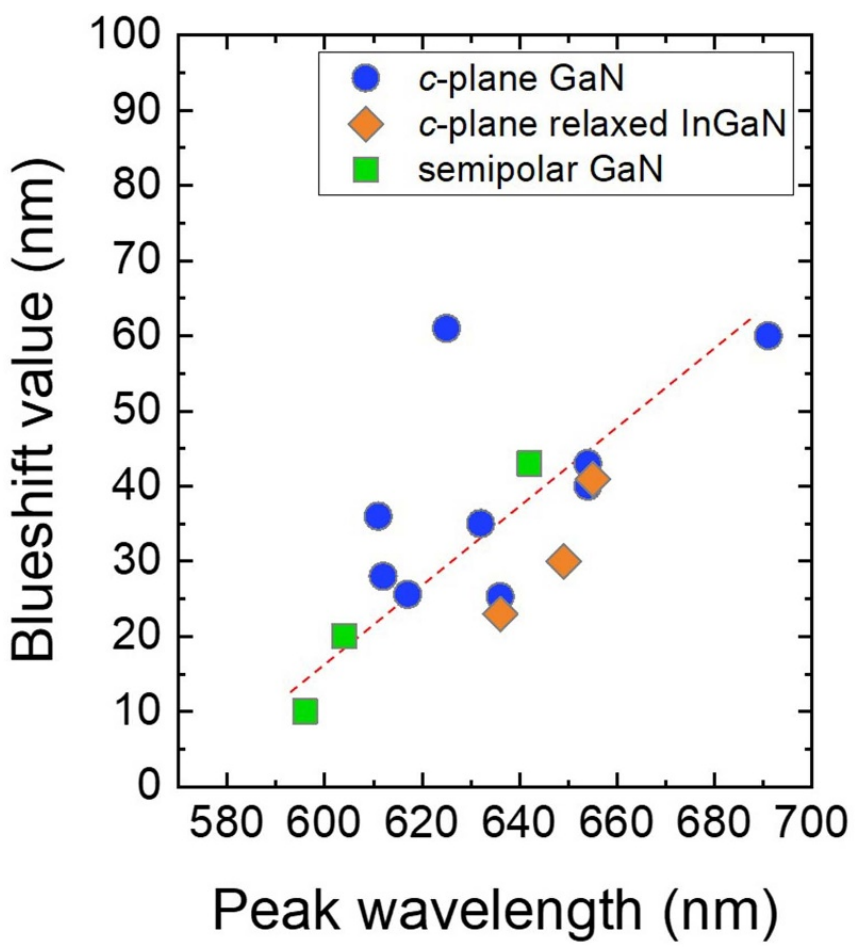

Figure 15. Blueshift behavior of InGaN-based LEDs with an orange-red spectral range. Blueshift values of the EL emissions explained differences in peak wavelengths between low $\left(0.1-3 \mathrm{~A} \mathrm{~cm}^{-2}\right)$ and high $\left(10-63 \mathrm{~A} \mathrm{~cm}^{-2}\right)$ current densities. Peak wavelengths are obtained at low current densities $\left(0.1-3 \mathrm{~A} \mathrm{~cm}^{-2}\right)$. The dashed line is a guide for the eye.

The minimum FWHM range of the red LEDs at $629 \mathrm{~nm}$ peak emission is $53 \mathrm{~nm}$ corresponding to $\sim 166 \mathrm{meV}$ [29]. In contrast, the FWHM of conventional InGaN-based blue LEDs is as small as $\sim 20 \mathrm{~nm}$ and corresponds to $\sim 120 \mathrm{meV}$ [221]. For example, it is possible for the FWHMs of red LEDs to be the same as the energy distribution of blue LEDs. In this case, the $630 \mathrm{~nm}$ apparent wavelength can satisfy the red color in the Rec. 2020 standard, which requires a peak wavelength over $640 \mathrm{~nm}$ with a FWHM of $40 \mathrm{~nm}$. Therefore, to achieve highefficiency InGaN-based LEDs with a pure red emission, it is essential to narrow the FWHMs of the emission spectra.

In general, the peak emission wavelengths of InGaN LEDs are shifted to shorter wavelength. Current injection increases due to screening of the QCSE and band filling of localized states. This phenomenon remarkably occurs when the In content in InGaN QWs increases. Figure 15 shows this blueshifting behavior of InGaN-based LEDs in the orange-red spectral range including the polar and semipolar orientations listed in table 5. The blueshift values are quantified as the peak wavelength differences between low (0.1-3 $\left.\mathrm{A} \mathrm{cm}^{-2}\right)$ and high (10-63 $\mathrm{A} \mathrm{cm}^{-2}$ ) current densities. Semipolar LEDs can have a minimized blueshift of the peak wavelength based on the reduction of the QCSE. Bai et al reported a blueshift as small as $10 \mathrm{~nm}$ at $596 \mathrm{~nm}$ with increasing injection current from $1 \mathrm{~mA}\left(\sim 1 \mathrm{~A} \mathrm{~cm}^{-2}\right)$ to $50 \mathrm{~mA}\left(\sim 46 \mathrm{~A} \mathrm{~cm}^{-2}\right)$ [133]. However, the blueshift value was similar to $c$-plane LEDs at $640 \mathrm{~nm}$, which suggests significant band filling of localized states due to large In fluctuation. Here, the red LEDs grown on Si substrates can have a reduced QCSE due to the strain reduction in the active region by V-pit structures. The strain-reduced InGaN QWs grown on novel InGaN templates can be mitigated by peak emission shifts via a small QCSE.

\subsection{Temperature stabilities}

Here, we discuss the thermal properties of InGaN-based red LEDs. It is well known that the temperature dependence of the EL measurement is an approach to study the reliability of LEDs. The increasing temperature degrades the lightoutput power, lifetime, and wavelength stability of LEDs. The EL intensities of LEDs usually decrease with temperature increases, i.e. thermal droop [228]. The thermal droops of EL intensity are described by [229]:

$$
I=I_{T=\mathrm{RT}} \exp \left(-\frac{T-\mathrm{RT}}{T_{\mathrm{ch}}}\right)
$$

where $I$ is the EL intensity, $I_{T=\mathrm{RT}}$ is the EL intensity at room temperature (RT), $T[\mathrm{~K}]$ is the temperature of the sampling stage, and $T_{\mathrm{ch}}[\mathrm{K}]$ is the characteristic temperature. The characteristic temperature is a standard quantitative parameter to evaluate the temperature stability of the LEDs' EL intensity. A larger characteristic temperature implies better temperature stability of EL intensities. Figure 16(a) presents the characteristic temperatures of InGaN-based red LEDs at various current densities [24, 29, 34, 217, 230, 231]. For comparison, we also plot the characteristic temperatures of AlGaInP-based LEDs [232, 233]. We explained the characteristic temperature by the 
Table 5. Blueshifts of the reported (0001) $c$-plane and semipolar orientated InGaN-based LEDs with yellow to red emission. The peak wavelengths were quantified at $0.1-3 \mathrm{~A} \mathrm{~cm}^{-2}$.

\begin{tabular}{|c|c|c|c|c|c|c|}
\hline Year & Affiliation & Orientation & Substrate & $\begin{array}{c}\lambda_{\text {peak }} \text { at } J= \\
0.1-3 \mathrm{~A} \mathrm{~cm}^{-2}(\mathrm{~nm})\end{array}$ & Blueshift (nm) & Reference \\
\hline 2006 & Kyoto Univ. & $(11-22)$ & GaN sub. & 604 & 20 & [132] \\
\hline 2014 & Toshiba & $(0001)$ & $c$-plane PSS & 654 & 43 & [29] \\
\hline 2015 & Chinese Academy of Sciences & $(0001)$ & $c$-plane PSS & 611 & 36 & [214] \\
\hline 2015 & University of Sheffield & $(11-22)$ & $m$-plane sapphire & 642 & 43 & {$[133]$} \\
\hline 2015 & University of Sheffield & $(11-22)$ & $m$-plane sapphire & 596 & 10 & {$[133]$} \\
\hline 2016 & Tokyo Univ. of Science & $(0001)$ & $c$-plane sapphire & 617 & 25.6 & {$[121]$} \\
\hline 2016 & Tokyo Univ. of Science & $(0001)$ & $c$-plane sapphire & 636 & 25.3 & [117] \\
\hline 2017 & Chonbuk National Univ. & $(0001)$ & $c$-plane PSS & 625 & 61 & [216] \\
\hline 2020 & Univ. of Grenoble-Alpes & $(0001)$ & InGaNOS & 636 & 23 & [77] \\
\hline 2020 & Univ. of Grenoble-Alpes & $(0001)$ & InGaNOS & 649 & 30 & [77] \\
\hline 2020 & KAUST & $(0001)$ & $c$-plane PSS & 654 & 40 & {$[35]$} \\
\hline 2020 & KAUST & $(0001)$ & $(-201) \beta-\mathrm{Ga}_{2} \mathrm{O}_{3}$ & 691 & 60 & [34] \\
\hline 2021 & UCSB & $(0001)$ & $\begin{array}{l}\text { InGaN on porous } \mathrm{GaN} / \\
c \text {-plane sapphire }\end{array}$ & 655 & 41 & [74] \\
\hline 2021 & KAUST & $(0001)$ & $c$-plane PSS & 632 & 35 & [24] \\
\hline
\end{tabular}
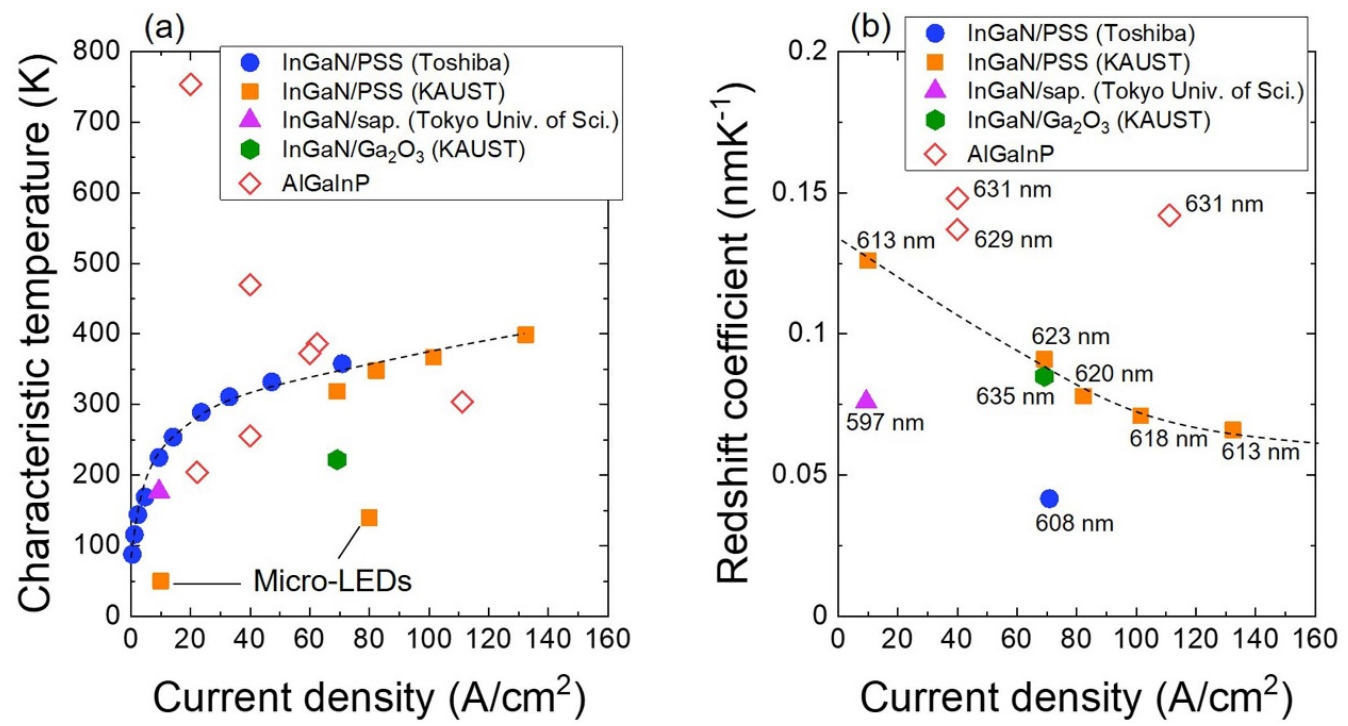

Figure 16. (a) Characteristic temperatures of InGaN- and AlGaInP-based red LEDs at various current densities. (b) Redshift coefficients of those red LEDs as a function of various current densities. The peak emission wavelengths at RT are shown. AlGaInP-based LEDs were studied under a pulse injection current. The dashed lines are a guide for the eye.

SRH nonradiative recombination [228] and carrier overflow. Note that the structures of InGaN-active regions are usually composed of a large band offset between the QWs and barriers, which probably implies a small carrier overflow. InGaN red LEDs exhibited increasing characteristic temperatures with increasing current densities suggesting that the nonradiative recombination centers play a key role in the total recombination. This phenomenon originated from the material quality and its polarization effect because of high-In-content InGaN active regions. At a low current density, those issues are significantly affected, and the characteristic temperature of InGaN is much worse than AlGaInP ones. Due to the SRH recombination process, the nonradiative recombination centers can be mitigated by high current injection, which indicates that the benefit of InGaN red LEDs in terms of temperature stability compared to the AlGaInP materials. The characteristic temperatures of micro-LEDs is low compared to standard LEDs [24, 217]. Micro-LEDs are significantly affected by temperature via non-radiative recombination centers on the sidewall surfaces.

In general, the peak wavelength of the InGaN-based red LEDs redshifts when the temperature is increased. This can be explained by the decrease in bandgap energy of the materials due to temperature increases. The redshift coefficients can be obtained by the temperature dependence of the EL measurement. The redshift coefficient of InGaN-based LEDs 
$[24,29,34,230,231]$ was smaller than that of AlGaInP ones [232, 233] (see figure 16(b)). The energy distribution of carriers in InGaN QWs transferred to high energy levels with temperature increases, which results in a blueshift of the peak wavelength [234]. This phenomenon may partially compensate for the redshift of the peak wavelength.

We also observed that the redshift coefficient reduced when the current density increased. The energy distribution of carriers at a high current density could be increased due to heat generation by a non-radiative recombination process [132], which mostly corresponded to a broadening of emission spectra toward the high energy side according to Chhajed et al [229]. The energy distribution of carriers at a high current density leads to blueshifting of the peak wavelength, which compensates for the redshift of the peak wavelength due to reduced bandgap energy. These results suggest that the redshift behavior originated from $\mathrm{InGaN}$-active regions such as crystalline quality, thickness, compositional fluctuation, and barrier materials.

\section{Conclusion}

We reviewed recent progress in the development of red LEDs by III-nitride semiconductors. The critical issues of the current InGaN-based red LEDs are crystalline quality and strain of InGaN active regions. The state-of-the-art of red LEDs performance is still much worse than conventional blue and green LEDs. Further improvements in InGaN-based red LED performance can explore breakthroughs in InGaN crystal growth. We summarized trends in the development of red LEDs by III-nitride semiconductors. The growth conditions required for high-In-content InGaN are extreme. Reactor design and simulation are required to develop a high-In-content InGaN for high-temperature growth. The strain compensating technique is helpful to improve the crystalline quality of InGaN active regions. Also, unique InGaN templates or nanostructures are required to improve the crystalline quality of InGaN active regions and reduce QCSE. Another issue is the hue of the InGaN QWs emission: it is determined by the spectral width. This is a key obstacle to realize pure red emissions. Also, the hue of the emission changes with different current densities, which influences the color stability of InGaN-based red LEDs. In contrast, GaN:Eu red LEDs have remarkable emission stability.

From the prospective view, III-nitride red LEDs are a very attractive material to develop full-color $\mu \mathrm{LED}$ displays by monolithically integrated RGB colors. This can lead to high EQE and temperature stability compared to that of AlGaInP systems especially when the device dimensions shrink. The great potential of III-nitride materials can lead to practical GaN-based optoelectronic devices for display applications.

\section{Data availability statement}

All data that support the findings of this study are included within the article (and any supplementary files).

\section{Acknowledgment}

Some results used in this paper were financially supported by King Abdullah University of Science and Technology (KAUST) (BAS/1/1676-01-01).

\section{ORCID iDs}

Daisuke Iida (D) https://orcid.org/0000-0002-5385-6238

Kazuhiro Ohkawa (D) https://orcid.org/0000-0002-8728-3503

\section{References}

[1] Araki T, Saito Y, Yamaguchi T, Kurouchi M, Nanishi Y and Naol H 2004 Radio frequency-molecular beam epitaxial growth of InN epitaxial films on (0001) sapphire and their properties J. Vac. Sci. Technol. B 22 2139-43

[2] Brunner D, Angerer H, Bustarret E, Freudenberg F, Höpler R, Dimitrov R, Ambacher O and Stutzmann M 1997 Optical constants of epitaxial AlGaN films and their temperature dependence J. Appl. Phys. 82 5090-6

[3] Hurni C A et al 2015 Bulk GaN flip-chip violet light-emitting diodes with optimized efficiency for high-power operation Appl. Phys. Lett. 106031101

[4] Narukawa Y, Ichikawa M, Sanga D, Sano M and Mukai T 2010 White light emitting diodes with super-high luminous efficacy J. Phys. D: Appl. Phys. 43354002

[5] Houser K W, Wei M, David A and Krames M R 2014 Whiteness perception under LED illumination Leukos $10165-80$

[6] Schubert E F and Kim J K 2005 Solid-state light sources getting smart Science 3081274

[7] Narukawa Y, Niki I, Izuno K, Yamada M, Murazaki Y and Mukai T 2002 Phosphor-conversion white light emitting diode using InGaN near-ultraviolet chip Jpn. J. Appl. Phys. 41 L371-3

[8] Hsiang E-L, Yang Z, Yang Q, Lan Y-F and Wu S-T 2021 Prospects and challenges of mini-LED, OLED, and micro-LED displays J. Soc. Inf. Disp. 29 446-65

[9] Bi Z, Chen Z, Danesh F and Samuelson L 2021 From nanoLEDs to the realization of RGB-emitting microLEDs Semicond. Semimet. 106 223-51

[10] Broell M, Sundgren P, Rudolph A, Schmid W, Vogl A and Behringer M 2014 New developments on high-efficiency infrared and InGaAlP light-emitting diodes at OSRAM opto semiconductors Proc. SPIE 9003 90030L

[11] Jiang F, Hyun B-R, Zhang Y and Liu Z 2021 Role of intrinsic surface states in efficiency attenuation of GaN-based micro-light-emitting-diodes Phys. Status Solidi 152000487

[12] Lee J-M, Huh C, Kim D-J and Park S-J 2003 Dry-etch damage and its recovery in InGaN/GaN multi-quantum-well light-emitting diodes Semicond. Sci. Technol. 18 530-4

[13] Olivier F, Tirano S, Dupré L, Aventurier B, Largeron C and Templier F 2017 Influence of size-reduction on the performances of GaN-based micro-LEDs for display application J. Lumin. 191 112-6

[14] Olivier F, Daami A, Licitra C and Templier F 2017 Shockley-Read-Hall and Auger non-radiative recombination in GaN based LEDs: a size effect study Appl. Phys. Lett. 111022104

[15] Bulashevich K A and Karpov S Y 2016 Impact of surface recombination on efficiency of III-nitride light-emitting diodes Phys. Status Solidi 10 480-4 
[16] Oh J-T et al 2018 Light output performance of red AlGaInP-based light emitting diodes with different chip geometries and structures Opt. Express 26 11194-200

[17] Boroditsky M, Gontijo I, Jackson M, Vrijen R, Yablonovitch E, Krauss T, Cheng C-C, Scherer A, Bhat R and Krames M 2000 Surface recombination measurements on III-V candidate materials for nanostructure light-emitting diodes J. Appl. Phys. 87 3497-504

[18] Zhao Y et al 20212000 PPI silicon-based AlGaInP red micro-LED arrays fabricated via wafer bonding and epilayer lift-off Opt. Express 29 20217-28

[19] Wong M S, Hwang D, Alhassan A I, Lee C, Ley R, Nakamura S and DenBaars S P 2018 High efficiency of III-nitride micro-light-emitting diodes by sidewall passivation using atomic layer deposition Opt. Express 26 21324-31

[20] Jiang X, Zheng C, Mo C, Wang X, Zhang J, Quan Z, Liu J and Jiang F 2019 Study on the performance of InGaN-based green LED by designing different preparing layers Opt. Mater. 89 505-11

[21] Lv Q, Liu J, Mo C, Zhang J, Wu X, Wu Q and Jiang F 2019 Realization of highly efficient InGaN green LEDs with sandwich-like multiple quantum well structure: role of enhanced interwell carrier transport ACS Photonics 6 130-8

[22] Li P P et al 2018 Very high external quantum efficiency and wall-plug efficiency $527 \mathrm{~nm}$ InGaN green LEDs by MOCVD Opt. Express 26 33108-15

[23] Ichikawa S, Shiomi K, Morikawa T, Timmerman D, Sasaki Y, Tatebayashi J and Fujiwara Y 2021 Eu-doped $\mathrm{GaN}$ and InGaN monolithically stacked full-color LEDs with a wide color gamut Appl. Phys. Express 14031008

[24] Zhuang Z, Iida D and Ohkawa K 2021 Investigation of InGaN-based red/green micro-light-emitting diodes Opt. Lett. 46 1912-5

[25] Robin Y, Pristovsek M, Amano H, Oehler F, Oliver R A and Humphreys C J 2018 What is red? On the chromaticity of orange-red InGaN/GaN based LEDs J. Appl. Phys. 124183102

[26] Takeuchi T, Sota S, Katsuragawa M, Komori M, Takeuchi H, Amano H and Akasaki I 1997 Quantum-confined Stark effect due to piezoelectric fields in GaInN strained quantum wells Jpn. J. Appl. Phys. 36 L382-5

[27] Takeuchi T, Wetzel C, Yamaguchi S, Sakai H, Amano H, Akasaki I, Kaneko Y, Nakagawa S, Yamaoka Y and Yamada N 1998 Determination of piezoelectric fields in strained GaInN quantum wells using the quantum-confined Stark effect Appl. Phys. Lett. 73 1691-3

[28] Mukai T, Yamada M and Nakamura S 1999 Characteristics of InGaN-based UV/blue/green/amber/red light-emitting diodes Jpn. J. Appl. Phys. 38 3976-81

[29] Hwang J-I, Hashimoto R, Saito S and Nunoue S 2014 Development of InGaN-based red LED grown on (0001) polar surface Appl. Phys. Express 7071003

[30] Koukitu A, Takahashi N, Taki T and Seki H 1997 Thermodynamic analysis of the MOVPE growth of $\mathrm{In}_{x} \mathrm{Ga}_{1-x} \mathrm{~N}$ J. Cryst. Growth 170 306-11

[31] Yamashita Y, Tamura H, Horio N, Sato H, Taniguchi K, Chinone T, Omori S and Funaoka C 2003 Control of emission wavelength of GaInN single quantum well, light emitting diodes grown by metalorganic chemical vapor deposition in a split-flow reactor Jpn. J. Appl. Phys. 42 4197-202

[32] Shimizu M, Kawaguchi Y, Hiramatsu K and Sawaki N 1997 Metalorganic vapor phase epitaxy of thick InGaN on sapphire substrate Jpn. J. Appl. Phys. 36 3381-4

[33] Holec D, Costa P M F J, Kappers M J and Humphreys C J 2007 Critical thickness calculations for InGaN/GaN J. Cryst. Growth 303 314-7
[34] Iida D, Zhuang Z, Kirilenko P, Velazquez-Rizo M and Ohkawa K 2020 Demonstration of low forward voltage InGaN-based red LEDs Appl. Phys. Express 13031001

[35] Iida D, Zhuang Z, Kirilenko P, Velazquez-Rizo M, Najmi M A and Ohkawa K 2020 633-nm InGaN-based red LEDs grown on thick underlying GaN layers with reduced in-plane residual stress Appl. Phys. Lett. 116162101

[36] Zhang S et al 2020 Efficient emission of InGaN-based light-emitting diodes: toward orange and red Photon. Res. 8 1671-5

[37] I-hsiu Ho G B S 1996 Solid phase immiscibility in GaInN Appl. Phys. Lett. 69 2701-3

[38] Ohkawa K, Ichinohe F, Watanabe T, Nakamura K and Iida D 2019 Metalorganic vapor-phase epitaxial growth simulation to realize high-quality and high-In-content InGaN alloys J. Cryst. Growth 512 69-73

[39] MacChesney J B, Bridenbaugh P M and O'Connor P B 1970 Thermal stability of indium nitride at elevated temperatures and nitrogen pressures Mater. Res. Bull. $5783-91$

[40] Belyaev K G, Rakhlin M V, Jmerik V N, Mizerov A M, Kuznetsova Y V, Zamoryanskaya M V, Ivanov S V and Toropov A A 2013 Phase separation in $\mathrm{In}_{x} \mathrm{Ga}_{1-x} \mathrm{~N}$ $(0.10<x<0.40)$ Phys. Status Solidi c $10527-31$

[41] Müller M, Smith G D W, Gault B and Grovenor C R M 2012 Phase separation in thick InGaN layers-a quantitative, nanoscale study by pulsed laser atom probe tomography Acta Mater. 60 4277-85

[42] Oliver R A, Kappers M J, Humphreys C J and Briggs G A D 2005 Growth modes in heteroepitaxy of InGaN on GaN J. Appl. Phys. 97013707

[43] Koleske D D, Lee S R, Crawford M H, Cross K C, Coltrin M E and Kempisty J M 2014 Connection between $\mathrm{GaN}$ and $\mathrm{InGaN}$ growth mechanisms and surface morphology J. Cryst. Growth 391 85-96

[44] Pantha B N, Wang H, Khan N, Lin J Y and Jiang H X 2011 Origin of background electron concentration in $\mathrm{In}_{x} \mathrm{Ga}_{1-x} \mathrm{~N}$ alloys Phys. Rev. B 84075327

[45] Pantha B N, Li J, Lin J Y and Jiang H X 2008 Single phase $\mathrm{In}_{x} \mathrm{Ga}_{1-x} \mathrm{~N}(0.25 \leqslant x \leqslant 0.63)$ alloys synthesized by metal organic chemical vapor deposition Appl. Phys. Lett. 93182107

[46] Ishikawa M, Ohba Y, Sugawara H, Yamamoto M and Nakanisi T 1986 Room-temperature cw operation of InGaP/InGaAlP visible light laser diodes on $\mathrm{GaAs}$ substrates grown by metalorganic chemical vapor deposition Appl. Phys. Lett. 48 207-8

[47] Ikeda M, Mori Y, Takiguchi M, Kaneko K and Watanabe N $1984 \mathrm{cw}$ operation of an AlGaInP double heterostructure laser diode at $77 \mathrm{~K}$ grown by atmospheric metalorganic chemical vapor deposition Appl. Phys. Lett. 45 661-3

[48] Van't Blik H, Boerrigter-Lammers J, Valster A and Acket G 1989 Index-guided GaAs/AlGaAs quantum well lasers grown by MOVPE Proc. SPIE 1025 48-51

[49] Kangawa Y, Ito T, Mori A and Koukitu A 2000 Anomalous behavior of excess energy curves of $\operatorname{In}_{x} \mathrm{Ga}_{1-x} \mathrm{~N}$ grown on $\mathrm{GaN}$ and InN J. Cryst. Growth 220 401-4

[50] Ohkawa K 2020 Simulation of nitride semiconductor MOVPE Digital Encyclopedia of Applied Physics (Wiley-VCH) pp 1-20

[51] Kangawa Y, Akiyama T, Ito T, Shiraishi K and Nakayama T 2013 Surface stability and growth kinetics of compound semiconductors: an ab initio-based approach Materials 6 3309-60

[52] Kusaba A, Kangawa Y, Honda Y, Amano H and Kakimoto K 2016 Theoretical approach to surface reconstruction of $\mathrm{InN}(0001)$ during raised-pressure metalorganic vapor-phase epitaxy Jpn. J. Appl. Phys. 55 05FM01 
[53] Matsuoka T, Liu Y, Kimura T, Zhang Y, Prasertsuk K and Katayama R 2011 Paving the way to high-quality indium nitride: the effects of pressurized reactor Proc. SPIE $\mathbf{7 9 4 5} 794519$

[54] Senevirathna M K I et al 2012 Effect of reactor pressure on the electrical and structural properties of InN epilayers grown by high-pressure chemical vapor deposition J. Vac. Sci. Technol. A 30031511

[55] Iida D, Nagata K, Makino T, Iwaya M, Kamiyama S, Amano H, Akasaki I, Bandoh A and Udagawa T 2010 Growth of GaInN by raised-pressure metalorganic vapor phase epitaxy Appl. Phys. Express 3075601

[56] Ohkawa K, Watanabe T, Sakamoto M, Hirako A and Deura M 2012 740-nm emission from InGaN-based LEDs on $c$-plane sapphire substrates by MOVPE J. Cryst. Growth 343 13-16

[57] Hashimoto R, Hwang J, Saito S and Nunoue S 2013 High-efficiency green-yellow light-emitting diodes grown on sapphire (0001) substrates Phys. Status Solidi c 10 1529-32

[58] Alhassan A I, Young N G, Farrell R M, Pynn C, Wu F, Alyamani A Y, Nakamura S, DenBaars S P and Speck J S 2018 Development of high performance green $c$-plane III-nitride light-emitting diodes Opt. Express 26 5591-601

[59] Rhode S L, Fu W Y, Moram M A, Massabuau F C P, Kappers M J, McAleese C, Oehler F, Humphreys C J, Dusane R O and Sahonta S L 2014 Structure and strain relaxation effects of defects in $\operatorname{In}_{x} \mathrm{Ga}_{1-x} \mathrm{~N}$ epilayers J. Appl. Phys. 116103513

[60] Smalc-Koziorowska J, Grzanka E, Czernecki R, Schiavon D and Leszczyński M 2015 Elimination of trench defects and V-pits from InGaN/GaN structures Appl. Phys. Lett. 106101905

[61] El Gmili Y, Orsal G, Pantzas K, Moudakir T, Sundaram S, Patriarche G, Hester J, Ahaitouf A, Salvestrini J P and Ougazzaden A 2013 Multilayered InGaN/GaN structure vs. single InGaN layer for solar cell applications: a comparative study Acta Mater. 61 6587-96

[62] Srinivasan S, Geng L, Liu R, Ponce F A, Narukawa Y and Tanaka S 2003 Slip systems and misfit dislocations in InGaN epilayers Appl. Phys. Lett. 83 5187-9

[63] Hiramatsu K, Kawaguchi Y, Shimizu M, Sawaki N, Zheleva T, Davis R F, Tsuda H, Taki W, Kuwano N and Oki K 1997 The composition pulling effect in MOVPE grown InGaN on $\mathrm{GaN}$ and $\mathrm{AlGaN}$ and its TEM characterization MRS Int. J. Nitride Semicond. Res. 211

[64] Mizuseki H, Gueriba J S, Empizo M J F, Sarukura N, Kawazoe Y and Ohkawa K 2021 Atomistic origin of compositional pulling effect in wurtzite $(\mathrm{B}, \mathrm{Al}$, In $)_{x} \mathrm{Ga}_{1-x} \mathrm{~N}$ : a first-principles study $J$. Appl. Phys. 130035704

[65] Senda R, Matsubara T, Iida D, Iwaya M, Kamiyama S, Amano H and Akasaki I 2009 Strong emission from GaInN/GaN multiple quantum wells on high-crystalline-quality thick $m$-plane GaInN underlying layer on grooved GaN Appl. Phys. Express 2061004

[66] Koslow I L, McTaggart C, Wu F, Nakamura S, Speck J S and DenBaars S P 2014 Improved performance of (20-21) long-wavelength light-emitting diodes grown with wide quantum wells on stress-relaxed $\operatorname{In}_{x} \mathrm{Ga}_{1-x} \mathrm{~N}$ buffer layers Appl. Phys. Express 7031003

[67] Pantzas K et al 2013 Semibulk InGaN: a novel approach for thick, single phase, epitaxial InGaN layers grown by MOVPE J. Cryst. Growth 370 57-62

[68] Eldred T B, Abdelhamid M, Reynolds J G, El-Masry N A, LeBeau J M and Bedair S M 2020 Observing relaxation in device quality InGaN templates by TEM techniques Appl. Phys. Lett. 116102104

[69] Däubler J, Passow T, Aidam R, Köhler K, Kirste L, Kunzer M and Wagner J 2014 Long wavelength emitting GaInN quantum wells on metamorphic GaInN buffer layers with enlarged in-plane lattice parameter Appl. Phys. Lett. 105111111

[70] Pasayat S S, Gupta C, Acker-James D, Cohen D A, DenBaars S P, Nakamura S, Keller S and Mishra U K 2019 Fabrication of relaxed InGaN pseudo-substrates composed of micron-sized pattern arrays with high fill factors using porous GaN Semicond. Sci. Technol. 34115020

[71] Pasayat S S, Gupta C, Wang Y, DenBaars S P, Nakamura S, Keller S and Mishra U K 2020 Compliant micron-sized patterned InGaN pseudo-substrates utilizing porous $\mathrm{GaN}$ Materials 13213

[72] Pasayat S S, Gupta C, Wong M S, Wang Y, Nakamura S, Denbaars S P, Keller S and Mishra U K 2020 Growth of strain-relaxed InGaN on micrometer-sized patterned compliant GaN pseudo-substrates Appl. Phys. Lett. 116111101

[73] Pasayat S S, Hatui N, Li W, Gupta C, Nakamura S, Denbaars S P, Keller S and Mishra U K 2020 Method of growing elastically relaxed crack-free AlGaN on GaN as substrates for ultra-wide bandgap devices using porous GaN Appl. Phys. Lett. 117062102

[74] Pasayat S S, Gupta C, Wong M S, Ley R, Gordon M J, DenBaars S P, Nakamura S, Keller S and Mishra U K 2021 Demonstration of ultra-small $(<10 \mu \mathrm{m}) 632 \mathrm{~nm}$ red InGaN micro-LEDs with useful on-wafer external quantum efficiency (>0.2\%) for mini-displays Appl. Phys. Express 14011004

[75] Even A, Laval G, Ledoux O, Ferret P, Sotta D, Guiot E, Levy F, Robin I C and Dussaigne A 2017 Enhanced In incorporation in full $\mathrm{InGaN}$ heterostructure grown on relaxed InGaN pseudo-substrate Appl. Phys. Lett. 110262103

[76] Cooper D, Boureau V, Even A, Barbier F and Dussaigne A 2020 Determination of the internal piezoelectric potentials and indium concentration in InGaN based quantum wells grown on relaxed InGaN pseudo-substrates by off-axis electron holography Nanotechnology 31475705

[77] Dussaigne A et al 2020 Full InGaN red light emitting diodes J. Appl. Phys. 128135704

[78] Dussaigne A, Barbier F, Samuel B, Even A, Templier R, Lévy F, Ledoux O, Rozhavskaia M and Sotta D 2020 Strongly reduced $\mathrm{V}$ pit density on InGaNOS substrate by using InGaN/GaN superlattice $J$. Cryst. Growth 533125481

[79] Samuel B, Cooper D, Rochat N, Mavel A, Barbier F and Dussaigne A 2021 Origins of nanoscale emission inhomogeneities of high content red emitting InGaN/InGaN quantum wells $J$. Appl. Phys. 129173105

[80] Kobayashi A, Ohta J and Fujioka H 2006 Low temperature epitaxial growth of $\mathrm{In}_{0.25} \mathrm{Ga}_{0.75} \mathrm{~N}$ on lattice-matched $\mathrm{ZnO}$ by pulsed laser deposition J. Appl. Phys. 99123513

[81] Shimomoto K, Kobayashi A, Ueno K, Ohta J, Oshima M, Fujioka H, Amanai H, Nagao S and Horie H 2009 Room-temperature epitaxial growth of high-quality $m$-plane InGaN films on $\mathrm{ZnO}$ substrates Phys. Status Solidi 3 124-6

[82] Kobayashi A, Ohta J and Fujioka H 2006 Characteristics of InGaN with high in concentrations grown on $\mathrm{ZnO}$ at low temperatures Jpn. J. Appl. Phys. 45 L611-3

[83] Kobayashi A, Ohta J and Fujioka H 2017 Pulsed sputtering epitaxial growth of $m$-plane InGaN lattice-matched to $\mathrm{ZnO}$ Sci. Rep. 712820 
[84] Yu H, Wang S, Li N, Fenwick W, Melton A, Klein B and Ferguson I 2008 MOVPE growth of AlGaN/GaN superlattices on $\mathrm{ZnO}$ substrates for green emitter applications J. Cryst. Growth 310 4904-7

[85] Hellman E S, Buchanan D N E, Wiesmann D and Brener I 1996 Growth of Ga-face and N-face GaN films using ZnO substrates MRS Int. J. Nitride Semicond. Res. 1 U117-23

[86] Hong S-K, Hanada T, Ko H-J, Chen Y, Yao T, Imai D, Araki K and Shinohara M 2000 Control of polarity of $\mathrm{ZnO}$ films grown by plasma-assisted molecular-beam epitaxy: $\mathrm{Zn}$ - and O-polar $\mathrm{ZnO}$ films on Ga-polar $\mathrm{GaN}$ templates Appl. Phys. Lett. 77 3571-3

[87] Xia Y et al 2013 Blue light-emitting diodes grown on $\mathrm{ZnO}$ substrates Appl. Phys. Express 6042101

[88] Wang S-J, Li N, Park E-H, Feng Z C, Valencia A, Nause J, Kane M, Summers C and Ferguson I 2008 MOCVD growth of GaN-based materials on $\mathrm{ZnO}$ substrates Phys. Status Solidi c 5 1736-9

[89] Lei Y, Xu J, Zhu K, He M, Zhou J, Gao Y, Zhang L and Chen Y 2013 A GaN-based LED with perpendicular structure fabricated on a $\mathrm{ZnO}$ substrate by MOCVD J. Disp. Technol. $9377-81$

[90] Ueta A, Ohno H, Yanagita N, Ryoki N, Miyano K, Ishibashi A and Nobuoka M 2019 High quality nitride semiconductors grown on novel $\mathrm{ScAlMgO}_{4}$ substrates and their light emitting diodes Jpn. J. Appl. Phys. 58 SC1041

[91] Ozaki T, Funato M and Kawakami Y 2015 InGaN-based visible light-emitting diodes on $\mathrm{ScAlMgO}_{4}(0001)$ substrates Appl. Phys. Express 8062101

[92] Ozaki T, Takagi Y, Nishinaka J, Funato M and Kawakami Y 2014 Metalorganic vapor phase epitaxy of $\mathrm{GaN}$ and lattice-matched $\mathrm{InGaN}$ on $\mathrm{ScAlMgO}_{4}(0001)$ substrates Appl. Phys. Express 7091001

[93] Ozaki T, Funato M and Kawakami Y 2019 Red-emitting $\mathrm{In}_{x} \mathrm{Ga}_{1-x} \mathrm{~N} / \mathrm{In}_{y} \mathrm{Ga}_{1-y} \mathrm{~N}$ quantum wells grown on lattice-matched $\mathrm{In}_{y} \mathrm{Ga}_{1-y} \mathrm{~N} / \mathrm{ScAlMgO}{ }_{4}(0001)$ templates Appl. Phys. Express 12011007

[94] Liu L and Edgar J H 2002 Substrates for gallium nitride epitaxy Mater. Sci. Eng. R 37 61-127

[95] Stanimirovic A, Balzaretti N M, Feldman A and Graebner J E 2001 Thermal conductivity and thermal diffusivity of selected oxide single crystals J. Mater. Res. 16 678-82

[96] Alam S, Sundaram S, Li X, El Gmili Y, Elouneg-Jamroz M, Robin I C, Patriarche G, Salvestrini J-P, Voss P L and Ougazzaden A 2017 Emission wavelength red-shift by using 'semi-bulk' InGaN buffer layer in InGaN/InGaN multiple-quantum-well Superlattices Microstruct. 112 279-86

[97] Abdelhamid M, Routh E L and Bedair S M 2021 The dependence of the emission from MQWs on the indium content in the underlying InGaN templates: experimental and modeling results Semicond. Sci. Technol. 36035018

[98] Röder C, Lipski F, Habel F, Leibiger G, Abendroth M, Himcinschi C and Kortus J 2013 Raman spectroscopic characterization of epitaxially grown $\mathrm{GaN}$ on sapphire J. Phys. D: Appl. Phys. $\mathbf{4 6} 285302$

[99] Johnson M C, Bourret-Courchesne E D, Wu J, Liliental-Weber Z, Zakharov D N, Jorgenson R J, Ng T B McCready D E and Williams J R 2004 Effect of gallium nitride template layer strain on the growth of $\operatorname{In}_{x} \mathrm{Ga}_{1-x} \mathrm{~N}$ $/ \mathrm{GaN}$ multiple quantum well light emitting diodes $J$. Appl. Phys. 96 1381-6

[100] Hiramatsu K, Detchprohm T and Akasaki I 1993 Relaxation mechanism of thermal stresses in the heterostructure of GaN grown on sapphire by vapor phase epitaxy Jpn. J. Appl. Phys. 32 1528-33

[101] Muhammed M M, Roldan M A, Yamashita Y, Sahonta S L, Ajia I A, Iizuka K, Kuramata A, Humphreys C J and
Roqan I S 2016 High-quality III-nitride films on conductive, transparent (201)-oriented beta- $\mathrm{Ga}_{2} \mathrm{O}_{3}$ using a GaN buffer layer Sci. Rep. 629747

[102] Qi W et al 2017 Effects of thickness ratio of InGaN to GaN in superlattice strain relief layer on the optoelectrical properties of InGaN-based green LEDs grown on $\mathrm{Si}$ substrates J. Appl. Phys. 122084504

[103] Tao X et al 2018 Performance enhancement of yellow InGaN-based multiple-quantum-well light-emitting diodes grown on Si substrates by optimizing the $\mathrm{InGaN} / \mathrm{GaN}$ superlattice interlayer Opt. Mater. Express 81221

[104] Jiang F et al 2019 Efficient InGaN-based yellow-light-emitting diodes Photon. Res. 7 141-8

[105] Zhang J, Xiong C, Liu J, Quan Z, Wang L and Jiang F 2014 High brightness InGaN-based yellow light-emitting diodes with strain modulation layers grown on Si substrate Appl. Phys. A 114 1049-53

[106] Haller C, Carlin J F, Jacopin G, Martin D, Butté R and Grandjean N 2017 Burying non-radiative defects in InGaN underlayer to increase InGaN/GaN quantum well efficiency Appl. Phys. Lett. 111262101

[107] Haller C, Carlin J F, Jacopin G, Liu W, Martin D, Butté R and Grandjean N $2018 \mathrm{GaN}$ surface as the source of non-radiative defects in InGaN/GaN quantum wells Appl. Phys. Lett. 113111106

[108] Akasaka T, Gotoh H, Saito T and Makimoto T 2004 High luminescent efficiency of InGaN multiple quantum wells grown on InGaN underlying layers Appl. Phys. Lett. 85 3089-91

[109] Akasaka T, Gotoh H, Kobayashi Y, Nakano H and Makimoto T $2006 \mathrm{InGaN}$ quantum wells with small potential fluctuation grown on $\mathrm{InGaN}$ underlying layers Appl. Phys. Lett. 89101110

[110] Hangleiter A, Hitzel F, Netzel C, Fuhrmann D, Rossow U, Ade $G$ and Hinze P 2005 Suppression of nonradiative recombination by $\mathrm{V}$-shaped pits in $\mathrm{GaInN} / \mathrm{GaN}$ quantum wells produces a large increase in the light emission efficiency Phys. Rev. Lett. 95127402

[111] Kim J, Cho Y H, Ko D S, Li X S, Won J Y, Lee E, Park S H, Kim J Y and Kim S 2014 Influence of V-pits on the efficiency droop in InGaN/GaN quantum wells $O p t$. Express 22 A857-66

[112] Netzel C, Bremers H, Hoffmann L, Fuhrmann D, Rossow U and Hangleiter A 2007 Emission and recombination characteristics of $\mathrm{Ga}_{1-x} \mathrm{In}_{x} \mathrm{~N} / \mathrm{GaN}$ quantum well structures with nonradiative recombination suppression by V-shaped pits Phys. Rev. B 76155322

[113] Chang C-Y, Li H, Shih Y-T and Lu T-C 2015 Manipulation of nanoscale V-pits to optimize internal quantum efficiency of InGaN multiple quantum wells Appl. Phys. Lett. 106091104

[114] Wu X, Liu J and Jiang F 2015 Hole injection from the sidewall of V-shaped pits into $c$-plane multiple quantum wells in InGaN light emitting diodes J. Appl. Phys. 118164504

[115] Li C-K, Wu C-K, Hsu C-C, Lu L-S, Li H, Lu T-C and Wu Y-R 2016 3D numerical modeling of the carrier transport and radiative efficiency for InGaN/GaN light emitting diodes with V-shaped pits AIP Adv. 6055208

[116] Kang D, Oh J-T, Song J-O, Seong T-Y, Kneissl M and Amano H 2019 Hole injection mechanism in the quantum wells of blue light emitting diode with $\mathrm{V}$ pits for micro-display application Appl. Phys. Express 12102016

[117] Iida D, Niwa K, Kamiyama S and Ohkawa K 2016 Demonstration of InGaN-based orange LEDs with hybrid multiple-quantum-wells structure Appl. Phys. Express 9111003

[118] Yoshida H, Hikosaka T, Nago H and Nunoue S 2015 Impact of dislocations and defects on the relaxation behavior of 
InGaN/GaN multiple quantum wells grown on $\mathrm{Si}$ and sapphire substrates Phys. Status Solidi b 252 917-22

[119] Meng Y, Wang L, Li F, Zhao G, Yao W, Yang S and Wang Z 2019 Growth and characterization of amber light-emitting diodes with dual-wavelength $\mathrm{InGaN} / \mathrm{GaN}$ multiple-quantum-well structures Mater. Res. Express $60850 \mathrm{c} 8$

[120] Yao W, Wang L, Meng Y, Yang S, Liu X, Niu H and Wang Z 2021 Stress engineering for reducing the injection current induced blue shift in InGaN-based red light-emitting diodes CrystEngComm 23 2360-6

[121] Iida D, Lu S, Hirahara S, Niwa K, Kamiyama S and Ohkawa K 2016 Enhanced light output power of InGaN-based amber LEDs by strain-compensating AlN/AlGaN barriers J. Cryst. Growth 448 105-8

[122] Koleske D D, Fischer A J, Bryant B N, Kotula P G and Wierer J J 2015 On the increased efficiency in InGaN-based multiple quantum wells emitting at $530-590 \mathrm{~nm}$ with AlGaN interlayers J. Cryst. Growth 415 57-64

[123] Doi T, Honda Y, Yamaguchi M and Amano H 2013 Strain-compensated effect on the growth of InGaN/AlGaN multi-quantum well by metalorganic vapor phase epitaxy Jpn. J. Appl. Phys. 52 08JB14

[124] Lekhal K, Damilano B, Ngo H T, Rosales D, de Mierry P, Hussain S, Vennéguès P and Gil B 2015 Strain-compensated (Ga,In)N/(Al,Ga)N/GaN multiple quantum wells for improved yellow/amber light emission Appl. Phys. Lett. 106142101

[125] Keller S, Fichtenbaum N A, Furukawa M, Speck J S, DenBaars S P and Mishra U K 2007 Growth and characterization of $\mathrm{N}$-polar InGaN/GaN multiquantum wells Appl. Phys. Lett. 90191908

[126] Nath D N, Gür E, Ringel S A and Rajan S 2010 Molecular beam epitaxy of N-polar InGaN Appl. Phys. Lett. 97071903

[127] Wernicke T, Schade L, Netzel C, Rass J, Hoffmann V, Ploch S, Knauer A, Weyers M, Schwarz U and Kneissl M 2012 Indium incorporation and emission wavelength of polar, nonpolar and semipolar InGaN quantum wells Semicond. Sci. Technol. 27024014

[128] Shojiki K, Tanikawa T, Choi J-H, Kuboya S, Hanada T, Katayama R and Matsuoka T 2015 Red to blue wavelength emission of N-polar (000-1) InGaN light-emitting diodes grown by metalorganic vapor phase epitaxy Appl. Phys. Express 8061005

[129] Wang Y, Shimma R, Yamamoto T, Hayashi H, Shiohama K-I, Kurihara K, Hasegawa R and Ohkawa K 2015 The effect of plane orientation on indium incorporation into InGaN/GaN quantum wells fabricated by MOVPE J. Cryst. Growth 416 164-8

[130] Akyol F, Nath D N, Gür E, Park P S and Rajan S 2011 $\mathrm{N}$-polar III-nitride green $(540 \mathrm{~nm})$ light emitting diode Jpn. J. Appl. Phys. 50052101

[131] Akyol F, Nath D N, Krishnamoorthy S, Park P S and Rajan S 2012 Suppression of electron overflow and efficiency droop in N-polar GaN green light emitting diodes Appl. Phys. Lett. 100111118

[132] Funato M, Ueda M, Kawakami Y, Narukawa Y, Kosugi T, Takahashi M and Mukai T 2006 Blue, green, and amber InGaN/GaN light-emitting diodes on semipolar $\{11-22\}$ GaN bulk substrates Jpn. J. Appl. Phys. 45 L659-62

[133] Bai J, Xu B, Guzman F G, Xing K, Gong Y, Hou Y and Wang T 2015 (11-22) semipolar InGaN emitters from green to amber on overgrown $\mathrm{GaN}$ on micro-rod templates Appl. Phys. Lett. 107261103

[134] Zhao Y, Fu H, Wang G T and Nakamura S 2018 Toward ultimate efficiency: progress and prospects on planar and
3D nanostructured nonpolar and semipolar InGaN light-emitting diodes Adv. Opt. Photon. 10246

[135] Shojiki K, Hanada T, Tanikawa T, Imai Y, Kimura S, Nonoda R, Kuboya S, Katayama R and Matsuoka T 2016 Homogeneity improvement of N-polar (000-1) InGaN/GaN multiple quantum wells by using $c$-plane sapphire substrate with off-cut-angle toward a-sapphire plane Jpn. J. Appl. Phys. 55 05FA09

[136] Tanikawa T, Shojiki K, Aisaka T, Kimura T, Kuboya S, Hanada T, Katayama R and Matsuoka T 2014 Enhancement of surface migration by $\mathrm{Mg}$ doping in the metalorganic vapor phase epitaxy of N-polar (000-1) GaN/sapphire Jpn. J. Appl. Phys. 53 05FL05

[137] Keller S, Fichtenbaum N A, Wu F, Brown D, Rosales A, DenBaars S P, Speck J S and Mishra U K 2007 Influence of the substrate misorientation on the properties of N-polar $\mathrm{GaN}$ films grown by metal organic chemical vapor deposition J. Appl. Phys. 102083546

[138] Tanikawa T, Kuboya S and Matsuoka T 2017 Control of impurity concentration in N-polar (000-1) GaN grown by metalorganic vapor phase epitaxy Phys. Status Solidi b 2541600751

[139] Lund C, Nakamura S, DenBaars S P, Mishra U K and Keller S 2019 Properties of N-polar InGaN/GaN quantum wells grown with triethyl gallium and triethyl indium as precursors Semicond. Sci. Technol. 34075017

[140] Li C, Zhang K, Qiaoyu Z, Yin X, Ge X, Wang J, Wang Q, He C, Zhao W and Chen Z 2020 High quality N-polar GaN films grown with varied V/III ratios by metal-organic vapor phase epitaxy RSC Adv. 10 43187-92

[141] Lund C et al 2017 Metal-organic chemical vapor deposition of high quality, high indium composition N-polar InGaN layers for tunnel devices J. Appl. Phys. 121185707

[142] Aisaka T, Tanikawa T, Kimura T, Shojiki K, Hanada T, Katayama R and Matsuoka T 2014 Improvement of surface morphology of nitrogen-polar GaN by introducing indium surfactant during MOVPE growth Jpn. J. Appl. Phys. 53085501

[143] Hatui N, Krishna A, Pasayat S S, Keller S and Mishra U K 2021 Metal organic vapor phase epitaxy of thick N-polar InGaN films Electronics 101182

[144] Cruz S C, Keller S, Mates T E, Mishra U K and DenBaars S P 2009 Crystallographic orientation dependence of dopant and impurity incorporation in $\mathrm{GaN}$ films grown by metalorganic chemical vapor deposition J. Cryst. Growth 311 3817-23

[145] Browne D A, Young E C, Lang J R, Hurni C A and Speck J S 2012 Indium and impurity incorporation in InGaN films on polar, nonpolar, and semipolar GaN orientations grown by ammonia molecular beam epitaxy J. Vac. Sci. Technol. A 30041513

[146] Dreyer C E, Alkauskas A, Lyons J L, Speck J S and Walle C G V D 2016 Gallium vacancy complexes as a cause of Shockley-Read-Hall recombination in III-nitride light emitters Appl. Phys. Lett. 108141101

[147] Ueno K, Kishikawa E, Ohta J and Fujioka H 2017 N-polar InGaN-based LEDs fabricated on sapphire via pulsed sputtering APL Mater. 5026102

[148] Seo Y G, Baik K H, Song H, Son J-S, Oh K and Hwang S-M 2011 Orange $a$-plane InGaN/GaN light-emitting diodes grown on $r$-plane sapphire substrates Opt. Express 19 12919-24

[149] Kawaguchi Y, Huang C-Y, Wu Y-R, Zhao Y, DenBaars S P and Nakamura S 2013 Semipolar (2021) single-quantum-well red light-emitting diodes with a low forward voltage Jpn. J. Appl. Phys. 52 08JC08

[150] Khoury M et al 2019 Demonstration of electrically injected semipolar laser diodes grown on low-cost and scalable 
sapphire substrates ACS Appl. Mater. Interfaces 11 47106-11

[151] Murayama M, Nakayama Y, Yamazaki K, Hoshina Y, Watanabe H, Fuutagawa N, Kawanishi H, Uemura T and Narui H 2018 Watt-class green $(530 \mathrm{~nm})$ and blue (465 nm) laser diodes Phys. Status Solidi a 2151700513

[152] Mehari S, Cohen D A, Becerra D L, Nakamura S and DenBaars S P 2018 Demonstration of enhanced continuous-wave operation of blue laser diodes on a semipolar 20-2-1 GaN substrate using indium-tin-oxide/thin-p-GaN cladding layers Opt. Express 26 1564-72

[153] Hamaguchi T et al 2020 Room-temperature continuous-wave operation of green vertical-cavity surface-emitting lasers with a curved mirror fabricated on $\{20-21\}$ semi-polar GaN Appl. Phys. Express 13041002

[154] Kikuchi A, Kawai M, Tada M and Kishino K 2004 InGaN/GaN multiple quantum disk nanocolumn light-emitting diodes grown on (111) Si substrate Jpn. J. Appl. Phys. 43 L1524-6

[155] Jahangir S, Mandl M, Strassburg M and Bhattacharya P 2013 Molecular beam epitaxial growth and optical properties of red-emitting $(\lambda=650 \mathrm{~nm}) \mathrm{InGaN} / \mathrm{GaN}$ disks-in-nanowires on silicon Appl. Phys. Lett. 102071101

[156] Vadivelu R, Igawa Y and Kishino K 2013633 nm red emissions from InGaN nanocolumn light-emitting diode by radio frequency plasma assisted molecular beam epitaxy Jpn. J. Appl. Phys. 52 08JE18

[157] Jahangir S, Schimpke T, Strassburg M, Grossklaus K A, Millunchick J M and Bhattacharya P 2014 Red-emitting $(\lambda=610 \mathrm{~nm}) \mathrm{In}_{0.51} \mathrm{Ga}_{0.49} \mathrm{~N} / \mathrm{GaN}$ disk-in-nanowire light emitting diodes on silicon IEEE J. Quantum Electron. 50 530-7

[158] Zhao C et al 2016 Droop-free, reliable, and high-power InGaN/GaN nanowire light-emitting diodes for monolithic metal-optoelectronics Nano Lett. 16 4616-23

[159] Zhao C, Ng T K, Wei N, Prabaswara A, Alias M S, Janjua B, Shen C and Ooi B S 2016 Facile formation of high-quality InGaN/GaN quantum-disks-in-nanowires on bulk-metal substrates for high-power light-emitters Nano Lett. 16 1056-63

[160] Bui H Q T, Velpula R T, Jain B, Aref O H, Nguyen H D, Lenka T R and Nguyen H P T 2019 Full-color InGaN/AlGaN nanowire micro light-emitting diodes grown by molecular beam epitaxy: a promising candidate for next generation micro displays Micromachines 10492

[161] Yanagihara A and Kishino K 2019 Red-emitting InGaN-based nanocolumn light-emitting diodes with highly directional beam profiles Phys. Status Solidi a 2171900771

[162] Nguyen H P, Zhang S, Connie A T, Kibria M G, Wang Q, Shih I and Mi Z 2013 Breaking the carrier injection bottleneck of phosphor-free nanowire white light-emitting diodes Nano Lett. 13 5437-42

[163] Ra Y-H, Rashid R T, Liu X, Lee J and Mi Z 2017 Scalable nanowire photonic crystals: molding the light emission of InGaN Adv. Funct. Mater. 271702364

[164] Sekiguchi H, Kishino K and Kikuchi A 2010 Emission color control from blue to red with nanocolumn diameter of InGaN/GaN nanocolumn arrays grown on same substrate Appl. Phys. Lett. 96231104

[165] Kishino K, Sakakibara N, Narita K and Oto T 2020 Two-dimensional multicolor (RGBY) integrated nanocolumn micro-LEDs as a fundamental technology of micro-LED display Appl. Phys. Express 13014003
[166] Ra Y H, Wang R, Woo S Y, Djavid M, Sadaf S M, Lee J, Botton G A and Mi Z 2016 Full-color single nanowire pixels for projection displays Nano Lett. 16 4608-15

[167] Hong Y J, Lee C H, Yoon A, Kim M, Seong H K, Chung H J, Sone C, Park Y J and Yi G C 2011 Visible-color-tunable light-emitting diodes Adv. Mater. 23 3284-8

[168] Monemar B, Ohlsson B J, Gardner N F and Samuelson L 2016 Nanowire-based visible light emitters, present status and outlook Semicond. Semimetal. 94 227-71

[169] Kum H, Seong H K, Lim W, Chun D, Kim Y I, Park Y and Yoo G 2017 Wafer-scale thermodynamically stable GaN nanorods via two-step self-limiting epitaxy for optoelectronic applications Sci. Rep. 740893

[170] Johar M A, Song H-G, Waseem A, Hassan M A, Bagal I V, Cho Y-H and Ryu S-W 2020 Universal and scalable route to fabricate $\mathrm{GaN}$ nanowire-based LED on amorphous substrate by MOCVD Appl. Mater. Today 19100541

[171] Kuykendall T R, Altoe M V, Ogletree D F and Aloni S 2014 Catalyst-directed crystallographic orientation control of GaN nanowire growth Nano Lett. 14 6767-73

[172] Bi Z et al 2020 Realization of ultrahigh quality InGaN platelets to be used as relaxed templates for red micro-LEDs ACS Appl. Mater. Interfaces 12 17845-51

[173] Bi Z et al 2019 InGaN platelets: synthesis and applications toward green and red light-emitting diodes Nano Lett. 19 2832-9

[174] Ko Y-H, Kim J-H, Gong S-H, Kim J, Kim T and Cho Y-H 2015 Red emission of InGaN/GaN double heterostructures on GaN nanopyramid structures ACS Photonics 2 515-20

[175] Chang S P, Chang J R, Sou K P, Liu M C, Cheng Y J, Kuo H C and Chang C Y 2013 Electrically driven green, olivine, and amber color nanopyramid light emitting diodes Opt. Express 21 23030-5

[176] Jindal V, Tripathi N, Tungare M, Paschos O, Haldar P and Shahedipour-Sandvik F 2008 Selective area heteroepitaxy of low dimensional $a$-plane and $c$-plane InGaN nanostructures using pulsed MOCVD Phys. Status Solidi c 5 1709-11

[177] Song J, Leung B, Zhang Y and Han J 2014 Growth, structural and optical properties of ternary InGaN nanorods prepared by selective-area metalorganic chemical vapor deposition Nanotechnology 25225602

[178] Sundaram S et al 2014 Nanoscale selective area growth of thick, dense, uniform, In-rich, InGaN nanostructure arrays on GaN/sapphire template J. Appl. Phys. 116163105

[179] Sundaram S, Gmili Y E, Puybaret R, Li X, Bonanno P L, Pantzas K, Patriarche G, Voss P L, Salvestrini J P and Ougazzaden A 2015 Nanoselective area growth and characterization of dislocation-free InGaN nanopyramids on AlN buffered Si(111) templates Appl. Phys. Lett. 107113105

[180] Bi Z, Gustafsson A, Lenrick F, Lindgren D, Hultin O, Wallenberg L R, Ohlsson B J, Monemar B and Samuelson L 2018 High In-content InGaN nano-pyramids: tuning crystal homogeneity by optimized nucleation of GaN seeds J. Appl. Phys. 123025102

[181] Schulz S and O'Reilly E P 2010 Theory of reduced built-in polarization field in nitride-based quantum dots Phys. Rev. B 82033411

[182] Zhao C, Tang C W, Lai B, Cheng G, Wang J and Lau K M 2020 Low-efficiency-droop InGaN quantum dot light-emitting diodes operating in the 'green gap' Photonics Res. 8 750-4

[183] Zhang M, Bhattacharya P and Guo W 2010 InGaN/GaN self-organized quantum dot green light emitting diodes with reduced efficiency droop Appl. Phys. Lett. 97011103 
[184] Meng Y, Wang L, Zhao G, Li F, Li H, Yang S and Wang Z 2018 Red emission of InGaN/GaN multiple-quantum-well light-emitting diode structures with indium-rich clusters Phys. Status Solidi a 2151800455

[185] Li H, Li P, Kang J, Ding J, Ma J, Zhang Y, Yi X and Wang G 2016 Broadband full-color monolithic InGaN light-emitting diodes by self-assembled InGaN quantum dots Sci. Rep. 635217

[186] Wang L et al 2021 Green InGaN quantum dots breaking through efficiency and bandwidth bottlenecks of micro-LEDs Laser Photonics Rev. 152000406

[187] Soh C B, Liu W, Chua S J, Tan R J N, Ang S S and Chow S Y 2011 Red emitting LEDs formed by indium rich quantum dots incorporated in MQWs Phys. Status Solidi a 208 1579-81

[188] Lv W, Wang L, Wang J, Xing Y, Zheng J, Yang D, Hao Z and Luo Y 2013 Green and red light-emitting diodes based on multilayer $\mathrm{InGaN} / \mathrm{GaN}$ dots grown by growth interruption method Jpn. J. Appl. Phys. 52 08JG13

[189] Park I-K and Park S-J 2011 Green gap spectral range light-emitting diodes with self-assembled ingan quantum dots formed by enhanced phase separation Appl. Phys. Express 4042102

[190] Heikenfeld J, Garter M, Lee D S, Birkhahn R and Steckl A J 1999 Red light emission by photoluminescence and electroluminescence from Eu-doped GaN Appl. Phys. Lett. 75 1189-91

[191] Lorenz K, Miranda S M, Alves E, Roqan I, O’Donnell K and Boćkowski M 2012 High pressure annealing of europium implanted GaN Proc. SPIE $826282620 \mathrm{C}$

[192] Faye D N et al 2016 Study of damage formation and annealing of implanted III-nitride semiconductors for optoelectronic devices Nucl. Instrum. Methods Phys. Res. B 379 251-4

[193] Wang R and Steckl A J 2010 Effect of growth conditions on $\mathrm{Eu}^{3+}$ luminescence in GaN J. Cryst. Growth 312 680-4

[194] Hori Y, Enjalbert F, Jalabert D, Monroy E, Dang L S, Biquard X, Tanaka M, Oda O and Daudin B 2003 Visible red light emission from Eu-doped GaN quantum dots grown by plasma-assisted MBE Phys. Status Solidi c 0 2695-8

[195] Andreev T, Liem N Q, Hori Y, Tanaka M, Oda O, Daudin B and Si Dang D L 2006 Comparative optical study of $\mathrm{Eu}^{3+}$ ions doping in $\mathrm{InGaN} / \mathrm{GaN}$ quantum dots and $\mathrm{GaN}$ layer grown by molecular beam epitaxy Opt. Mater. 28 775-9

[196] Takagi Y, Suwa T, Sekiguchi H, Okada H and Wakahara A 2011 Effect of $\mathrm{Mg}$ codoping on $\mathrm{Eu}^{3+}$ luminescence in GaN grown by ammonia molecular beam epitaxy Appl. Phys. Lett. 99171905

[197] Wakahara A, Sekiguchi H, Okada H and Takagi Y 2012 Current status for light-emitting diode with Eu-doped GaN active layer grown by MBE J. Lumin. 132 3113-7

[198] Sekiguchi H, Takagi Y, Otani T, Okada H and Wakahara A 2013 Emission enhancement mechanism of GaN:Eu by Mg codoping J. Appl. Phys. 113013105

[199] Sekiguchi H, Sakai M, Kamada T, Yamane K, Okada H and Wakahara A 2019 Observation of single optical site of Eu and $\mathrm{Mg}$ codoped $\mathrm{GaN}$ grown by $\mathrm{NH}_{3}$-source molecular beam epitaxy J. Appl. Phys. 125175702

[200] Sukegawa A, Sekiguchi H, Matsuzaki R, Yamane K, Okada H, Kishino K and Wakahara A 2018 Self-organized Eu-doped GaN nanocolumn light-emitting diode grown by RF-molecular-beam epitaxy Phys. Status Solidi a 2161800501

[201] Zhu W, Mitchell B, Timmerman D, Koizumi A, Gregorkiewicz T and Fujiwara Y 2017 High-power Eu-doped $\mathrm{GaN}$ red LED based on a multilayer structure grown at lower temperatures by organometallic vapor phase epitaxy MRS Adv. 2 159-64

[202] Zhu W, Mitchell B, Timmerman D, Uedono A, Koizumi A and Fujiwara Y 2016 Enhanced photo/electroluminescence properties of Eu-doped GaN through optimization of the growth temperature and $\mathrm{Eu}$ related defect environment APL Mater. 4056103

[203] Mitchell B et al 2016 Utilization of native oxygen in $\mathrm{Eu}(\mathrm{RE})$-doped $\mathrm{GaN}$ for enabling device compatibility in optoelectronic applications Sci. Rep. 618808

[204] Mitchell B, Poplawsky J, Lee D, Koizumi A, Fujiwara Y and Dierolf V 2014 The role of donor-acceptor pairs in the excitation of Eu-ions in GaN:Eu epitaxial layers J. Appl. Phys. 115204501

[205] Lee D-G, Nishikawa A, Terai Y and Fujiwara Y 2012 Eu luminescence center created by $\mathrm{Mg}$ codoping in Eu-doped GaN Appl. Phys. Lett. 100171904

[206] Nishikawa A, Furukawa N, Kawasaki T, Terai Y and Fujiwara Y 2010 Improved luminescence properties of Eu-doped GaN light-emitting diodes grown by atmospheric-pressure organometallic vapor phase epitaxy Appl. Phys. Lett. 97051113

[207] Nishikawa A, Kawasaki T, Furukawa N, Terai Y and Fujiwara Y 2009 Room-temperature red emission from a p-type/europium-doped/n-type gallium nitride light-emitting diode under current injection Appl. Phys. Express 2071004

[208] Lee D-G, Wakamatsu R, Koizumi A, Terai Y and Fujiwara Y 2013 Control of Eu luminescence centers by codoping of $\mathrm{Mg}$ and $\mathrm{Si}$ into Eu-doped GaN Jpn. J. Appl. Phys. $5208 J M 01$

[209] Mitchell B, Dierolf V, Gregorkiewicz T and Fujiwara Y 2018 Perspective: toward efficient GaN-based red light emitting diodes using europium doping $J$. Appl. Phys. 123160901

[210] Mukai T, Narimatsu H and Nakamura S 1998 Amber InGaN-based light-emitting diodes operable at high ambient temperatures Jpn. J. Appl. Phys. 37 L479-81

[211] Mukai T 2002 Recent progress in group-III nitride light-emitting diodes IEEE J. Sel. Topics Quantum Electron. 8 264-70

[212] Chen H-S, Lu C-F, Yeh D-M, Huang C-F, Huang J-J and Yang C-C 2006 Orange-red light-emitting diodes based on a prestrained $\mathrm{InGaN}-\mathrm{GaN}$ quantum-well epitaxy structure IEEE Photon. Technol. Lett. 18 2269-71

[213] Shon J W, Ohta J, Ueno K, Kobayashi A and Fujioka H 2014 Fabrication of full-color InGaN-based light-emitting diodes on amorphous substrates by pulsed sputtering $S \mathrm{Si}$. Rep. 45325

[214] Li P, Li H, Li Z, Kang J, Yi X, Li J and Wang G 2015 Strong carrier localization effect in carrier dynamics of $585 \mathrm{~nm}$ InGaN amber light-emitting diodes J. Appl. Phys. 117073101

[215] Lee K, Choi I, Lee C-R, Chung T-H, Kim Y S, Jeong K-U, Chung D C and Kim J S 2017 Flower-like internal emission distribution of LEDs with monolithic integration of InGaN-based quantum wells emitting narrow blue, green, and red spectra Sci. Rep. 77164

[216] Lee K, Lee H, Lee C-R, Chung T-H, Kim Y S, Leem J-Y, Jeong K-U and Kim J S 2017 Yellow-red light-emitting diodes using periodic Ga-flow interruption during deposition of InGaN well Opt. Express 25 15152-60

[217] Zhuang Z, Iida D, Velazquez-Rizo M and Ohkawa K 2021 606-nm InGaN amber micro-light-emitting diodes with an on-wafer external quantum efficiency of $0.56 \%$ IEEE Electron Device Lett. 42 1029-32

[218] Li H, Cheng H-Y, Chen W-L, Huang Y-H, Li C-K, Chang C-Y, Wu Y-R, Lu T-C and Chang Y-M 2017 Three 
dimensional characterization of GaN-based light emitting diode grown on patterned sapphire substrate by confocal Raman and photoluminescence spectromicroscopy Sci. Rep. 745519

[219] Keller S et al 2014 Recent progress in metal-organic chemical vapor deposition of (000-1) N-polar group-III nitrides Semicond. Sci. Technol. 29113001

[220] Mizokami Y, Werner J S, Crognale M A and Webster M A 2006 Nonlinearities in color coding: compensating color appearance for the eye's spectral sensitivity $J$. Vis. 6 996-1007

[221] Damilano B and Gil B 2015 Yellow-red emission from (Ga,In)N heterostructures J. Phys. D: Appl. Phys. 48403001

[222] Xu T, Nikiforov A Y, France R, Thomidis C, Williams A and Moustakas T D 2007 Blue-green-red LEDs based on InGaN quantum dots grown by plasma-assisted molecular beam epitaxy Phys. Status Solidi a 204 2098-102

[223] Soh C B, Liu W, Chua S J, Ang S S, Tan R J N and Chow S Y 2010 Generation of amber III-nitride based light emitting diodes by indium rich InGaN quantum dots with InGaN wetting layer and AlN encapsulation layer J. Appl. Phys. 108093501

[224] Nguyen H P T, Zhang S, Cui K, Korinek A, Botton G A and Mi Z 2012 High-efficiency InGaN/GaN dot-in-a-wire red light-emitting diodes IEEE Photon. Technol. Lett. 24 321-3

[225] Kishino K, Nagashima K and Yamano K 2013 Monolithic integration of InGaN-based nanocolumn light-emitting diodes with different emission colors Appl. Phys. Express 6012101

[226] Kishino K, Yanagihara A, Ikeda K and Yamano K 2015 Monolithic integration of four-colour InGaN-based nanocolumn LEDs Electron. Lett. 51 852-4
[227] Philip M R, Choudhary D D, Djavid M, Le K Q, Piao J and Nguyen H P T 2017 High efficiency green/yellow and red InGaN/AlGaN nanowire light-emitting diodes grown by molecular beam epitaxy J. Sci.: Adv. Mater. Devices 2 150-5

[228] Meyaard D S, Shan Q, Cho J, Fred Schubert E, Han S-H, Kim M-H, Sone C, Jae O S and Kyu Kim J 2012 Temperature dependent efficiency droop in GaInN light-emitting diodes with different current densities Appl. Phys. Lett. 100081106

[229] Chhajed S, Xi Y, Li Y L, Gessmann T and Schubert E F 2005 Influence of junction temperature on chromaticity and color-rendering properties of trichromatic white-light sources based on light-emitting diodes J. Appl. Phys. 97054506

[230] Iida D, Lu S, Hirahara S, Niwa K, Kamiyama S and Ohkawa K 2016 Investigation of amber light-emitting diodes based on InGaN/AlN/AlGaN quantum wells Jpn. J. Appl. Phys. 55 05FJ06

[231] Zhuang Z, Iida D and Ohkawa K 2020 Effects of size on the electrical and optical properties of InGaN-based red light-emitting diodes Appl. Phys. Lett. 116173501

[232] Lee H K, Lee D H, Song Y M, Lee Y T and Yu J S 2011 Thermal measurements and analysis of AlGaInP/GaInP MQW red LEDs with different chip sizes and substrate thicknesses Solid.State Electron. 56 79-84

[233] Kim M S, Lee H K and Yu J S 2013 Device characteristics and thermal analysis of AlGaInP-based red monolithic light-emitting diode arrays Semicond. Sci. Technol. 28025005

[234] Mukai T, Yamada M and Nakamura S 1998 Current and temperature dependences of electroluminescence of InGaN-based UV/blue/green light-emitting diodes Jpn. J. Appl. Phys. 37 L1358-61 